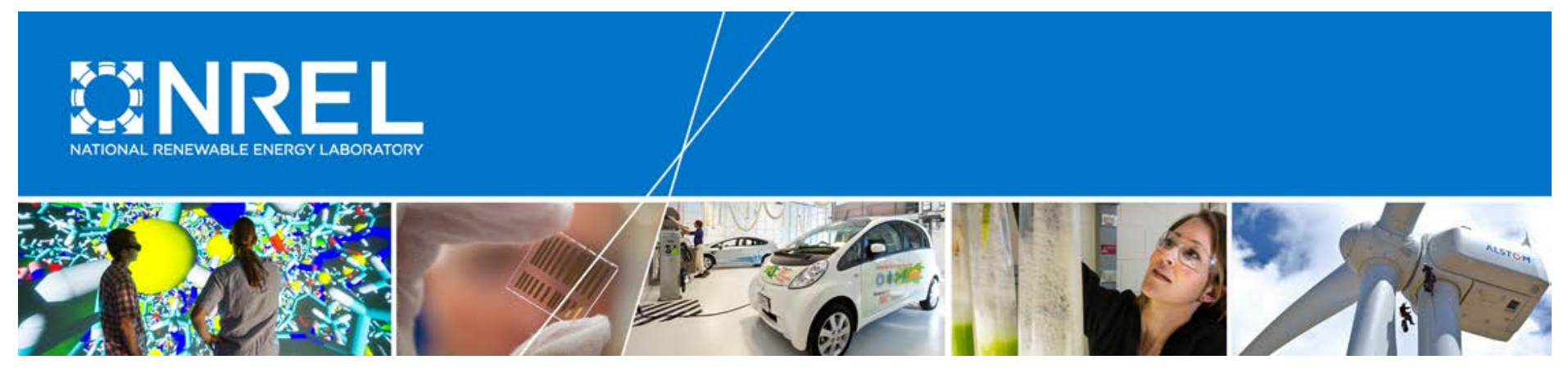

\title{
The Value of Wind Technology Innovation: Implications for the U.S. Power System, Wind Industry, Electricity Consumers, and Environment
}

Trieu Mai, Eric Lantz, and Matthew Mowers National Renewable Energy Laboratory

Ryan Wiser

Lawrence Berkeley National Laboratory

NREL is a national laboratory of the U.S. Department of Energy Office of Energy Efficiency \& Renewable Energy Operated by the Alliance for Sustainable Energy, LLC

This report is available at no cost from the National Renewable Energy Laboratory (NREL) at www.nrel.gov/publications.

Technical Report

NREL/TP-6A20-70032

September 2017 


\section{The Value of Wind Technology Innovation: Implications for the U.S. Power System, Wind Industry, Electricity Consumers, and Environment}

Trieu Mai, Eric Lantz, and Matthew Mowers National Renewable Energy Laboratory

Ryan Wiser

Lawrence Berkeley National Laboratory

Prepared under Task No. WEPG.10348.05.01.04

NREL is a national laboratory of the U.S. Department of Energy Office of Energy Efficiency \& Renewable Energy Operated by the Alliance for Sustainable Energy, LLC

This report is available at no cost from the National Renewable Energy Laboratory (NREL) at www.nrel.gov/publications.

National Renewable Energy Laboratory 15013 Denver West Parkway Golden, CO 80401

303-275-3000 • www.nrel.gov
Technical Report

NREL/TP-6A20-70032

September 2017

Contract No. DE-AC36-08GO28308 


\section{NOTICE}

This report was prepared as an account of work sponsored by an agency of the United States government. Neither the United States government nor any agency thereof, nor any of their employees, makes any warranty, express or implied, or assumes any legal liability or responsibility for the accuracy, completeness, or usefulness of any information, apparatus, product, or process disclosed, or represents that its use would not infringe privately owned rights. Reference herein to any specific commercial product, process, or service by trade name, trademark, manufacturer, or otherwise does not necessarily constitute or imply its endorsement, recommendation, or favoring by the United States government or any agency thereof. The views and opinions of authors expressed herein do not necessarily state or reflect those of the United States government or any agency thereof.

This report is available at no cost from the National Renewable Energy Laboratory (NREL) at www.nrel.gov/publications.

Available electronically at SciTech Connect http:/www.osti.gov/scitech

Available for a processing fee to U.S. Department of Energy and its contractors, in paper, from:

U.S. Department of Energy

Office of Scientific and Technical Information

P.O. Box 62

Oak Ridge, TN 37831-0062

OSTI http://www.osti.gov

Phone: 865.576.8401

Fax: 865.576.5728

Email: reports@osti.gov

Available for sale to the public, in paper, from:

U.S. Department of Commerce

National Technical Information Service

5301 Shawnee Road

Alexandria, VA 22312

NTIS http://www.ntis.gov

Phone: 800.553 .6847 or 703.605 .6000

Fax: 703.605.6900

Email: orders@ntis.gov 


\section{Acknowledgments}

This report would not be possible without supporting data and analysis from many other researchers at the National Renewable Energy Laboratory (NREL). In particular, we thank Maureen Hand and Mike Maness (for their support with the wind technology projections), David Keyser (for running the JEDI model for the jobs analysis), Jordan Macknick (for his support with the water use analysis), and Wesley Cole (for data for the SunShot 2030 sensitivity). Mike Meshek and Stacy Buchanan (NREL) provided editing and graphics support. We are also grateful to the following individuals for their thoughtful reviews, comments, and suggestions: Katherine Dykes, Kelly Eurek, Jeffrey Logan, David Mooney, Gian Porro, Brian Smith, and Daniel Steinberg (NREL); Paul Donohoo-Vallett (DOE); Charles G. Rossmann (Southern Company); and James Walker (EDF Renewable Energy). We thank the Department of Energy's (DOE's) Office of Energy Efficiency and Renewable Energy's Wind Energy Technologies Office (WETO) for primary funding support for this analysis. We especially thank Patrick Gilman (DOE), Rich Tusing (Allegheny Science and Technology, senior advisor to the WETO), and Jose Zayas (DOE) for their leadership, insights, and support relating to the work presented in this report. This research was funded by the U.S. Department of Energy (DOE) under contract numbers DE-AC36-08GO28308 (NREL) and DE-AC02-05CH11231 (LBNL). Any errors or omissions are the sole responsibility of the authors. 


\section{Executive Summary}

Technology deployment and innovation often go hand-in-hand. Technological advancements stimulate adoption by lowering costs and improving performance while deployment can, in turn, motivate greater investments in research and development. The dynamic between technology advancement and deployment is particularly interesting for U.S. wind power for a few reasons. Wind technology continues to mature and improve and is now the leading renewable technology deployed in the United States in terms of installed operating capacity. At the same time, recent trends suggest growing challenges to future wind power deployment primarily from competition from generation powered by low-cost natural gas and by solar photovoltaics (PV), which have experienced recent dramatic price declines. Uncertainties in supporting policies and limited electricity demand growth can further contribute to challenges to wind development. To understand the potential effects of wind technology advancement within this dynamic environment, we estimate the potential wind deployment opportunities across a range of technology advancement projections. In addition, we explore how these deployment scenarios may impact the electricity system, electricity consumers, the environment, and the wind-related workforce.

Our analysis relies on a long-term capacity expansion model — the Regional Energy Deployment System model - to assess the impacts of a range of wind technology advancement trajectories. In addition, we explore sensitivity of our results to a range of assumptions about future electricity market conditions, including natural gas prices, non-wind renewable (e.g., solar PV) costs, as well as the relative ease of building interregional transmission. All scenarios reflect 2017 policies only, including the scheduled reduction and expiration of the federal renewable energy production tax credit.

Recently developed wind cost projections implemented for our scenario analysis include:

- Three projections from an expert elicitation of wind energy experts (referred to as IEA Median, IEA Low, and IEA High)

- A projection recently used by the U.S. government and national laboratories reflecting estimates from the broader literature published prior to 2015 (ATB Mid)

- A projection based on estimated impacts of the U.S. Department of Energy Atmosphereto-electrons (A2e) wind power research initiative.

Table ES-1 provides details on the five wind projections modeled, including, where available, specific corresponding wind technology innovations envisioned. 
Table ES-1. Wind Technology Projections Modeled

\begin{tabular}{|c|c|}
\hline Projection & Description \\
\hline $\begin{array}{l}\text { ATB Mid } \\
\text { NREL (2016) }\end{array}$ & $\begin{array}{l}\text { The ATB } 2016 \text { Mid-cost projection represents the median cost reduction } \\
\text { estimate (in percentage terms) from a collection of studies published prior } \\
\text { to } 2015 \text {. }\end{array}$ \\
\hline $\begin{array}{l}\text { IEA Median } \\
\text { Wiser et al. } \\
(2016)\end{array}$ & $\begin{array}{l}\text { The IEA Median projection represents the "most-likely" case from a survey } \\
\text { of } 163 \text { of the world's leading wind experts. Improvements in upfront capital } \\
\text { costs, ongoing operational costs, and capacity factors are anticipated, as } \\
\text { are increased project life and a reduction in the cost of finance. Experts } \\
\text { view continued scaling in turbine size to be a primary-but not sole- } \\
\text { means of achieving these advancements. }\end{array}$ \\
\hline $\begin{array}{l}\text { IEA Low } \\
\text { Wiser et al. } \\
\text { (2016) }\end{array}$ & $\begin{array}{l}\text { The IEA Low wind cost estimates are from the same survey of global wind } \\
\text { experts but reflect a } 10^{\text {th }} \text { percentile (i.e., } 10 \% \text { chance of occurrence) cost } \\
\text { reduction scenario. }\end{array}$ \\
\hline $\begin{array}{l}\text { IEA High } \\
\text { Wiser et al. } \\
\text { (2016) }\end{array}$ & $\begin{array}{l}\text { The IEA High wind projection represents the } 90^{\text {th }} \text { percentile (i.e., } 90 \% \\
\text { chance of occurrence) cost reduction scenario from the same expert } \\
\text { elicitation study. Wind costs, and implicitly, technologies, in this projection } \\
\text { remain largely unchanged over time. }\end{array}$ \\
\hline $\begin{array}{l}\text { A2e } \\
\text { Dykes et al. } \\
(2017)\end{array}$ & $\begin{array}{l}\text { The A2e projection anticipates turbine scaling, with larger turbine capacity, } \\
\text { taller towers, and larger rotors. It also envisions an array of science-based } \\
\text { innovations, such as optimized site-specific plant design, integrated wind } \\
\text { plant design, control, and operational strategies, and innovative rotor and } \\
\text { drivetrain technology. }\end{array}$ \\
\hline
\end{tabular}

These wind projections span a wide range of possible cost and technology innovation trajectories (Figure ES-1, left). On the lowest-cost end of the range considered (A2e), wind energy costs are assumed to be reduced $63 \%$ by 2050 from 2015 levels; on the other end of the range, wind costs remain essentially unchanged from today (IEA High). This range reflects the inherent uncertainty both in scope and success of continued wind energy $\mathrm{R} \& \mathrm{D}$, as well as the extent to which incremental technical, manufacturing, process, and/or workforce efficiency improvements can be leveraged through continued market growth. In this report, we quantify the wind deployment opportunities associated with this range of cost projections and estimate potential electric system, environmental, and economic impacts.

Overall, our analysis finds that wind technology innovation can have consequential implications for future wind power development throughout the United States and it can impact the broader electricity system, lower electric system and consumer costs, provide potential environmental benefits, and expand the U.S. wind workforce. 

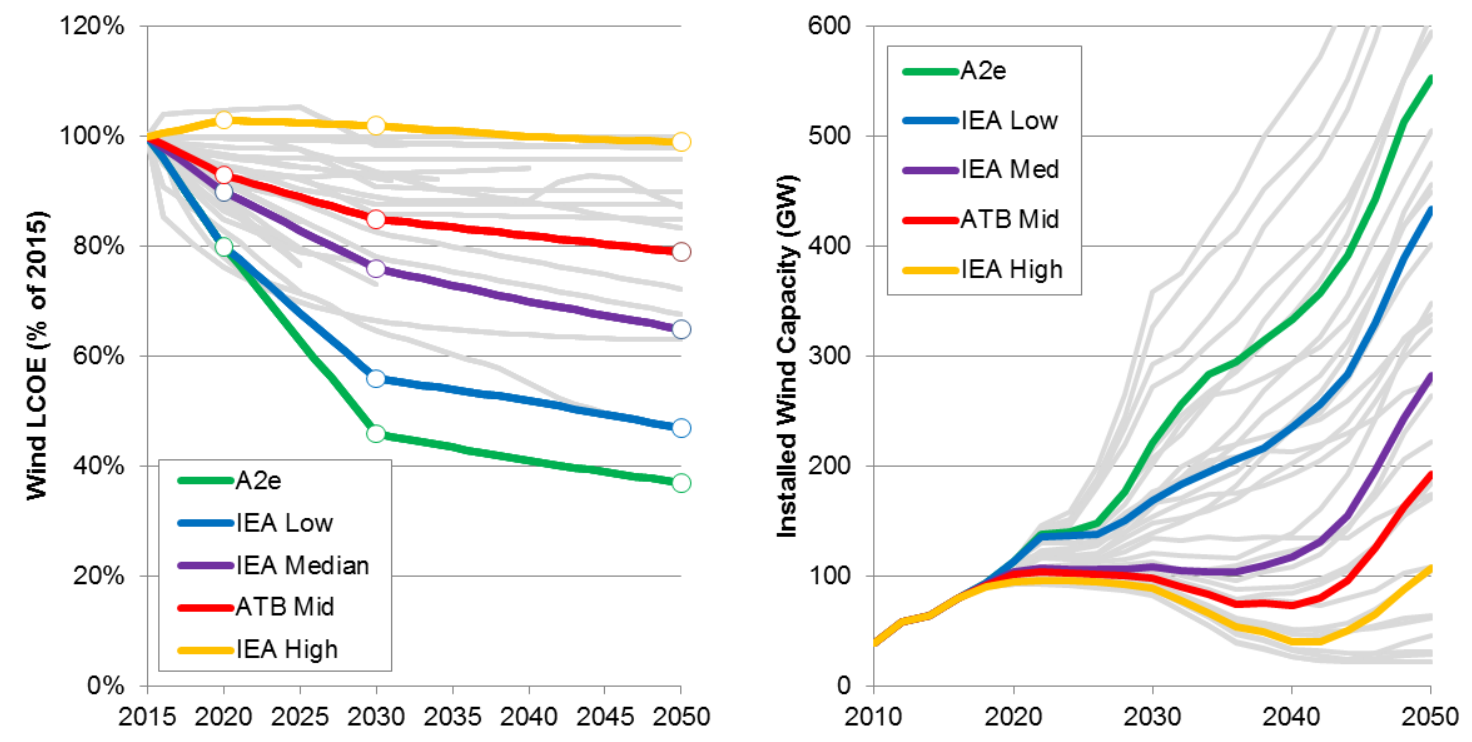

Figure ES-1. Wind technology advancement (left) and deployment projections (right)

Gray lines in left figure reflect projections of levelized cost of electricity (LCOE) from a wide range of literature presented in Wiser et al. (2016). For the right figure, the colored lines show results from the core modeled scenarios and gray lines show sensitivities modeled.

Specific key findings from our analysis are as follows:

Innovation success is essential to maintaining continued growth of U.S. wind power over the next three decades. Figure ES-1(right) shows that under reference market and electricity demand conditions, varying wind technology advancement assumptions result in ranges of installed wind capacity totaling 89-221 gigawatts (GW) in 2030 and 107-553 GW in 2050. Changes in future market conditions, including natural gas prices and non-wind renewable technology costs lead to a wider range of possibilities (as indicated by the gray lines). Even under relatively unfavorable conditions for wind power deployment, wind technology advancement can have a substantial impact on deployment, indicating that innovation can act as a hedge against these unfavorable conditions. 

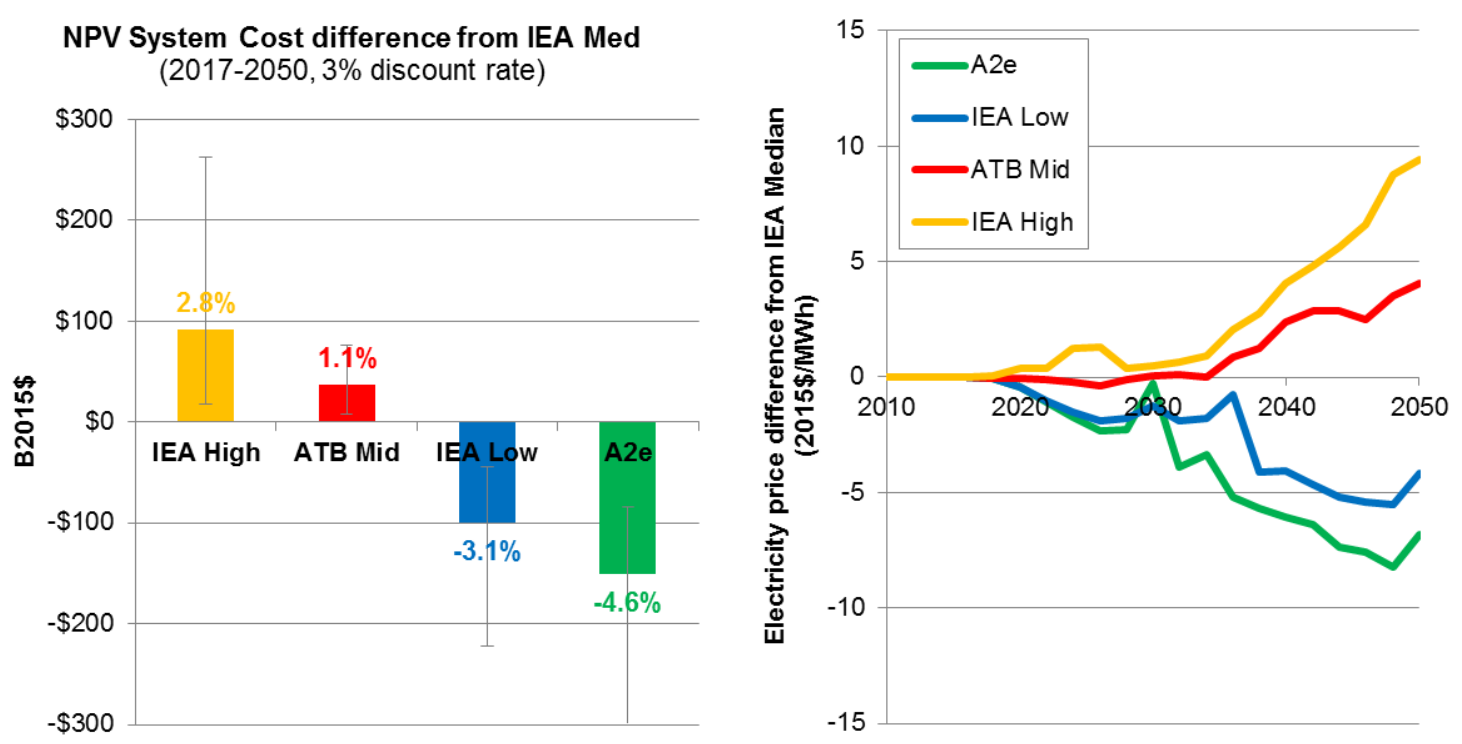

Figure ES-2. Incremental cumulative system costs (left) and average electricity price impacts (right), relative to the IEA Median scenario

Error bars in the figure on the left show the range across all sensitivities.

Aggressive wind technology advancement could help sustain U.S. wind installations in the 2020s, accelerate annual wind deployment to record levels thereafter, and lower electric sector costs. With 44\% wind cost reductions by 2030 and 53\% reductions by 2050 (IEA Low), sustained and consistent wind installations are found, leading to over $169 \mathrm{GW}$ of installed wind capacity by 2030 and $433 \mathrm{GW}$ by 2050 . In this scenario, wind energy comprises over $38 \%$ of total 2050 generation. As a result of this deployment, system costs are estimated to be $\$ 99$ billion $(3.1 \%)$ lower than in the IEA Median scenario over the full period of analysis and electricity prices are estimated to also be reduced (Figure ES-2). Greater advancements (A2e scenario) can yield even larger amounts of wind deployment ( $553 \mathrm{GW}$ by $2050,46 \%$ of 2050 generation) and cost savings ( $\$ 151$ billion, $4.6 \%$ ).

Wind technology advancement leads to widespread wind deployment and associated benefits across all regions in the United States. Wind deployment is found to be most robust in the central "wind belt" regions of the country (Figure ES-3); however, several regions that have not experienced as much wind development historically show significant upside deployment potential from technology advancement; these regions include the Great Lakes region and the Southeast. Greater wind deployment in these regions results from a combination of factors: technology improvements increasing economic competitiveness in these regions; greater challenges to transmitting wind power from remote sites in the central regions with highest quality resources: higher costs for, or more-limited access to, transmission interconnections; limited availability of the highest-resource (windiest) sites; and the benefits of geospatial diversity for wind integration. 


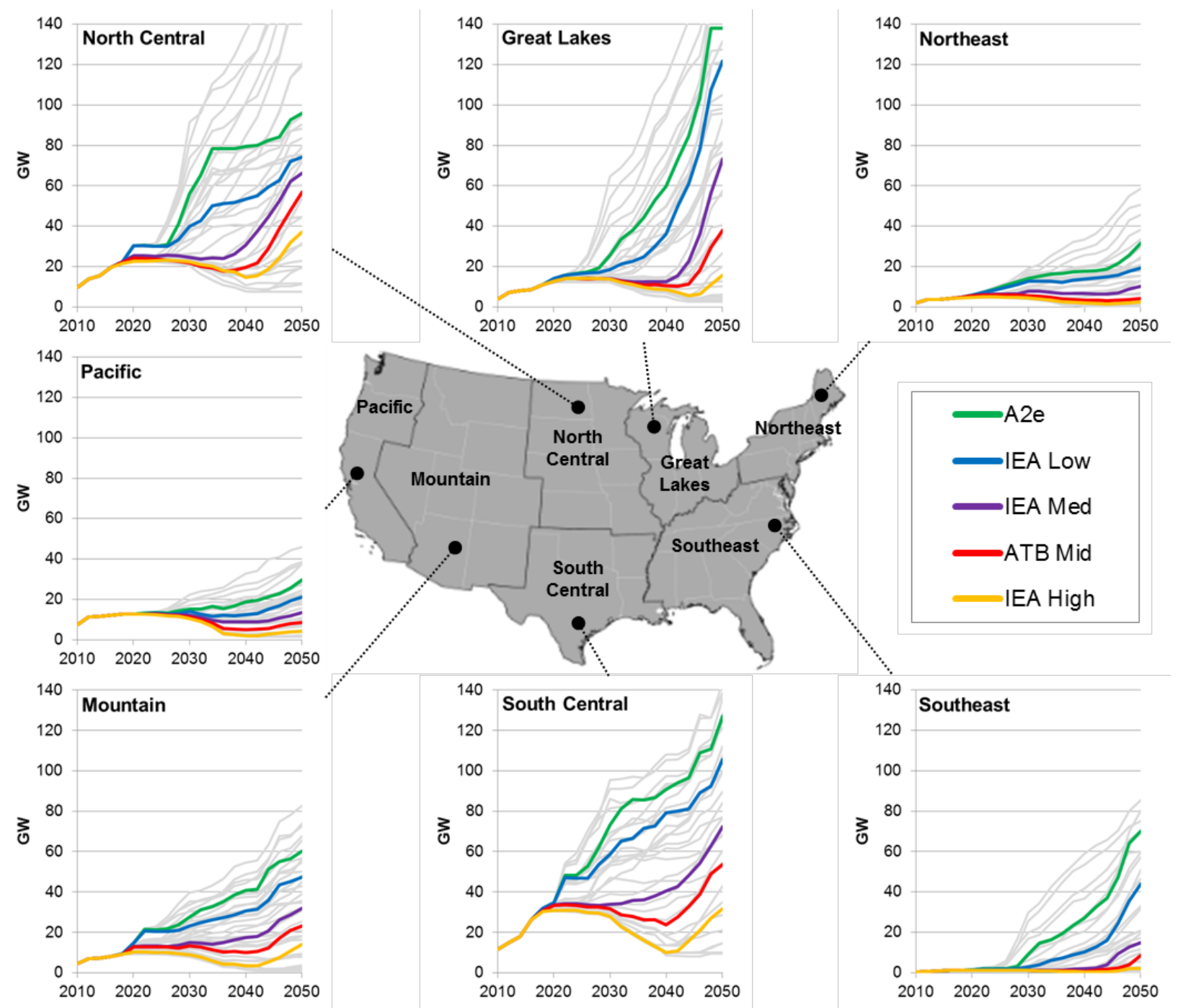

Figure ES-3. Regional wind capacity deployment over time

Colored lines show results from core scenarios; gray lines show sensitivities.

Constraining transmission expansion reduces national wind deployment, but the magnitude of this reduction can be muted through more geographically distributed wind development.

An inability to construct new long-distance transmission lines is found to reduce estimated wind capacity particularly in scenarios with the greatest wind penetration (and lowest wind cost). We estimate that the reduction is relatively minor with only up to a $6 \%$ decline in 2050 installed national wind capacity. Larger impacts occur regionally, with wind capacity in some regions (e.g., the Southeast) estimated to increase due to transmission expansion limits. This result reveals the large and shallow nature of the U.S. wind supply curve, where technology innovation can help enable economically viable wind even in regions with relatively low wind quality. Further analysis is required to confirm this result due to the complex array of factors related to transmission development, including technical power flow considerations, transmission and generation siting issues, transmission cost allocation, and non-economic factors. 
Incremental wind generation, through innovation-driven deployment, is found to primarily offset generation from new natural gas and solar capacity as well as fossil fuel-based generation from existing power plants. Sufficient technology advancements can enable wind to be economically competitive with the variable costs of existing units as well as total life-cycle costs of new units. Of the cumulative (2017-2050) displaced generation that resulted from greater wind generation in the IEA Low scenario (relative to IEA Median), $81 \%$ was from fossil fuel-based sources ( $45 \%$ natural gas, $36 \%$ coal), $18 \%$ from solar, and the small remainder from other sources. The amount and type of generation displaced by wind vary substantially by region, depending on region-specific marginal generation costs, generation mixes, and resource potential and quality.

The impacts of wind technology advancements extend beyond the electric system as technology advancement is also shown to lead to potential environmental benefits and growth in the windrelated workforce. Figure ES-4 (next page) summarizes estimated power sector air emission (sulfur dioxide $\left[\mathrm{SO}_{2]}\right.$, nitrogen oxides $\left[\mathrm{NO}_{\mathrm{x}}\right]$, and carbon dioxide $\left[\mathrm{CO}_{2}\right]$ ) and water use (consumption and withdrawals) impacts as a function of wind technology advancement. For all three air pollutants considered, we estimate a $16 \%-19 \%$ reduction in 2050 emissions for the IEA Low scenario (relative to IEA Median) and a 26\%-30\% reduction for the A2e scenario. Similar water use savings (on a percent basis) are found for these scenarios. Figure ES-4 also shows how average annual wind-related workforce can expand by $38 \%$ and $50 \%$ over the full analysis period for the IEA Low and A2e scenarios, respectively, relative to the IEA Median scenario.

Relative to recent "mid" or moderately aggressive projections derived from the broader literature, the "most-likely" outlook of international wind energy experts results in greater opportunities for long-term U.S. wind deployment and lower electric system costs. The median or "most-likely" projection from the expert elicitation research (IEA Median) results in nearly $90 \mathrm{GW}$ greater wind capacity than the ATB Mid scenario in 2050, $\$ 37$ billion (1.1\%) in electricity system cost savings (over the full analysis period). The greater apparent optimism of wind power experts (represented in the IEA scenarios), compared to the broader literature (represented in ATB Mid), may result in part from the experts' consideration of a larger set of innovations that can yield both cost and performance improvements. The broader literature may narrowly apply cost reductions via initial capital expenditures solely, without full appreciation for the potential of performance improvements. However, both the expert survey study and the broader literature reveal significant uncertainty in future wind costs.

Sizable lost wind deployment opportunities are found in the absence of technology innovation. Higher system costs and greater emissions are found as a result of the reduced wind deployment. With little change to projected wind technology costs (IEA High), installed wind capacity is found to stagnate or even decline over time as supporting federal policies lapse and greater competition from natural gas and solar PV generation emerges. As a result of the more-limited growth in wind, greater reliance on other sources of electricity, including fossil fuel-fired generation would be required and is found to increase system costs (relative to IEA Median) by $\$ 91$ billion (2.8\%) and to increase emissions and water use. Furthermore, a comparison of the scenario with essentially no wind cost reductions (IEA High) and one reflecting the broader literature (ATB Mid) reveals the value of even moderate technology advancements; the two scenarios differ by $86 \mathrm{GW}$ of wind in $2050, \$ 54$ billion in electric system costs throughout the study period, and measurable amounts of power sector emissions, water use, and wind-related jobs. 


\begin{tabular}{|c|c|c|c|c|c|}
\hline & $\begin{array}{l}\text { IEA Med } \\
\text { (Absolute value) }\end{array}$ & IEA High & ATB Mid $_{(\% \text { of IE }}$ & $\underset{\text { ledian) }}{\text { IEA Low }}$ & $\mathrm{A} 2 \mathrm{e}$ \\
\hline $\begin{array}{l}\text { WIND INSTALLED } \\
\text { CAPACITY } 2050 \\
\text { (GW) }\end{array}$ & 282 & $-62 \%$ & $-32 \%$ & $+53 \%$ & $+96 \%$ \\
\hline $\begin{array}{c}\text { WIND GENERATION } 2050 \\
\text { (TWh) }\end{array}$ & 1,238 & $-66 \%$ & $-29 \%$ & $+50 \%$ & $+76 \%$ \\
\hline $\begin{array}{l}\text { PYSTEM COSTS } \\
2017-2050 \\
\text { (BILLION \$) }\end{array}$ & 3,250 & $+2.8 \%$ & $+1.1 \%$ & $-3.1 \%$ & $-4.6 \%$ \\
\hline $\begin{array}{l}S_{2} \text { EMISSIONS } 2050 \\
\text { (THOUSAND TONS) }\end{array}$ & 651 & $+5.0 \%$ & $+3.8 \%$ & $-19 \%$ & $-30 \%$ \\
\hline $\begin{array}{l}\text { NO EMISSIONS } 2050 \\
\text { (THOUSAND TONS) }\end{array}$ & 887 & $+12 \%$ & $+6.4 \%$ & $-18 \%$ & $-28 \%$ \\
\hline $\mathrm{CO}_{2}$ EMISSIONS 2050 & 1,527 & $+15 \%$ & $+6.9 \%$ & $-16 \%$ & $-26 \%$ \\
\hline $\begin{array}{l}\text { WATER } \\
\text { CONSUMPTION 2050 } \\
\text { (BILLION GALLONS) }\end{array}$ & 878 & $+14 \%$ & $+6.2 \%$ & $-16 \%$ & $-25 \%$ \\
\hline $\begin{array}{l}\text { WATER } \\
\text { WITHDRAWALS 2050 } \\
\text { (BILLION GALLONS) }\end{array}$ & 7,716 & $+7.5 \%$ & $+4.4 \%$ & $-15 \%$ & $-32 \%$ \\
\hline $\begin{array}{l}\text { AVERAGE WIND } \\
\text { JOBS 2017-2050 } \\
\text { (THOUSAND FTES) }\end{array}$ & 170 & $-51 \%$ & $-21 \%$ & $+38 \%$ & $+50 \%$ \\
\hline
\end{tabular}

Figure ES-4. Estimated impacts associated with the wind technology advancement scenarios 
In summary, these findings illustrate the significant effects that wind technology innovation could have on the future of wind energy in the U.S. electricity sector. The wide range of opportunities identified by our analysis further suggests that future U.S. or global assessments of wind deployment might improve by considering a more complete range of wind innovation trajectories. While wind technology innovation can impact the near- and long-term contribution of wind power to the electric sector in a substantial way, it is also critical to enabling access to economically deployed wind technology, helping lower electricity rates and achieving air quality and water use benefits throughout the nation, including in regions that historically have not developed much wind. Continued innovation in wind power is found to support-and, especially absent new policies, might be necessary for-furthering U.S. wind capacity growth. This growth is estimated to support a lower cost and cleaner electricity system. 


\section{Table of Contents}

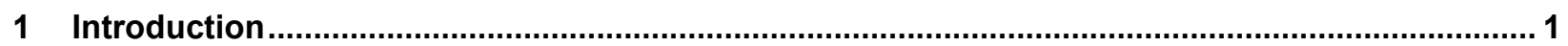

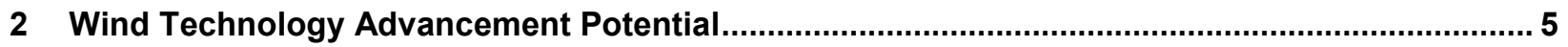

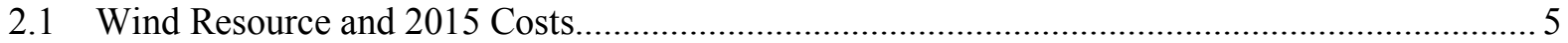

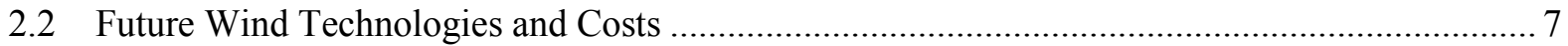

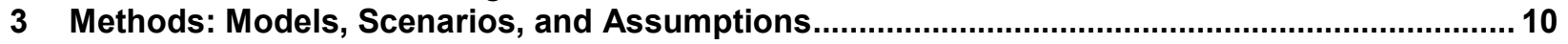

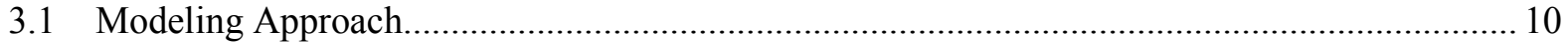

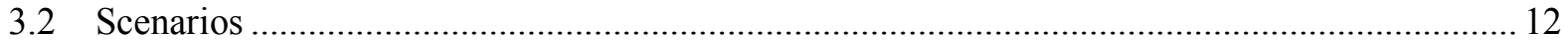

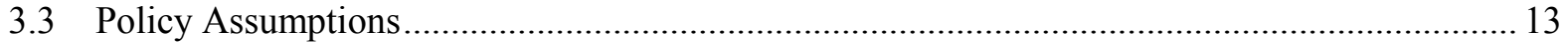

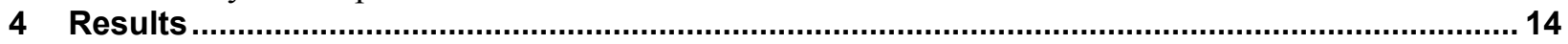

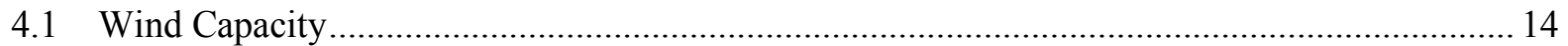

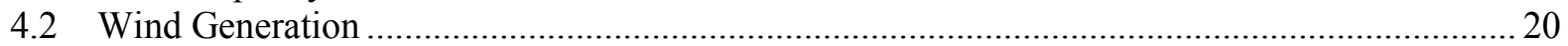

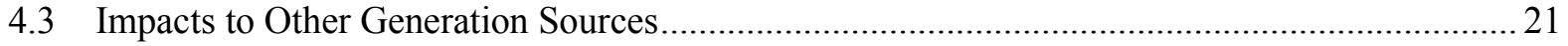

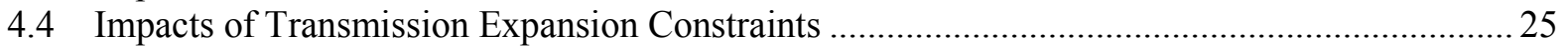

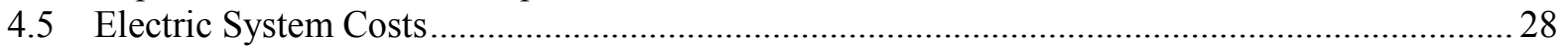

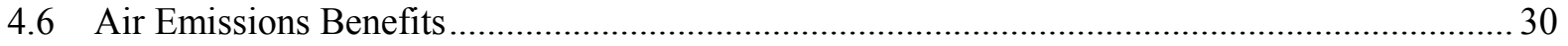

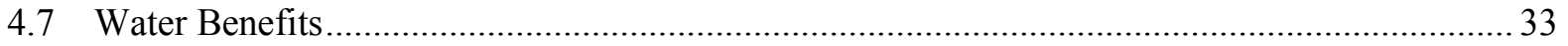

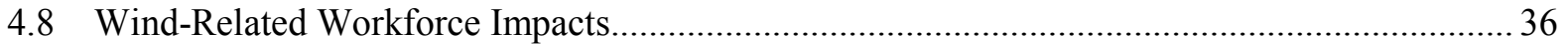

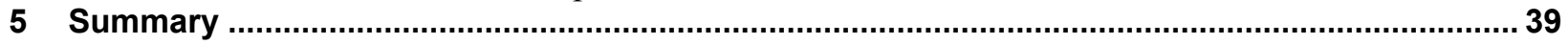

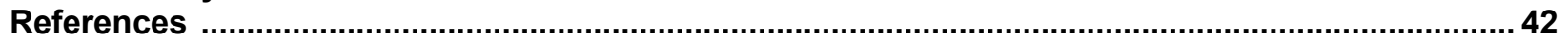

Appendix A: Wind Technology Cost and Performance Data ..................................................... 48

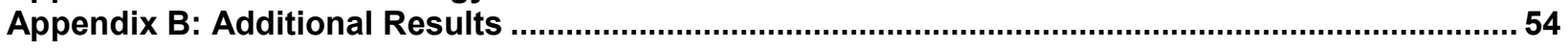




\section{List of Figures}

Figure ES-1. Wind technology advancement (left) and deployment projections (right) vi

Figure ES-2. Incremental cumulative system costs (left) and average electricity price impacts (right), relative to the IEA Median scenario

Figure ES-3. Regional wind capacity deployment over time ...............................................................viii

Figure ES-4. Estimated impacts associated with the wind technology advancement scenarios .................. $\mathrm{x}$

Figure 1. Historical U.S. wind (left) deployment and (right) cost ......................................................... 2

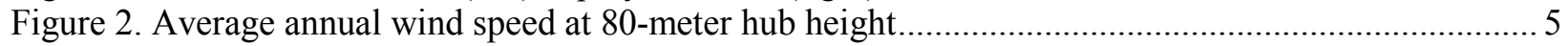

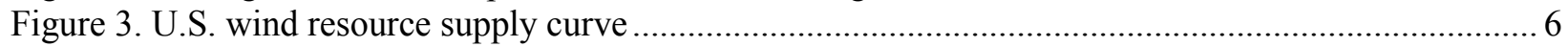

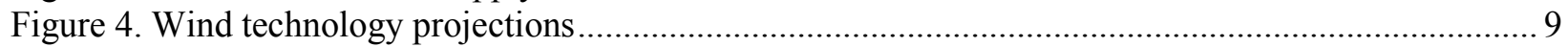

Figure 5. Assumptions for natural gas price (left) and utility PV capital cost (right)............................. 12

Figure 6 . Installed wind capacity for core and sensitivity scenarios...................................................... 15

Figure 7. Regional wind capacity deployment over time …............................................................ 17

Figure 8. Average annual wind capacity installations (left) and cumulative (2017-2050) new and repower

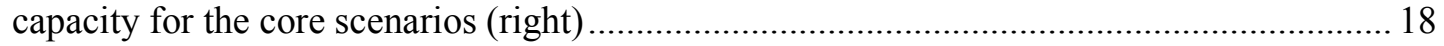

Figure 9. 2050 installed wind capacity ranges by driver .................................................................. 20

Figure 10. Wind penetration for the core scenarios (colored) and sensitivity scenarios (gray)................. 21

Figure 11. National generation difference from the IEA Median scenarios .......................................... 22

Figure 12. Regional generation difference between the IEA Low and the IEA Median scenarios ............ 23

Figure 13. Wind, PV, and total RE generation (left) and capacity (right) in select RE

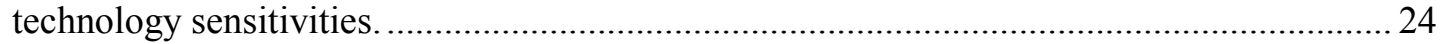

Figure 14. Installed wind capacity in constrained transmission expansion sensitivities........................... 26

Figure 15. Differences in regional wind capacity due to transmission expansion constraints....................27

Figure 16. Total system cost for core scenarios (left) and incremental system cost relative to IEA Median

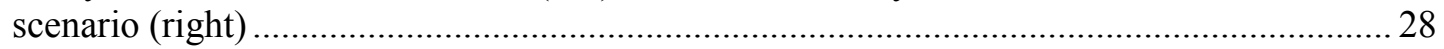

Figure 17. Average retail electricity price (left) and monthly household utility bill impacts (right)......... 29

Figure 18. Direct power sector air pollution emissions: $\mathrm{SO}_{2}$ (left), $\mathrm{NO}_{\mathrm{x}}$ (center), and $\mathrm{CO}_{2}$ (right) ............ 30

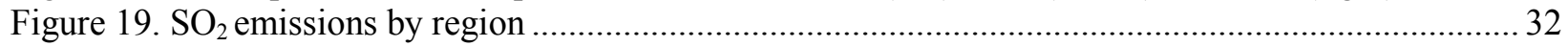

Figure 20. Operational power sector water use: consumption (left) and withdrawals (right)................... 33

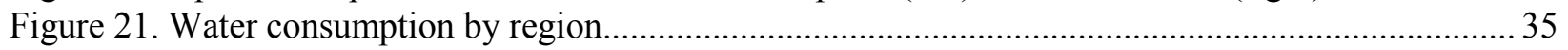

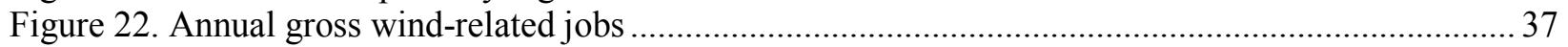

Figure 23. Average annual gross wind-related jobs by job category: (Left) Induced, supply chain, and

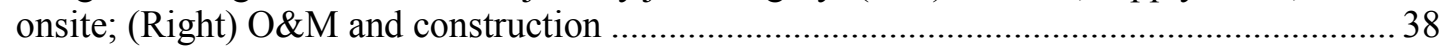

Figure 24. Estimated impacts associated with the wind technology advancement scenarios ..................... 40

Figure B-1. Capacity (left) and generation (right) mix in the IEA Median scenario................................ 54

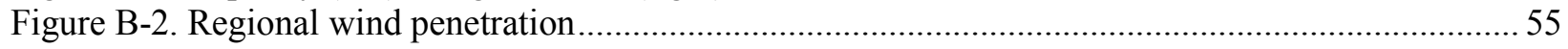

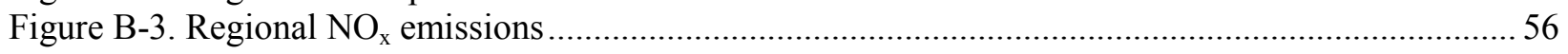

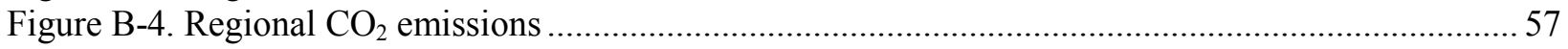

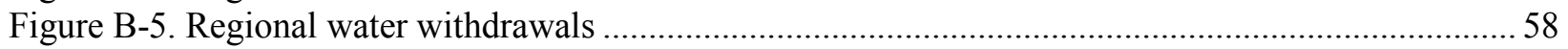

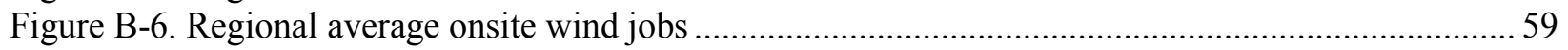




\section{List of Tables}

Table ES-1. Wind Technology Projections Modeled ............................................................................

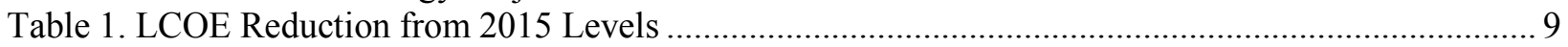

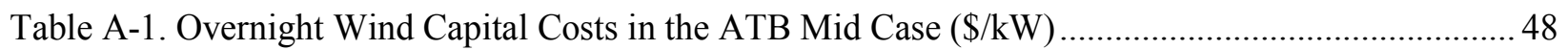

Table A-2. Wind Net Capacity Factor in the ATB Mid Case .................................................................. 48

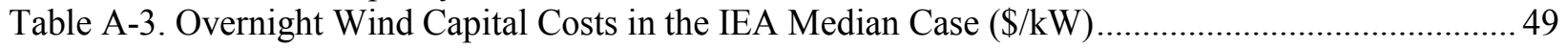

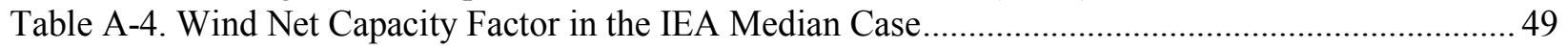

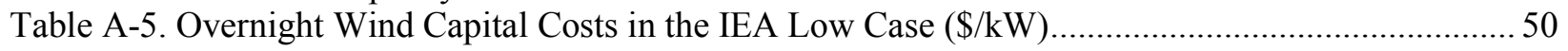

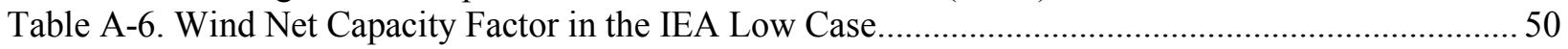

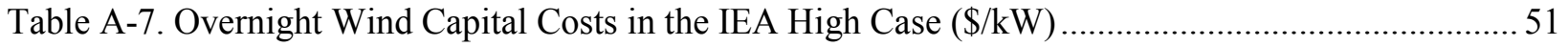

Table A-8. Wind Net Capacity Factor in the IEA High Case ............................................................ 51

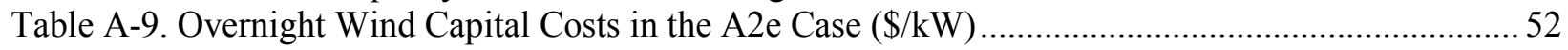

Table A-10. Wind Net Capacity Factor in the A2e Case ......................................................................... 52

Table A-11. Fixed O\&M Costs for Each Wind Cost Projection............................................................. 53

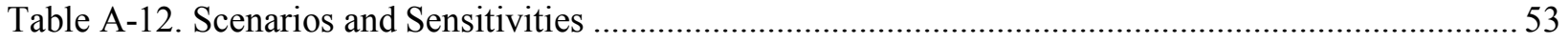

Table A-13. Wind Technology Domestic Content Assumptions............................................................. 53

\section{List of Text Boxes}

Text Box 1. SunShot 2030 Initiative Sensitivity 


\section{Introduction}

The significant growth in U.S. wind power capacity and generation since the turn of the millennium (Figure 1, left) is well-known and well-documented (AWEA 2017; Wiser and Bolinger 2017; EIA 2017a), with installed capacity reaching 82 gigawatts (GW) and 5.6\% of total U.S. generation coming from wind in 2016. Annual wind capacity installations have averaged about $7 \mathrm{GW} / \mathrm{yr}$ over the past five- and ten-year periods; however, year-to-year installations have varied due in part to changes in the federal wind production tax credit (PTC) policy. In addition to federal financial incentives, state policies - primarily renewable portfolio standards (RPS), but also state and local tax incentives, environmental policies, and interconnection policies - have played a role in recent wind power growth (Barbose 2017). In combination with these demandpull policies, ${ }^{1} \mathrm{R} \& \mathrm{D}$ investments and learning-by-doing have led to declining wind technology costs over this same period (Figure 1, right).

Technology deployment, spurred in part by supporting policies in the case of U.S. wind power, and innovation often go hand-in-hand. Technological advancements stimulate adoption by lowering costs and improving performance while deployment can in turn support technology learning and potentially stimulate greater investments in research and development. Historical changes in wind technologies have resulted in lower turbine costs and increased energy capture. In particular, taller hub heights and, more recently, larger rotor diameters have helped enable more economical deployment of wind power plants (Wiser and Bolinger 2017; Lantz et al. 2017). Other wind technology advancements, such as design and material improvements, manufacturing efficiencies, and advanced controls have also started to improve wind turbine costs and performance (Wiser and Bolinger 2017). The result of these wind technology advancements are record-low levelized cost of electricity (LCOE) and power purchase agreement (PPA) prices for U.S. projects under development today. Most notably, PPA prices for contracts signed in 2016 were \$22 per megawatt-hour (MWh) with the PTC, making wind competitive with other generation sources (Wiser and Bolinger 2017). LCOE values (Figure 1, right) in 2015 were the lowest on record and averaged $\$ 46 / \mathrm{MWh}$ across all projects tracked, with some LCOE values estimated to be as low as \$36/MWh (Wiser and Bolinger 2017).

\footnotetext{
${ }^{1}$ Corporate demand for and procurement of wind power has also emerged as an important deployment driver (Wiser and Bolinger 2017).
} 

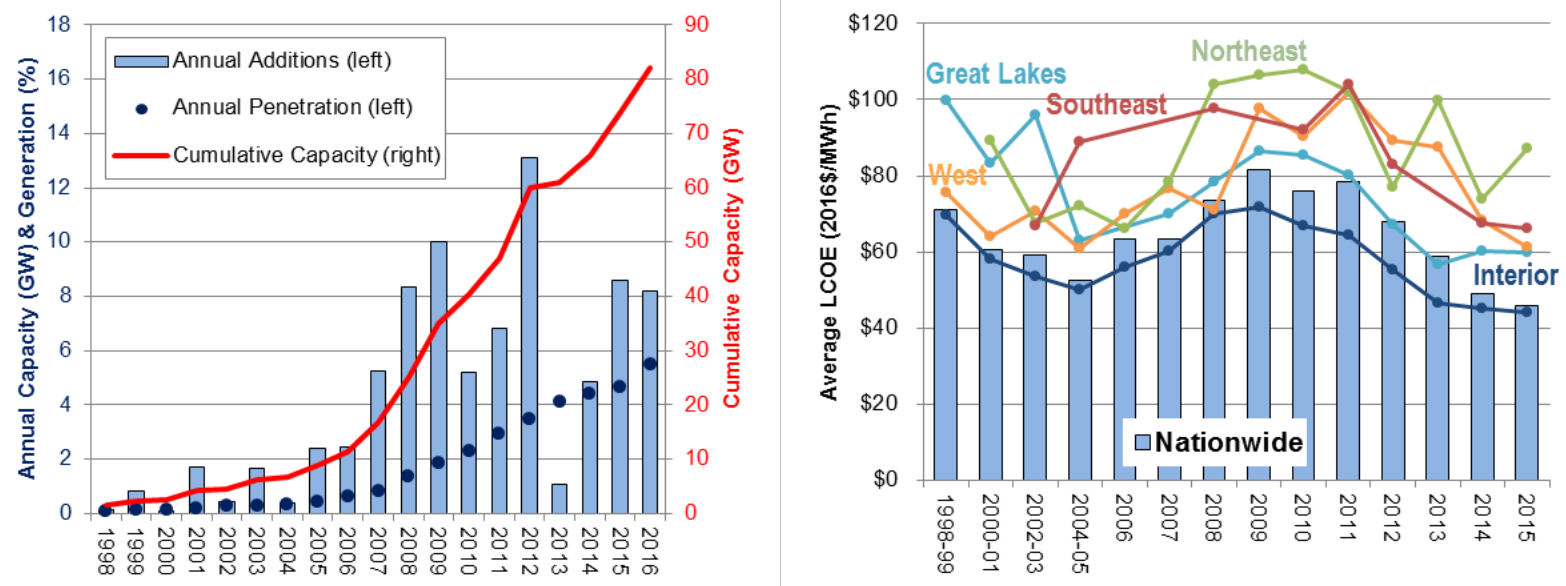

Figure 1. Historical U.S. wind (left) deployment and (right) cost

These figures are reproduced from Wiser and Bolinger (2017). Wind penetration on the left figure is defined as wind generation divided by total generation. The figure on the right reflects generation-weighted average LCOE values over time, nationwide and by region. Regional definitions from Wiser and Bolinger (2017) differ from our analysis.

The impacts of wind technology improvements and resulting deployment extend beyond the wind industry. Historical wind deployment has yielded public health and environmental benefits; Millstein et al. (2017) estimated that wind generation in 2015 avoided about 128 million metric tons (MMT) of carbon dioxide $\mathrm{CO}_{2}$ emissions, 147 thousand metric tons of sulfur dioxide $\left(\mathrm{SO}_{2}\right)$ emissions, 92 thousand metric tons of nitrogen oxides $\left(\mathrm{NO}_{\mathrm{x}}\right)$ emissions, and 4 thousand metric tons particulate matter $\left(\mathrm{PM}_{2.5}\right)$ emissions from the power sector. Emissions reductions yield benefits in terms of avoided premature mortalities and global climate change-related damages. The future amount of wind-driven health and environmental benefits likely depends on the level of continued wind technology development. In addition to potential externality benefits, continuing to reduce wind costs could lead to direct economic and consumer benefits (DOE 2015).

However, the degree to which technology advancements will continue is highly uncertain and will undoubtedly depend on future technology R\&D investments, including global ${ }^{2}$ and domestic investments, and public ${ }^{3}$ and private investments. Prior studies have estimated the technology advancement potential for wind power using a wide variety of methods. ${ }^{4}$ For example, Wiser et al. (2016) applied an expert elicitation survey of 163 global wind energy experts to develop projections of wind energy costs through 2050. Others (Lantz et al. 2012; DOE 2015; NREL 2016) rely on a literature review to inform future wind cost projections. Still other studies (e.g., Dykes et al 2017; Fingersh et al. 2006; Crown Estate 2012; Valpy and English 2014) rely on a

\footnotetext{
${ }^{2}$ Total installed wind capacity globally reached $487 \mathrm{GW}$ by year-end 2016 with a growing share of installations of, and investments in, wind power occurring outside the United States (AWEA 2017).

${ }^{3}$ For example, the U.S. Department of Energy's Wind Energy Technologies Office Atmosphere to Electrons applied research program seeks to catalyze engineering innovations to increase production and lower costs of future wind plants (Dykes et al. 2017). Horner et al. (2013) estimates impacts of historical public R\&D investments to wind technologies and compares these impacts to those from other energy policies. Schmidt and Sewerin (2017) discuss the relationships between technology innovation and public policy.

${ }^{4}$ See Lindman and Soderholm 2012; Rubin et al. 2015; Mukora et al. 2009; Fingersh, Hand, and Laxson 2006; Cohen et al. 2008; Neij 2008; The Crown Estate 2012; Valpy and English 2014; Lantz, Wiser, and Hand 2012; Wiser et al. 2016; DOE 2015; and NREL 2016.
} 
technology assessment to explore cost reduction opportunities through specific R\&D programs. Top-down approaches that typically rely on learning rates and deployment trends have also been used to estimate future wind costs, although these learning rate-based approaches sometimes focus solely on capital cost reductions and may omit performance improvement opportunities as is discussed in some detail by Wiser et al. (2012) and Rubin et al. (2015). In Section 2, we provide details on the outcomes of select studies that are most relevant to our analysis.

Technology projections are often used to develop technology deployment estimates, which are, in turn, used to inform investment and infrastructure planning and procurement, as well as within the context of academic studies. For example, the Energy Information Administration of the U.S. Department of Energy (DOE) periodically publishes future outlooks developed using optimization modeling that relies on assumed technology characterizations for wind and other generation sources (EIA 2017b). National laboratories (e.g., Cole et al. 2016a; Mai et al. 2016a), the electric utilities (Wilkerson et al. 2014), industry consultants ${ }^{5}$, and other researchers (MacDonald et al. 2016; Clarke et al. 2014) also use technology projections to develop future electricity or energy scenarios.

Another use of technology projections is to assess the cost and impacts of achieving specific scenarios or policy objectives (e.g., EPA 2015; DOE 2015; Mai et al. 2016b). These uses sometimes rely on a single projection of future wind costs or few technology sensitivities, but often with a focus on a central scenario or typically without well-documented support for the underlying technology assumptions. The wide range of possibilities for future technology innovation suggests that the global and U.S. scenario analysis could benefit from examining a broader range of wind improvement opportunities.

In this paper, we build on this large body of work and present a detailed assessment of future land-based wind deployment using 45 scenarios of the future U.S. electricity system. ${ }^{6}$ In addition, we examine impacts to electric system costs, air emissions $\left(\mathrm{SO}_{2}, \mathrm{NO}_{\mathrm{x}}\right.$, and $\left.\mathrm{CO}_{2}\right)$ and water use (consumption and withdrawals), and the wind-related workforce. Given substantial uncertainty among an array of input variables, including wind power costs, natural gas prices, and solar PV costs, we rely on a large number of sensitivities to more fully characterize the potential range and distribution of outcomes. Although future energy policies are highly uncertain, we consider 2017 policy conditions only in order to focus on the deployment impacts of wind technology advancements. In most scenarios, existing policies are found to be nonbinding or have limited impact in the long term, and therefore our analysis is designed primarily to explore the economical deployment of U.S. wind power and could be used to inform R\&D strategies by public and private entities.

Although many others have developed projections for U.S. wind deployment, as referenced above, our analysis adds several novel contributions. First, we assess scenarios using multiple wind cost projections from Wiser et al. (2016), who rely on the largest expert elicitation of technology advancement published to date. We compare these results with additional scenarios that rely on cost projections developed through other means. Section 2 details these assumptions. Second, we apply a detailed electric sector model designed specifically to represent the unique

\footnotetext{
${ }^{5}$ See Wiser and Bolinger (2017) for a summary of recent industry projections.

${ }^{6}$ Cole et al. (2017) applies a similar scenario analysis approach for solar PV technologies.
} 
aspects of wind and other variable renewable energy technologies. This model captures the region-specific and time-varying costs and value of wind power to weigh its competitiveness with other generation options. Third, we consider the impact of uncertainty in key non-wind variables, including natural gas prices, non-wind renewable power costs, and constraints to developing new long-distance transmission lines. Our methods, scenarios, and assumptions are presented in Section 3. Finally, we explore additional electric sector metrics of interest beyond wind deployment. Scenario results are presented in Section 4 and cover a broad range of impacts of wind technology advancement, including impacts to future wind capacity deployment and generation, electric sector and consumer costs, air emissions, power sector water use, and the wind-related workforce. We present our results at the national level as well as for various subU.S. regions through 2050. We summarize our findings in Section 5. Notably, our analysis does not explore the impacts of additional cost reduction scenarios (e.g., from Wiser et al. 2016) for offshore wind; however, these cost projections as well as others could be explored in future work. 


\section{Wind Technology Advancement Potential}

In this section we present how wind resource and technologies are characterized in our modeling analysis of deployment potentials. We describe characterizations of recent (2015) technologies as well as the advancement assumptions under five distinct projections.

\subsection{Wind Resource and 2015 Costs}

The U.S. wind resource is abundant, but the wind quality and the amount of land area available for economical wind development vary significantly across regions (Lopez et al. 2012; Brown et al. 2015). For example, Figure 2 shows a high-resolution map of average annual wind speed at 80-meter hub height, which impacts annual energy production and the wind LCOE. Other factors, including local permitting, siting and labor costs as well as proximity and availability of transmission infrastructure can also differentiate the cost of wind power between regions.

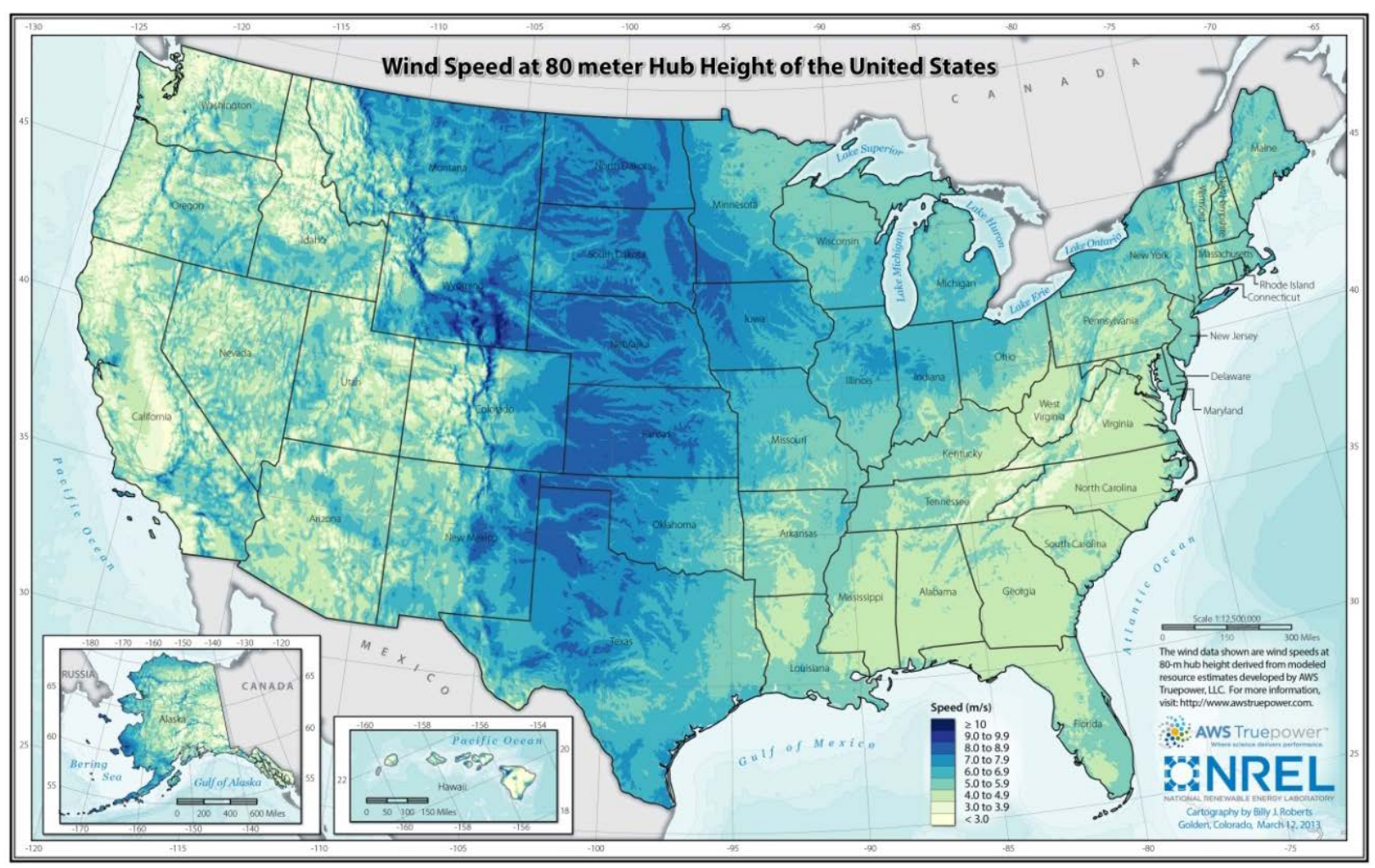

Figure 2. Average annual wind speed at 80 -meter hub height

The wind data shown are average annual wind speeds at the 80-meter hub height, derived from modeled resource estimates developed by AWS Truepower, LLC. Cartography by Billy Roberts (NREL), March 12, 2013. 
By applying wind technology costs for 2015, wind resource quality, estimated grid connection costs, and local cost factors, we develop an aggregate supply curve for land-based wind in the contiguous United States. ${ }^{7}$ We estimate abundant wind resources in the contiguous United States, with a land-based wind resource potential of $10,640 \mathrm{GW} .{ }^{8}$ However, not all wind resources are economically competitive, as about half of the wind resource is estimated to have 2015 (unsubsidized) LCOEs exceeding \$90/MWh. Nonetheless, an abundance of lower-cost wind sites are available for development at 2015 costs, including sites that encompass over 600 $\mathrm{GW}$ of resource below $\$ 60 / \mathrm{MWh}$.

Figure 3 shows the full wind supply curve based on high-resolution (200-meter) data from AWS Truepower, which is used as an input in our modeling analysis. Whether wind power can be economically deployed, given regional costs, value, and competition, as well as the degree of technology advancement cannot be deduced from the supply curve alone. Indeed, these questions are the primary focus of our analysis.

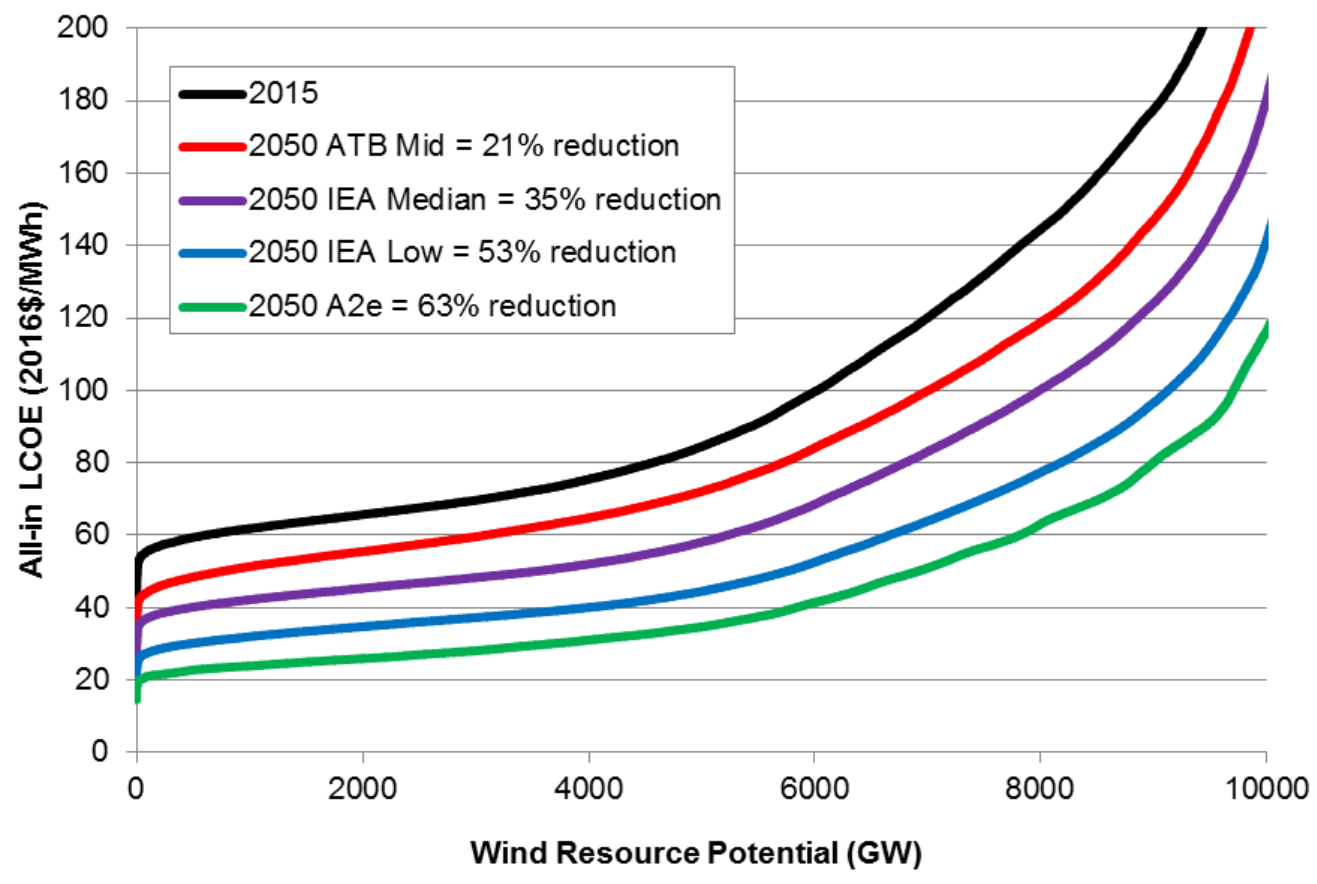

Figure 3. U.S. wind resource supply curve

LCOEs include plant capital and operation and maintenance (O\&M) costs, grid connection costs, financing costs, regional capital cost multipliers. They are based on 80 -meter hub heights for all locations. The federal PTC is not included.

\footnotetext{
${ }^{7}$ The methodology to generate this supply curve is consistent with the method reported in Appendix $\mathrm{H}$ of the Wind Vision study (DOE 2015). We assume 80 -meter hub heights and a wind power plant density of $3 \mathrm{MW} / \mathrm{km}^{2}$. The resource assessment relies on NREL standard land area exclusions (Lopez et al. 2012). Financing assumptions are consistent with default assumptions from the 2016 Annual Technology Baseline (NREL 2016); the federal production tax credit incentive is not included in the LCOEs in Figure 3.

${ }^{8}$ This estimate is based on land-area exclusion assumptions from Lopez et al. (2012) and a wind power plant density of $3 \mathrm{MW} / \mathrm{km}^{2}$ (Denholm et al. 2009).
} 


\subsection{Future Wind Technologies and Costs}

To assess the future deployment opportunities for U.S. wind power, we construct five projections of wind technology advancement through 2050. The projections are from three separate sources:

1. The 2016 Annual Technology Baseline (ATB) (NREL 2016) used in recent studies by the federal government and national laboratories (DOE 2015; DOE 2016; Cole et al. 2016a; EPA 2015)

2. An expert elicitation survey of future wind cost reductions conducted by Wiser et al. (2016) under the International Energy Agency (IEA) Wind agreement

3. A recent analysis of the cost reduction potential when considering the impacts of the DOE Atmosphere to Electrons (A2e) research initiative (Dykes et al., 2017).

Although all three studies examine advancement opportunities for wind power, they employ different methodologies, were conducted at different times, and consider or assume different sources and magnitudes of technology advancement. Our analysis makes no attempt to compare in detail these differences or assess the relative merits of the approaches. Instead, we simply rely on the reported wind cost reductions from these studies as inputs to our own modeling. As described below, the wind cost projections from these studies span a wide range and, in some instances, correspond to specific sets of market conditions and/or technology improvements identified by experts and the broader literature. We summarize the five wind cost projections and, where possible, the corresponding technology innovations assumed as follows: ${ }^{9}$

- ATB Mid: The Annual Technology Baseline 2016 Mid-cost projection (ATB Mid) was developed based on a collection of studies published prior to 2015. Specifically, the "mid-cost" projection was developed using the median cost reduction estimates (in percentage terms) from a base year and, as such, it reflects in a narrow sense the "mostlikely" reduction levels from the reviewed literature. The ATB analysis includes "lowcost" and "high-cost" projections and covers a broad suite of generation technologies. ${ }^{10}$ Under the ATB Mid case, land-based wind LCOEs are estimated to decline by $7 \%$ (from 2015 ) by $2020,15 \%$ by 2030 , and $21 \%$ by $2050 .{ }^{11}$

- IEA Median: Wiser et al. (2016) reports a case similar to the ATB projection that is a "most-likely" case based on the median cost reduction value; however, the median value is taken from a survey of 163 global wind energy experts conducted by the study authors instead of having relied on the published literature. In aggregate, the experts anticipate improvements in upfront capital costs, ongoing operational costs, and capacity factors, as well as increased project life and a reduction in the cost of finance. Experts view continued scaling in turbine size to be a primary — but not sole - means of achieving these advancements, with turbines installed in North America in 2030 expected to reach an average capacity of $3.25 \mathrm{MW}$, rotor diameter of 135 meters, and hub height of 115

\footnotetext{
${ }^{9}$ Our modeling does not explicitly consider learning-by-doing and interactive effects between deployment and costs, which would require global considerations.

${ }^{10}$ As described in Section 3, we rely on ATB 2016 cost projections for non-wind renewable energy technologies in our core and multiple sensitivity scenarios.

${ }^{11}$ An updated version the Annual Technology Baseline (NREL 2017) was released after the completion of our analysis and, for some technologies, applies new methodologies to develop cost projections. For wind technologies, the ATB 2017 version applies the projections from Wiser et al. (2016).
} 
meters (compared to 2.15 MW, 108 meters, and 83 meters in 2016). As a result, in this case wind costs are projected to decline by 10\%, 24\%, and 35\% (from 2015 LCOEs) by 2020, 2030, and 2050 respectively. We refer to this case as the IEA Median case.

- IEA Low: Wiser et al. (2016) also report a lower-cost projection, which we refer to as the IEA Low projection. It is based on the same expert elicitation but assumes a $10^{\text {th }}$ percentile (i.e., 10\% chance of occurrence) cost reduction scenario. In this case, wind LCOEs are estimated to decline by $20 \%$ (from 2015 ) by $2020,44 \%$ by 2030 , and $53 \%$ by 2050 .

- IEA High: We also model an IEA High projection, based on a $90^{\text {th }}$ percentile $(90 \%$ chance of occurrence) scenario from Wiser et al. (2016). Under these conditions, wind energy costs and, implicitly, wind technologies are assumed to remain largely static over time, with only minor near-term increases and slight long-term reductions.

- A2e: Finally, we consider an advanced R\&D case from Dykes et al. (2017). We refer to this case as the A2e projection, where the A2e label is derived from the name of the U.S. Department of Energy's research program Atmosphere to Electrons ("A2e"), which is targeting scientific advancements that will seed future public and private sector innovation efforts. More specifically, this case anticipates even-greater turbine scaling than the IEA Median case, to average turbine capacities of $3.25 \mathrm{MW}$ but with taller towers (135 meters) and larger rotors (131-156 meters, depending on site-specific average wind speed). This projection envisions an array of science-based innovations, including but not limited to sophisticated measurement and high performance computing to model full wind plant physics with high resolution in order to optimize site-specific plant design; integrated wind plant design, control, and operational strategies to optimize performance and actively manage and direct wind flow; and innovative rotor and drivetrain technology enabled by accurate characterization of the wind turbine operating environment at higher heights. This projection reflects the most optimistic cost reductions we considered, including LCOE reductions of 54\% (from 2015) by 2030 and 63\% by 2050 .

Figure 4 and Table 1 summarize the cost reduction levels envisioned under all five cases. For context, Figure 4 also shows how the cost reductions modeled in our analysis compare with cost reductions estimated in the broader literature as presented in Wiser et al. (2016). In our analysis, LCOE reductions are applied equally to the full wind resource potential. This is a simplifying assumption, as the studies and projections rely on different technology advancement mechanisms (e.g., higher hub heights, larger rotors, improved project financing, and reduced losses) and would therefore impact wind energy costs differently by region and between projections. However, given the challenges of self-consistently identifying cost and performance impacts by component and region, as well as the inconsistencies in reporting across the three studies, we apply LCOE reductions uniformly across all sites based on the LCOE reductions described previously. We note that because our modeling does not directly rely on LCOEs (see Section 3), functionally we apply different trajectories for plant capital costs, O\&M costs, and capacity factors depending on resource quality (see Appendix A for data tables). All technology improvements are applied to the core plant cost and performance values only; we assume no changes to grid interconnection costs or to local capital cost multipliers. The latter is based on differences in permitting, siting, and labor costs, which we assume to remain static over time (Eurek et al. 2016). 
To illustrate how the wind supply curve might shift given the cost reductions envisioned, Figure 3 shows the wind supply curve, assuming all sites achieve the 2050 LCOE cost reductions in four of the cases: ATB Mid (red), IEA Median (purple), IEA Low (blue), and A2e (green) projections. ${ }^{12}$ These achievements would result in all-in future LCOEs of less than $\$ 40 / \mathrm{MWh}$ for nearly $5 \mathrm{GW}, 500 \mathrm{GW}, 4000 \mathrm{GW}$, and $6000 \mathrm{GW}$ respectively, of available wind resource. For the IEA Low and A2e projections, over $450 \mathrm{GW}$ and 3,600 $\mathrm{GW}$ of wind resource respectively are estimated to have levelized costs below $\$ 30 / \mathrm{MWh}$ by 2050 . These resource magnitudes under the various LCOE levels are only used to generally illustrate the shape and size of the wind supply curve, under different cost reduction projections; they are not intended to suggest a likely level of deployment. Deployment estimates would also need to consider the demand for and value of wind.

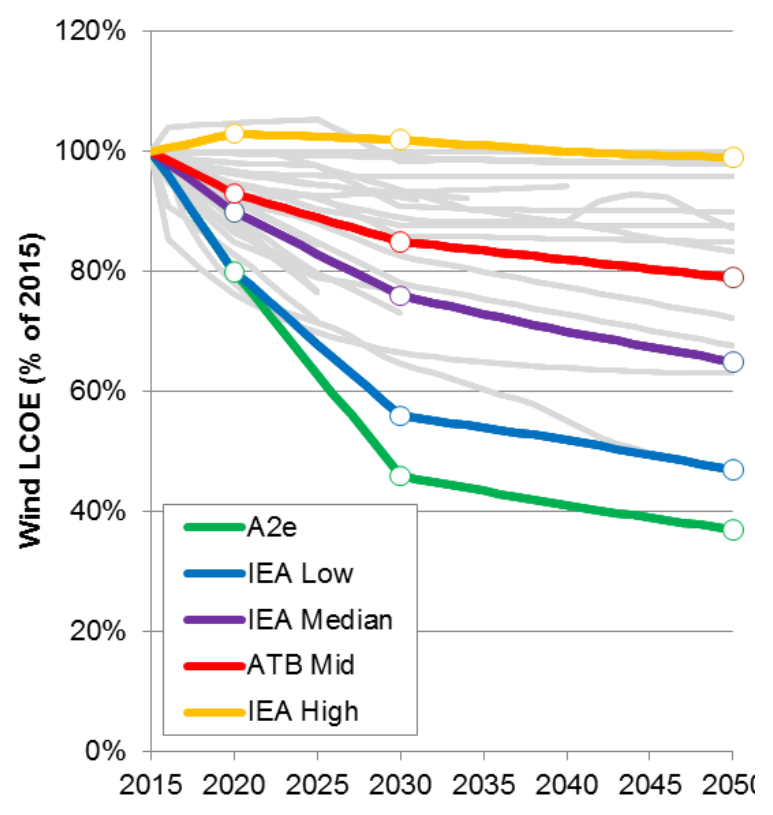

Figure 4. Wind technology projections

Gray lines in reflect LCOE projections from a wide range of literature presented in Wiser et al. (2016).

Table 1. LCOE Reduction from 2015 Levels

\begin{tabular}{lrrrr}
\hline Wind Cost Projection & $\mathbf{2 0 2 0}$ & $\mathbf{2 0 3 0}$ & $\mathbf{2 0 4 0}$ & $\mathbf{2 0 5 0}$ \\
\hline A2e & $20 \%$ & $54 \%$ & $59 \%$ & $63 \%$ \\
IEA Low & $20 \%$ & $44 \%$ & $48 \%$ & $53 \%$ \\
IEA Median & $10 \%$ & $24 \%$ & $30 \%$ & $35 \%$ \\
ATB Mid & $7 \%$ & $15 \%$ & $18 \%$ & $21 \%$ \\
IEA High & $-3 \%$ & $-2 \%$ & $0 \%$ & $1 \%$ \\
\hline
\end{tabular}

${ }^{12}$ The IEA High 2050 projection closely follows the " 2015 " line. 


\section{Methods: Models, Scenarios, and Assumptions}

We rely on electric sector modeling to assess the impact of wind technology advancements on future wind deployment as well as other downstream impacts. In total, we simulate 45 scenarios based on a range of market and technology assumptions. Although none of the scenarios reflects a forecast, the scenario framework and modeling methodology allows for a self-consistent examination of future U.S. electricity systems and wind deployment therein. In this section, we briefly describe our modeling methods, scenarios, and core assumptions.

\subsection{Modeling Approach}

The NREL Regional Energy Deployment System (ReEDS) model (Eurek et al. 2016) ${ }^{13}$ serves as the analytic backbone of our analysis. ReEDS is a capacity expansion model used to generate scenarios of the contiguous U.S. electricity system through 2050. It relies on optimization methods to construct the least-cost capacity and generation mix subject to electric system, resource, policy, and other constraints. Technology portfolios are selected from a full suite of major generation options - including multiple fossil technologies, nuclear power, hydropower, solar, wind, and other renewable technologies - and supporting electric system infrastructure, such as transmission and storage. ${ }^{14}$

We choose ReEDS for this analysis because it is specifically designed to address the unique characteristics of variable renewable energy, including wind and solar energy. In particular, ReEDS relies on high spatial resolution to capture the location-specific nature of wind resources and the regional variations in wind power production (see Figure 2). The network model in ReEDS includes 134 model "balancing areas" (BAs) for the contiguous United States where load balancing constraints and many technology options are represented. ${ }^{15}$ For wind, even higher spatial resolution is applied in ReEDS, as 356 wind resource regions are modeled, 10 technology-resource groups (TRGs) are considered for each resource region, and five supply curve steps are available for each TRG to model grid interconnection costs for each resource region. TRGs are model technology categories used to reflect the regional variations in wind quality (average wind speed) within each ReEDS model wind resource region (DOE 2015; Eurek et al. 2016). Altogether, the optimization model in ReEDS selects from 17,800 (356 regions X 10 TRGs X 5 supply curve steps) different wind options with distinct cost, performance, and

\footnotetext{
${ }^{13}$ We use the 2017 Early Release version of ReEDS.

${ }^{14}$ The ReEDS documentation (Eurek et al. 2016) lists the complete set of technology categories and subcategories modeled in ReEDS. For wind, it models land-based and offshore wind resources and technologies; however, our analysis is focused solely on land-based wind, as offshore wind technology advancement projections consistent with the land-based ones assumed (Section 2) were unavailable at the time our analysis was complete. We include the 30MW Block Island offshore power plant installed in 2016 in our reporting, but we disallow growth in offshore capacity otherwise. This limitation is not meant to suggest that U.S. offshore wind will not grow economically or through policy interventions, including offshore mandates under existing and future state renewable portfolio standards.

${ }^{15}$ ReEDS' model BAs do not perfectly align with actual balancing authority areas as defined and registered by the North American Electric Reliability Corporation ("Glossary of Terms Used in NERC Reliability Standards," August 1, 2017, http://www.nerc.com/files/glossary of terms.pdf). In ReEDS, BAs are sub-state regions that comprise the model transmission network.
} 
available resource characteristics. ${ }^{16}$ The spatial structure in ReEDS enables it to decide between deploying wind capacity in, for example, windier regions that are more remote to load and less windy regions that are more proximate to load centers. It also enables the model to endogenously consider, based on cost and reliability measures, transmission expansion for long-distance (interBA and inter-state) transmission capacity as well as spur lines for new wind capacity.

In addition to addressing the dispersed nature of variable renewable energy, ReEDS is also designed to model the impacts of the temporal variability and uncertainty of wind and solar output profiles. This is accomplished through ReEDS' reduced-form dispatch, which uses both 17 time-slices to model seasonal and diurnal profiles of electricity consumption and production of variable renewable energy, and additional statistical calculations to reflect impacts of shortertimescale variability and uncertainty. Specifically, ReEDS uses a statistical approach to represent variable renewable energy capacity value, forecast error reserves, and curtailment. In summary, the ReEDS model is designed to consider the regional- and system-dependent costs and value of different generation options, including variable renewable energy, within its investment and dispatch decision-making to develop plausible future reliable U.S. electric systems. The model documentation (Eurek et al. 2016) describes the ReEDS model in detail and provides important caveats and necessary simplifying assumptions.

ReEDS has been used to generate scenarios for numerous studies of the U.S. electricity system, including technology assessments (DOE 2016; DOE 2015; DOE 2012; DOE 2008; NREL 2012; Donohoo-Vallett et al. 2017; Mai et al. 2014), policy analysis (Mai et al. 2016b; Mai et al. 2016c; Cole et al. 2015; Lantz et al. 2014; Mignone et al. 2012), and electric system outlooks (Mai et al. 2016a; Cole et al. 2016a; Sullivan et al. 2015; Logan et al. 2012). The DOE Wind Vision study (DOE 2015), which assessed the impacts of achieving wind penetration of $35 \%$ by 2050, also relied on the ReEDS model.

Although ReEDS represents the bulk power system, it does not endogenously represent decisions on the demand side. To this end, we rely on the U.S. Energy Information Administration (EIA) Annual Energy Outlook (AEO) 2017 Reference case (EIA 2017b) for our demand growth projections and exogenous scenarios from the Distributed Generation model (Sigrin et al. 2015) for rooftop PV deployment. In our scenarios, distributed PV projections are taken directly from the NREL 2016 Standard Scenarios Report (Cole et al. 2016a). No other distributed generation options are modeled.

In addition to the capacity and generation mix, ReEDS also reports electric system costs, electricity rates, select air emissions, and power system water use. Our analysis also estimates gross wind-related workforce requirements in our scenarios. To accomplish this, we rely on the NREL Jobs and Economic Impact (JEDI) model, ${ }^{17}$ an input-output tool that uses componentlevel assessment to estimate the number and type of jobs and economic impact of wind investments. For our analysis, we use wind investment estimates from the ReEDS scenarios as input to JEDI. This linked method has been used in prior studies for wind and other renewable technologies (DOE 2015; DOE 2016; Mai et al. 2016c).

\footnotetext{
${ }^{16}$ In effect, the high-resolution supply curve shown in Figure 3 is characterized using the 17,800 land-based wind resource options modeled in ReEDS. Note that because some model regions do not include any suitable land area for wind development the actual number of non-zero options modeled is 11,208.

${ }^{17}$ http://www.nrel.gov/analysis/jedi/
} 


\subsection{Scenarios}

To isolate the impact of different levels of wind technology advancement, we focus our analysis on five core scenarios where the only variations are in the wind technology projections as described in Section 2. The remaining assumptions used for these core scenarios are identical and are referred to as "reference" conditions. ${ }^{18}$ These include fossil fuel prices based on the AEO 2017 Reference case (EIA 2017b) and non-wind technology assumptions from the NREL ATB 2016 Mid-cost case (NREL 2016). Figure 5 shows the projections of natural gas prices and utility PV capital costs under the reference conditions. ${ }^{19}$ The non-wind technology assumptions used include capital cost reductions and/or performance improvements for nearly all technologies and we include select sensitivities with greater and lesser advancements for certain technologies as described below.
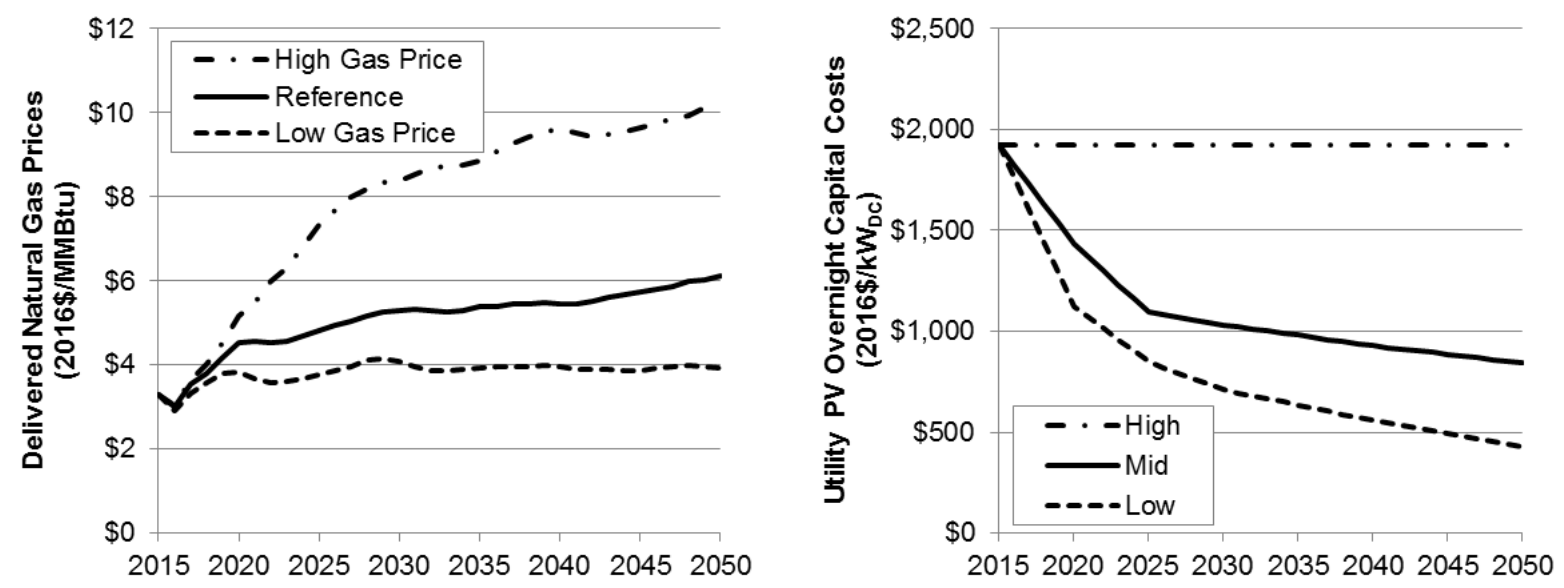

Figure 5. Assumptions for natural gas price (left) and utility PV capital cost (right)

Recognizing that future market conditions are highly uncertain over a multi-decadal horizon, we supplement the five core scenarios with 30 additional market and technology sensitivities. These sensitivities span a plausible range of future natural gas prices and non-wind renewable technology advancement projections. Although other driving factors could potentially impact future wind competiveness and deployment (e.g., Cole et al. 2016a), we focus on these two factors as prior analyses (Mai et al. 2016a) suggest that natural gas and solar generation will likely be the primary competitors to large scale wind development. ${ }^{20}$ Our sensitivity analysis includes scenarios with lower and higher natural gas prices than the reference conditions based on the AEO 2017 High Oil \& Gas Resource and Technology (HOGRT) and the Low Oil \& Gas Resource and Technology (LOGRT) cases (EIA 2017b) respectively. Similarly, we assume higher and lower non-wind renewable technology advancement scenarios based on the ATB 2016 Low- and High-cost projections (NREL 2016). Figure 5 shows the range of assumptions

\footnotetext{
${ }^{18}$ Other default assumptions in ReEDS are presented in Eurek et al. (2016) and Cole et al. (2016a).

${ }^{19}$ ReEDS endogenously represents dynamic interactions between prices and power sector consumption of natural gas, so the scenario outcomes might result in prices that differ from the base values shown in Figure 5. ReEDS also models regional and seasonal variations in prices. Similarly, it includes regional-varying capital costs for all technologies, including PV and wind technologies.

${ }^{20}$ Further advancements or higher costs in other technologies could impact our results, but the other analyses cited suggest that they would have less-significant impacts than the natural gas and non-wind renewable technology sensitivities modeled unless dramatic changes occur (e.g., technology breakthrough or major policy changes).
} 
for natural gas prices and utility PV capital costs under the reference and sensitivity conditions. We also model bounding scenarios with unfavorable (low natural gas prices combined with low non-wind renewable energy [RE] technology costs) and favorable (high natural gas prices combined with high non-wind RE technology costs) conditions for wind deployment.

We also model sensitivities with more-constrained transmission representations than our default treatment, which allows for endogenous economical transmission expansion (DOE 2015). In addition to economic and technical considerations, new transmission expansion faces other hurdles that may not be fully captured by the model. We model transmission sensitivities to assess the degree to which large scale national and regional wind deployment might require successful transmission infrastructure expansion. In particular, we include two constrained transmission variants for each of the five wind cost projections, one disallowing any new interstate transmission expansion and the second disallowing new interregional transmission expansion between any pair of the 134 model BAs. ${ }^{21}$

Table A-12 (Appendix A) summarizes the sets of assumptions used in all scenarios and sensitivities modeled.

\subsection{Policy Assumptions}

In all scenarios, we represent current (2017) policies only. In particular, we model the federal renewable energy tax incentives, including the wind production tax credit (PTC), with the rampdown and under-construction provision as legislated (Mai et al. 2016b). ${ }^{22}$ State renewable portfolio standards are modeled based on legislation enacted through January 2017 (Barbose 2017; Mai et al. 2016c). Other state and regional policies, including the Regional Greenhouse Gas Initiative in the New England states and carbon caps in California ${ }^{23}$ are also reflected in all scenarios. The Clean Power Plan federal regulation on power sector emissions, which is currently under review, is not included in any of the scenarios. ${ }^{24}$

Although new energy policies at the state and federal levels are possible or even probable over the 35-year study horizon, our analysis is restricted to only current policies as our aim is to assess the potential impact of wind R\&D on future deployment in isolation from new policies. Favorable energy policies to wind might lower technology advancement requirements to achieve the same or similar level of deployment. Conversely, a repeal of current renewable policies or enactment of new policies that are more favorable to other energy sources could increase the wind technology advancement needs to achieve the deployment levels estimated.

\footnotetext{
${ }^{21}$ The second is more restrictive, as model BAs fall within state boundaries and most states are comprised of multiple model BAs. Transmission projects that are already under construction are allowed to be completed (by about 2020) even for the constrained transmission sensitivities.

${ }^{22}$ In particular, we assume the wind PTC has no impact after 2022. We also limit near-term (2017-2020) wind development to an upper limit of $61 \mathrm{GW}$ of new capacity based on the project pipeline from the ABB Velocity Suite (ABB 2017).

${ }^{23}$ Our analysis includes a representation of California's AB32 carbon cap, but it does not include the recently passed and more-stringent carbon cap after 2020. We include California's 50\% RPS policy.

${ }^{24}$ Mai et al. (2016a) includes scenarios with the Clean Power Plan and discusses potential implications of the regulation on future wind development.
} 


\section{Results}

Using the modeling assessment, we identify opportunities for land-based wind deployment through 2050. We quantify the extent to which successful wind technology advancements can sustain U.S. wind capacity growth. Importantly, we also estimate how lowering wind costs can yield measurable electricity system cost savings and consumer savings. We demonstrate how generation from greater wind capacity, driven by technology advancements, can help offset other generation sources and yield potential reductions in air pollution and water use. Finally, we estimate the gross wind deployment-driven workforce that might occur in our scenarios.

\subsection{Wind Capacity}

Uncertainties in future market and policy conditions drive significant uncertainty in future U.S. wind deployment. One major factor driving deployment uncertainty is the degree to which wind technologies will continue to advance. While this is true for any energy technology, it is particularly relevant to wind because of the technology innovations recently adopted by the U.S. wind industry (Wiser and Bolinger 2017) and advancement possibilities for future machines (Lantz et al 2017; Dykes et al. 2017). In addition, the legislated reduction and elimination of federal wind tax credit subsidies could heighten the need for technology advancements to enable economically competitive wind power. Our scenarios suggest that wind technology advancements can play a major role in shaping the long-term growth of U.S. wind and could thereby impact the entire electricity system.

Figure 6 shows estimated installed wind capacity through 2050 in 35 modeled scenarios, including scenarios under "core" reference conditions as well as our natural gas price and nonwind renewable cost sensitivities. Focusing first on the five core scenarios (highlighted by the colored lines in the left panel of Figure 6) we find that uncertainty in wind technology advancements and innovation is associated with a wide range of future installed wind capacity; wind capacity is estimated to differ by $132 \mathrm{GW}$ from the lowest-cost (A2e) case to the highestcost (IEA High) case in 2030 and by $445 \mathrm{GW}$ in 2050.

Comparing individual scenarios reveals insights that are not apparent from the full range of scenarios. For example, a comparison of the newer IEA Median scenario (reflecting the "mostlikely" projection from the most-recent global survey of wind experts [Wiser et al. 2016]) with the older ATB Mid-cost (reflecting the aggregate of projections produced prior to 2015) suggests that recent wind advancement projections used by the U.S. government, national laboratories, and others over the past several years may be underestimating wind cost reduction possibilities, potentially leading to low deployment projections. ${ }^{25}$ One possible reason for the differences between the expert expectations (IEA Median) and the broader literature (represented by the ATB projection) is that the experts may be considering a broader set of wind advancement possibilities (e.g., increased performance, extended project lifetimes, and lower operating costs). ${ }^{26}$ Nonetheless, our analysis shows that considering this larger set of advancements results

\footnotetext{
${ }^{25}$ See Cole et al. (2016b) for a list of recent users of the ATB data.

${ }^{26}$ As described in Section 2, for the "IEA" scenarios we apply the LCOE reduction, on a percentage basis, reported in Wiser et al. (2016) for all wind resource regions by modifying the capital cost, O\&M cost, and capacity factors (see Appendix A). We retain ReEDS' default treatment of project lifetimes and financing parameters. As a result, while total LCOEs are aligned with the experts' expectations, individual component cost reductions or improvements are not perfectly aligned between our assumptions and the source studies.
} 
in relatively minor wind capacity differences in 2030 (109 GW in IEA Median vs. 99 GW in ATB), but becomes substantial by 2050 (282 GW vs. $193 \mathrm{GW})$.
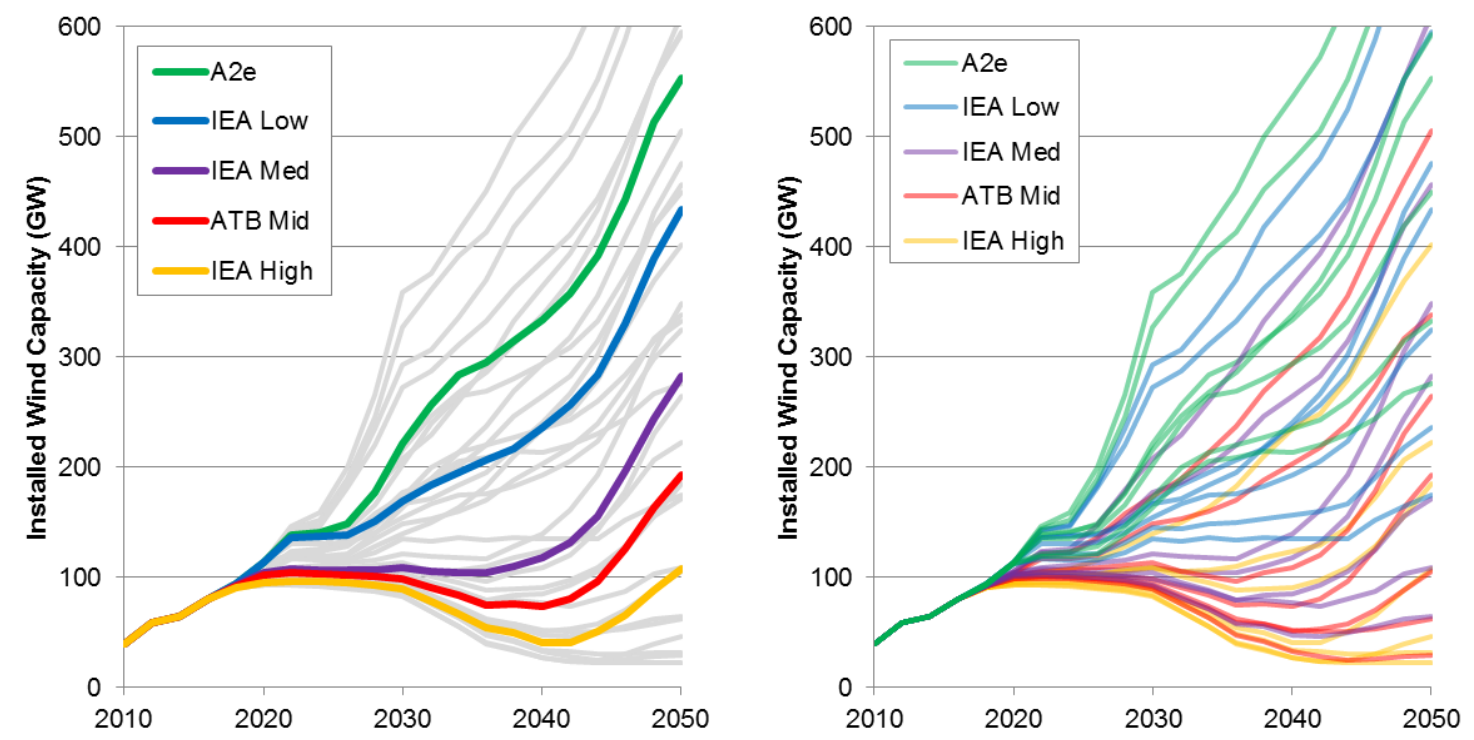

Figure 6. Installed wind capacity for core and sensitivity scenarios

For the left figure, the colored lines show results from core scenarios and gray lines show sensitivities. All sensitivities are shown on the right figure with color-coded lines identifying the wind cost assumptions used.

Figure 6 also shows how aggressive wind technology advancement, as reflected in the IEA Low and A2e scenarios, could yield even greater wind deployment. These deployment impacts are found to occur in the near- and medium-term (installed wind capacity is estimated to reach 169 GW and $221 \mathrm{GW}$ in the two scenarios respectively by 2030) and over the full study horizon (433 GW and $553 \mathrm{GW}$ respectively by 2050). The consistent and sustained development of wind in these scenarios are loosely consistent with deployment levels found in the DOE Wind Vision study (DOE 2015; Lantz et al. 2016), thereby identifying the technology innovation requirements needed to achieve the wind levels envisioned in the study without additional policy support.

Wind technology advancement can also lead to regionally widespread deployment, enabling wind to provide benefits on a national basis. Figure 7 shows estimated installed wind capacity in seven subnational regions based on groupings of the nine U.S. census divisions. Historically, wind installations have been somewhat concentrated in the central regions of the country (North and South Central regions in Figure 7) with more-modest deployment in the western (Pacific and Mountain) and Great Lakes regions. Very limited wind deployment has occurred in the eastern part of the country; by year-end 2016, wind capacity totaled only about $5 \mathrm{GW}$ combined in the Northeast and Southeast regions, compared with $82 \mathrm{GW}$ nationwide.

These regional trends are estimated to hold in the near term under many of the scenarios, including the A2e and IEA Low scenarios, as the lowest-cost wind resources from the central regions are generally relied on first. However, we find that wind technology advancements can broaden deployment to a wider number of regions. For example, we find significant long-term opportunities for wind in the Great Lakes and Southeast regions with installed capacity exceeding $120 \mathrm{GW}$ and $40 \mathrm{GW}$ respectively by 2050 if wind advancements reach levels 
envisioned in the IEA Low and A2e scenarios. ${ }^{27}$ In these scenarios and regions, growth in wind development signifies that technology advancements can enable economical wind deployment even in locations with lower average wind speeds than sites in the central "wind belt" of the country. Deployment in these regions is supported by a combination of factors: greater challenges to transmitting wind power from remote sites in the central regions to load centers near the coasts, higher costs for or more-limited access to transmission interconnections, depletion of the windiest sites, and the benefits of geospatial diversity for wind integration. These factors can contribute to saturation in the central wind belt and, when combined with higher hub heights and other technology advancements implied by the A2e and IEA Low scenarios, lead to a wider deployment distribution. Another factor that contributes to greater capacity deployment in the Great Lakes and Southeast regions is their current reliance on older coal and nuclear capacity, which we assume experience significant retirements by $2050 .^{28}$ Retirements, along with load growth, can open up opportunities for new capacity and a large share of these opportunities are found to be met by wind under the lowest-cost wind scenarios.

\footnotetext{
${ }^{27}$ As shown in Figure 7, growth in the central and mountain regions are also quite significant under the A2e and IEA Low scenarios.

${ }^{28}$ We use ReEDS default retirement assumptions, including 65- or 75-year lifetimes for coal plants and 60-year lifetimes for nuclear plants (Eurek et al. 2016).
} 


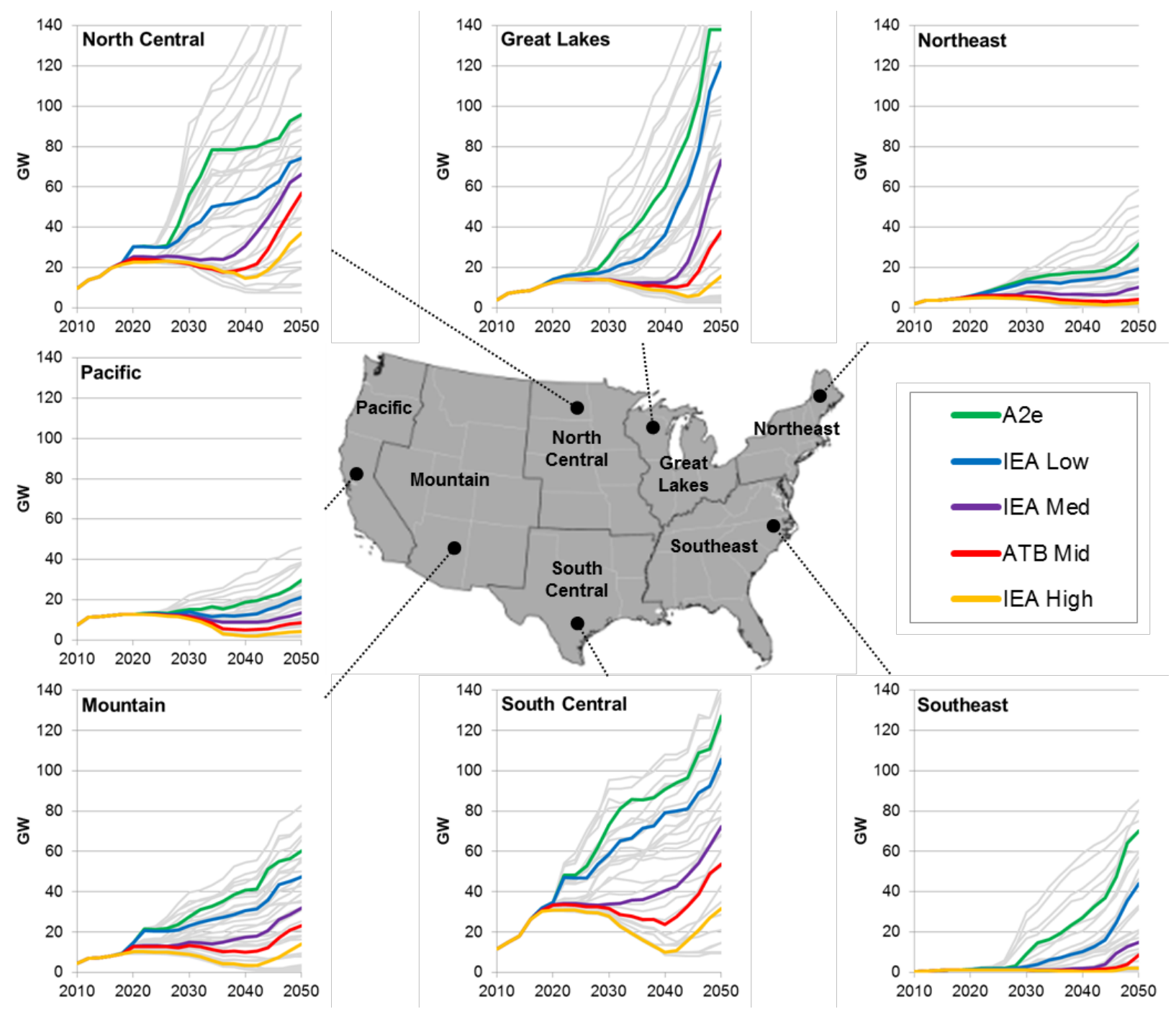

Figure 7. Regional wind capacity deployment over time

Colored lines show results from core scenarios; gray lines show sensitivities.

Although Figures 6 and 7 demonstrate large potential opportunities for technology advancementdriven wind deployment, they also reveal the challenges in the absence of technology improvements. In particular, failing to achieve advancements in wind technologies could result in sizable lost opportunities for wind, yielding reduced wind installations and higher costs. For example, in the IEA High scenario, where wind costs are expected to remain largely unchanged over time, due to increasing competition from other generation sources and without new policy support, installed wind capacity is anticipated to stay flat or even decline over the next three decades as older turbines reach their useful lives but are not replaced. The limited net growth in wind capacity after 2020 in this scenario is the result of continued competition from low-price natural gas as well as increasing competition from solar PV. In effect, solar PV and natural gas are found to outcompete new wind generation in the absence of measurable technology cost 
reductions and/or an extension of the federal production tax credit (or other supporting policy). ${ }^{29}$ In this scenario, wind capacity reaches a nadir of about $41 \mathrm{GW}$ in the early 2040s and recovers to $107 \mathrm{GW}$ by 2050 . New wind turbines, in the IEA High scenario, are only deployed in interior regions while coastal regions experience little repowering in the long term, nearly leading to the elimination of wind power in the eastern and Pacific regions.

Figure 8 provides additional detail on estimated wind capacity installations for the five core scenarios. The left panel shows average annual installations - including new green-field capacity and repowered capacity - over four different periods. ${ }^{30}$ From 2017 to 2020, in part due to the PTC, wind development is estimated to be robust across technology projections and largely aligned with recent deployment levels of about $7 \mathrm{GW} /$ year. After 2020, we estimate a sizeable impact from wind technology advancements. During the 2020s, when delivered gas prices are estimated to remain below $\$ 5 / \mathrm{MMBtu}$ and solar technologies are assumed to continue their dramatic cost decline (Figure 5), annual wind installations are estimated to be less than $2 \mathrm{GW} /$ year absent significant reductions in the cost of wind energy. Despite these challenging market conditions, however, achieving wind cost reductions to levels from the IEA Low scenario can help sustain healthy annual installations. Achieving the A2e advancement could yield average annual deployments during the 2020s that exceed historical records. After 2030, we estimate much greater wind deployment across all scenarios, including annual deployments that well exceed historical record levels when successful technology advancements are assumed. The significant annual installation rates in the long term occur due to continued wind energy cost reductions and rising natural gas prices, as well as because of increasing room for new wind due to modeled fossil and nuclear plant retirements and demand growth. Nonetheless, even in the long term there remains a very sizable range in annual average deployment across the five cost scenarios.
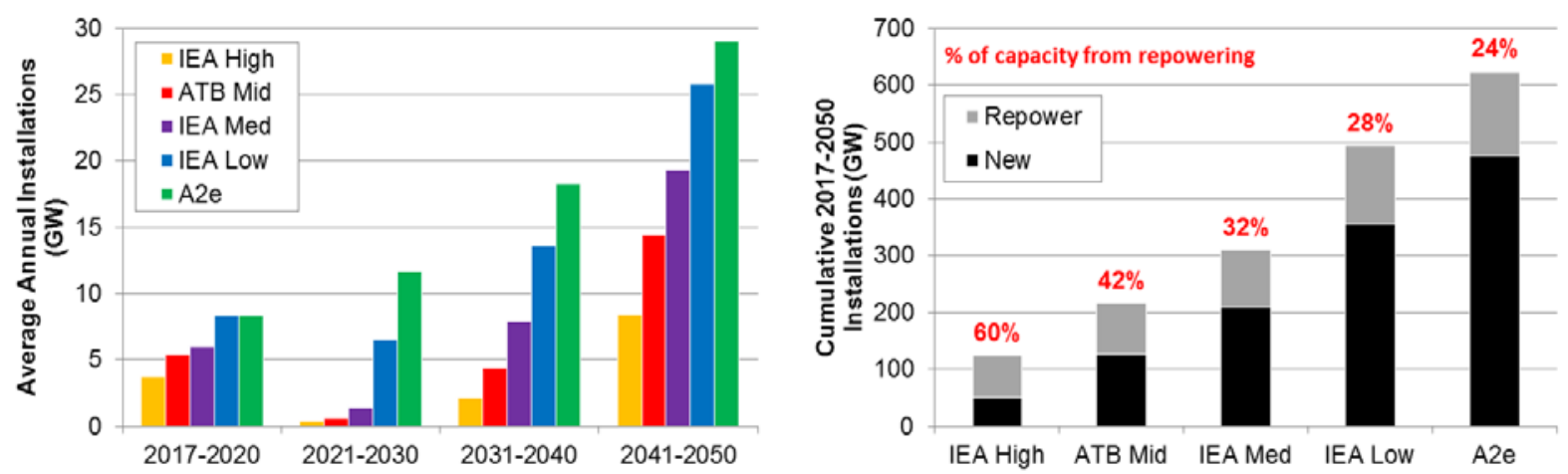

Figure 8. Average annual wind capacity installations (left) and cumulative (2017-2050) new and repower capacity for the core scenarios (right)

\footnotetext{
${ }^{29}$ In fact, limited growth in wind capacity immediately after the early-2020s is found in many scenarios for the same reasons. However, the amount of time it takes and the extent to which new wind growth recovers is strongly dependent on future wind cost reductions as shown in our scenarios and in Mai et al. (2016a).

${ }^{30}$ Figure 8 shows gross installations and not net installations. The latter is lower (and possibly negative in some cases and years) due to retirements.
} 
Another source of the larger annual installation estimates found in the 2030s and 2040s is repowering, or the replacement of older turbines at the end of their useful lives with newer machines. We assume a 24-year lifetime for all turbines, so the 2016 fleet would be retired or repowered by $2040 .^{31}$ The right panel in Figure 8 shows how repowering can comprise a significant share of cumulative installed capacity. In fact, repowered capacity is estimated to comprise the majority share of all wind installations under the IEA High scenario. In absolute terms, the amount of repowered capacity over the full analysis period (2017-2050) is estimated to exceed today's installed capacity of $82 \mathrm{GW}$ in all scenarios except the IEA High scenario.

Although the five wind technology projections already produce a wide range of deployment possibilities, an even wider range is modeled in our natural gas price and non-wind renewable technology cost sensitivities. As shown by Figures 6 and 7, ranges of national and regional installed wind capacity span an enormous range particularly in the long run. For example, installed wind capacity is estimated to reach $292 \mathrm{GW}$ and $359 \mathrm{GW}$ in 2030 under the most favorable (high natural gas prices combined with high non-wind RE technology costs) conditions for wind if the IEA Low and A2e wind advancements are achieved, respectively. In 2050 and with these same favorable conditions, wind capacity can exceed 700-800 GW under these scenarios. These favorable conditions indicate substantial upside deployment opportunities if natural gas prices rise faster than anticipated and/or if solar and other non-wind RE technologies do not achieve the same cost reductions anticipated in the reference scenario. On the other hand, unfavorable conditions would lower the opportunity space for wind deployment. The right panel in Figure 7 uses color-coded lines to show how the individual wind cost projections fair under the full range of scenarios. Figure 9 summarizes the magnitude of impact to 2050 installed wind capacity from three separate drivers: wind technology advancement, natural gas prices, and nonwind RE costs. It suggests that, in aggregate across all scenarios and sensitivities, the upside possibilities exceed the downside ones. Furthermore, wind technology advancements offer a hedge for future U.S. wind deployment in the case that less favorable conditions prevail. For example, 2030 wind capacity is higher in the IEA Low scenario even with low natural gas prices compared to the IEA Median scenario under reference natural gas prices (145 GW vs. $109 \mathrm{GW}$ ).

\footnotetext{
${ }^{31} \mathrm{We}$ assume, perhaps conservatively, that repowering requires full turbine and balance of station equipment replacement, but with the advantage of not requiring additional grid interconnection equipment costs. The newest available vintage of machines with any associated performance improvements are assumed when repowering.
} 


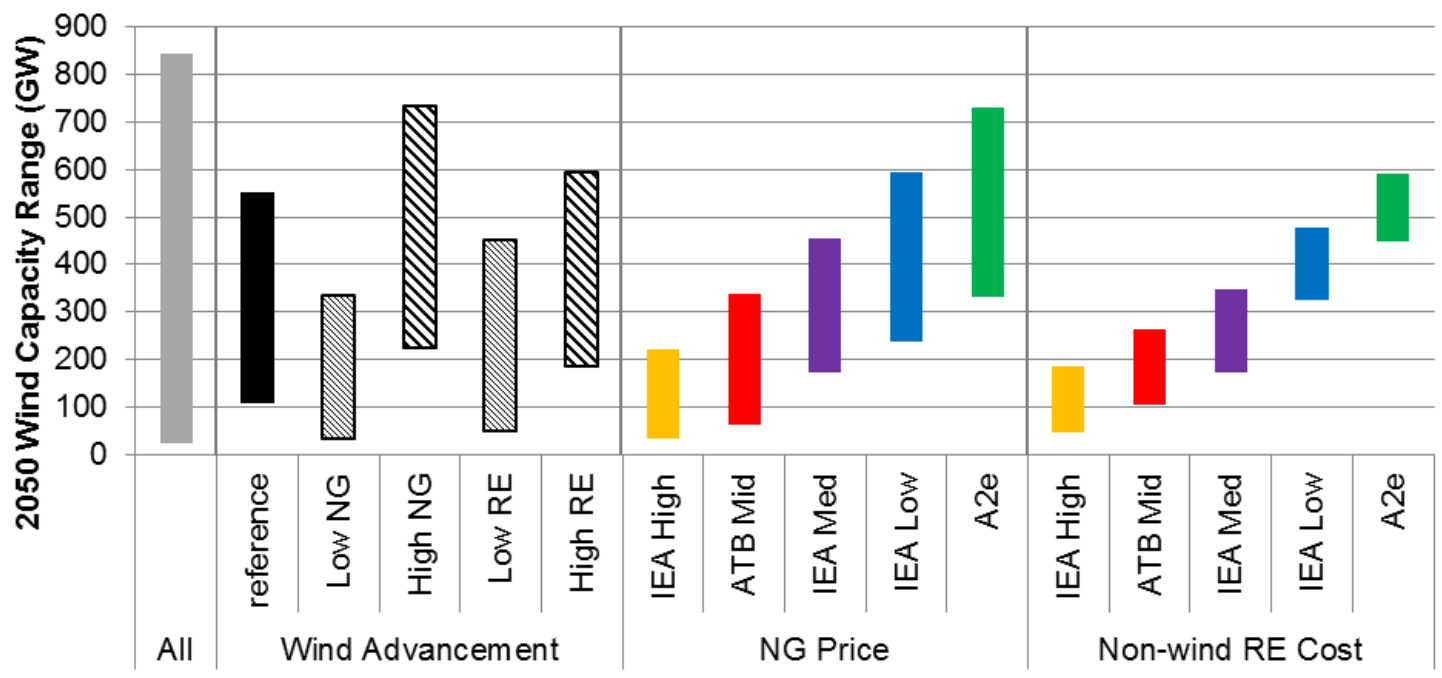

Figure 9. 2050 installed wind capacity ranges by driver

The horizontal text in the $x$-axis identifies the driver of the range shown by the floating bars. Lowest (highest) results in the "All" bar correspond to the IEA High with low natural gas and low non-wind RE costs (A2e with high natural gas and high non-wind RE costs) scenarios. The ranges of the "Wind Advancement" bars are driven by the IEA High and

A2e scenario under the market conditions shown. The ranges of the "NG Price" and "Non-wind RE Cost" bars are driven by the low/high natural gas and RE technology costs, respectively.

\subsection{Wind Generation}

U.S. wind generation shares are estimated to grow from about 5.6\% in 2016 (EIA 2017a) to 7\%$10 \%$ in 2020 under all scenarios (Figure 10). After 2020, wind penetration is projected to vary widely depending on wind technology advancements. For example, 2030 wind penetration is estimated to fall within a narrow range $(7 \%-9 \%)$ across three of the core scenarios (IEA High, ATB Mid, and IEA Median) but reaches $15 \%$ and 19\% under the IEA Low and A2e scenarios respectively. ${ }^{32}$ Technology advancements in the IEA Low and A2e scenarios lead to wind penetrations of $38 \%$ and $45 \%$ respectively, in 2050 . In fact, we estimate wind penetrations exceeding 50\%-60\% for some sensitivities and some regions (Figure 10 and Appendix B).

The high and increasing wind penetration levels from the reference IEA Low and A2e scenarios, and from the most-extreme sensitivities, suggest that despite increasing grid integration challenges sufficient wind technology advancements can enable wind power to still provide system value even at very high penetration levels. For example, despite potentially high marginal curtailment rates, sufficiently low wind power costs can enable cost-effective deployment. However, our modeling analysis does not capture all potential technical or economic challenges of high wind penetration. Detailed grid integration studies (e.g., Bloom et al. 2016 and Lew et al. 2013) find that integrating up to $30 \%-35 \%$ variable wind and solar generation is technically feasible and requires minimal changes to system operations. A more limited number of highfidelity studies have been conducted with wind and solar penetrations exceeding those levels. ${ }^{33}$

\footnotetext{
${ }^{32}$ We define wind penetration based on total generation. As a fraction of end-use electricity consumption, the metric used in the Wind Vision study (DOE 2015), wind penetration would be higher. For example, wind penetration as a fraction of end-use consumption is estimated to exceed $20 \%$ in 2030 under the A2e scenario.

${ }^{33}$ NREL (2012) evaluates $80 \%$ renewable electricity scenarios and 40\%-50\% variable generation scenarios for the continental United States using hourly modeling. Brinkman (2015) applies sub-hourly unit commitment modeling to
} 
New research would be required to more-comprehensively assess the technical and economic feasibility of achieving the highest wind penetration scenarios shown in Figure 10.

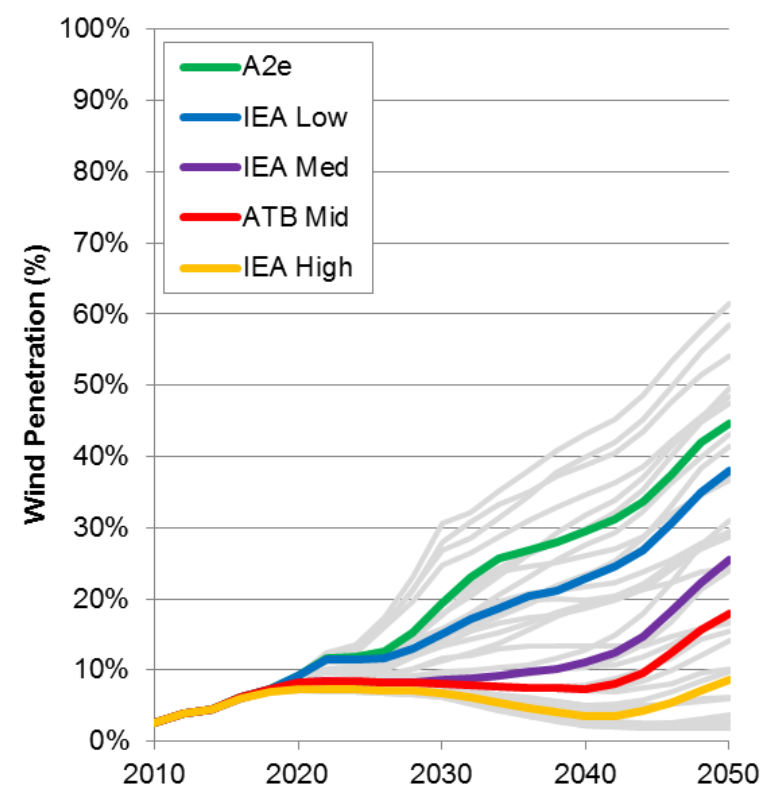

Figure 10. Wind penetration for the core scenarios (colored) and sensitivity scenarios (gray)

\subsection{Impacts to Other Generation Sources}

Greater wind generation would come at the expense of other generation sources. Figure 11 shows national annual generation differences by fuel type relative to the IEA Median scenario for the core scenarios. ${ }^{34}$ In the two scenarios with the greatest amount of wind technology advancement (A2e and IEA Low), increased wind generation is found to occur at the expense of fossil fuel-based generation as well as solar generation. For example, on a cumulative (20172050) basis, of the total displaced generation, $81 \%$ was from fossil fuel-based sources (45\% natural gas, $36 \%$ coal), $18 \%$ from solar, and a negligible remainder from other sources in the IEA Low scenario relative to the IEA Median. Generation differences in these scenarios are caused by a combination of capacity factor reductions in existing facilities (both coal and gas), avoided generation from new capacity (gas and solar), and increased retirements (coal). This result suggests that technology advancements can enable wind to be economically competitive with the variable costs of existing units as well as total life-cycle costs of new units.

Generation differences in the ATB Mid or IEA High scenarios relative to the IEA Median scenario are also shown in Figure 11. In these scenarios, the long-term trade-offs between wind, natural gas, and solar are also apparent, while the impact to coal-fired generation is minor (less than 51 terawatt-hours in all years). Although trade-offs between wind and solar generation have limited environmental benefits, the amount of generation displacement between wind and solar is small compared to differences between wind and natural gas. Text Box 1 discusses comparisons among scenarios with successful advancements in both wind and PV technologies.

assess the operational feasibility of western U.S. scenarios with greater than $80 \%$ renewable energy (greater than $40 \%$ variable generation).

${ }^{34}$ Appendix B shows capacity and generation mixes for the IEA Median scenario. 

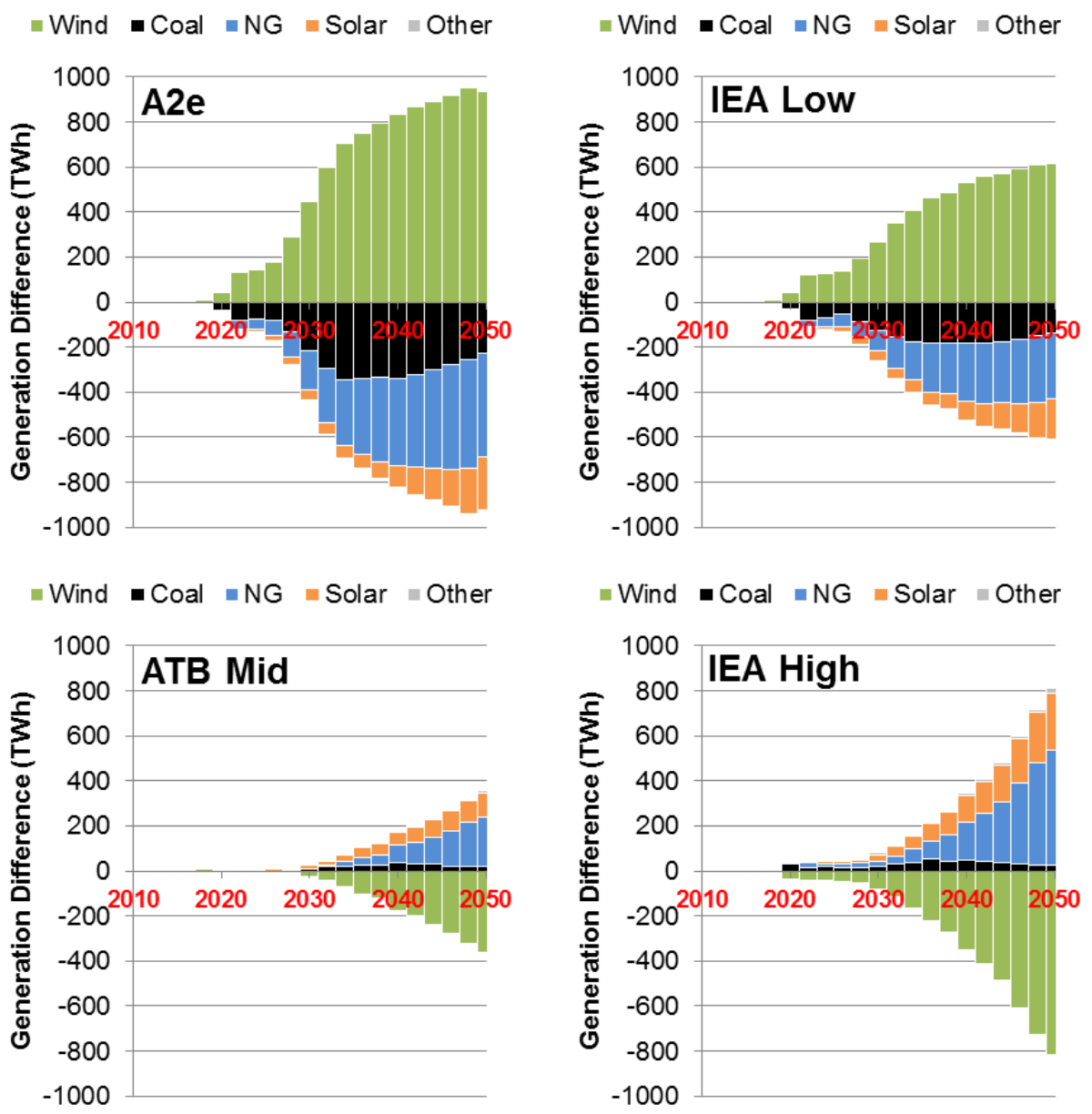

Figure 11. National generation difference from the IEA Median scenarios

Positive values indicate greater generation in the labeled scenario relative to the IEA Median scenario and negative values show the opposite.

The impact of wind on avoided generation can also vary substantially between regions, as each region possesses distinct portfolio mixes and marginal generation costs. Figure 12 shows regional differences in generation between the IEA Low and IEA Median scenarios. Although natural gas generation is most severely impacted by the higher wind generation from the IEA Low scenario on an aggregate national basis (Figure 11), coal and solar can be the generation sources most impacted in certain regions. For example, in the coal-heavy North Central region, we find that displaced generation from incremental wind is comprised almost entirely of coal. On the other hand, in regions that do not heavily rely on coal, such as the Pacific and Northeast, we find avoided generation from primarily natural gas and solar. The avoided generation mix is split more evenly between coal and natural gas in the South Central region, reflecting the current and anticipated generation mix of that region.

Electricity imports and exports between regions also vary between technology advancement scenarios. For example, in the IEA Low scenario, very significant wind deployment in the North Central and Great Lakes regions lead to greater amounts of electricity exports in many years, which is shown by the net increase in regional generation from the IEA Median scenario in 
Figure 12. The Northeast, Southeast, and Pacific regions experience the opposite: increased imports or reduced exports. The ability to export or import electricity depends on transmission availability and, potentially, transmission expansion. Our modeling methodology considers this in its system least-cost decision-making (Eurek et al. 2016). However, because transmission expansion can be impacted by non-economic factors, we also test sensitivities of different transmission expansion constraints in the following section.

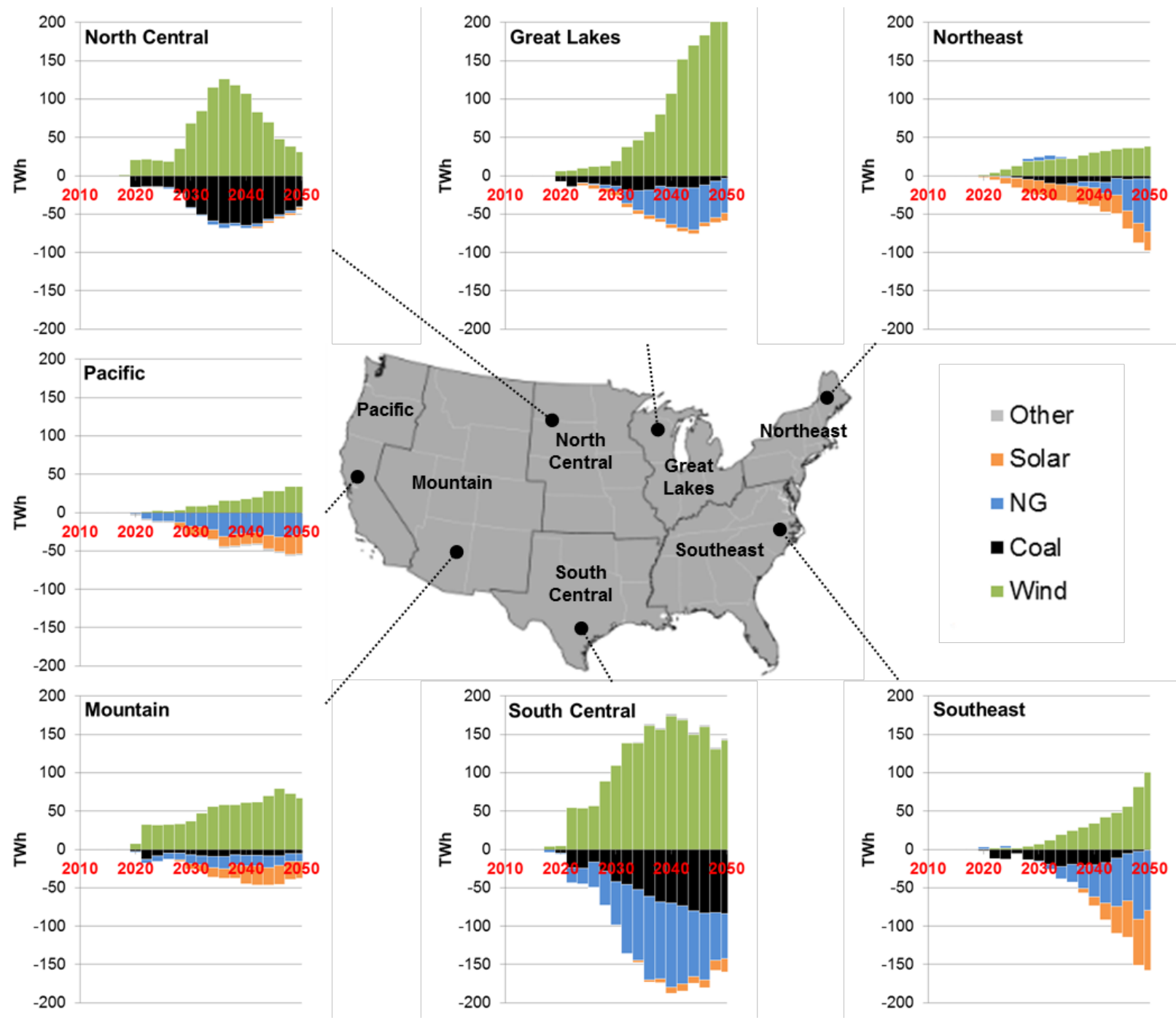

Figure 12. Regional generation difference between the IEA Low and the IEA Median scenarios

Positive values indicate greater generation in the IEA Low scenario and negative values show greater generation in the IEA Median scenario. 


\section{Text Box 1. SunShot 2030 Initiative Sensitivity}

Our analysis primarily focuses on the impacts of wind technology advancements under a wide range of future market conditions, including a range of non-wind RE technology costs. However, this range does not encompass all possibilities and excludes the U.S. DOE's recently-announced SunShot 2030 initiative (https://energy.gov/eere/sunshot/sunshot-2030; Cole et al. (2017)) which presents PV technology cost reduction goals that exceed reductions in the lowest cost projections modeled in our primary scenarios (i.e., ATB 2016 Low). In this text box we show RE capacity and generation results assuming successes in both wind and PV technologies by using the A2e and SunShot 2030 projections, respectively. These results are compared to those from a scenario where wind reaches the same A2e projections, but PV is assumed to follow ATB Low projections. Differences in costs and deployment are estimated for utility-scale as well as distributed technologies. Both scenarios use ATB Low costs for all other RE technologies and reference fossil fuel and demand growth assumptions.

The solid lines in Figure 13 show annual generation and capacity results from the "RE Technology Success" scenario. In this scenario, total RE generation grows consistently over time and is projected to serve a large majority of total generation needs by 2050 . In 2050, wind and solar generation together comprise nearly $90 \%$ of all RE generation. Installed capacity results follow similar trends with total RE capacity exceeding $1300 \mathrm{GW}$ by 2050, including over $400 \mathrm{GW}$ from wind and over $800 \mathrm{GW}$ from solar technologies.

The dotted lines in the Figure also show results for a scenario with more-modest solar technology advancements. As would be expected, solar penetration and deployment is lower in this scenario and wind growth is greater than in the RE Technology Success scenario. However, we find that aggregate RE generation and capacity are higher when both wind and solar achieve their greatest technology advancements modeled demonstrating that successful technology innovations in both would yield even greater system benefits than success in any single individual technology.
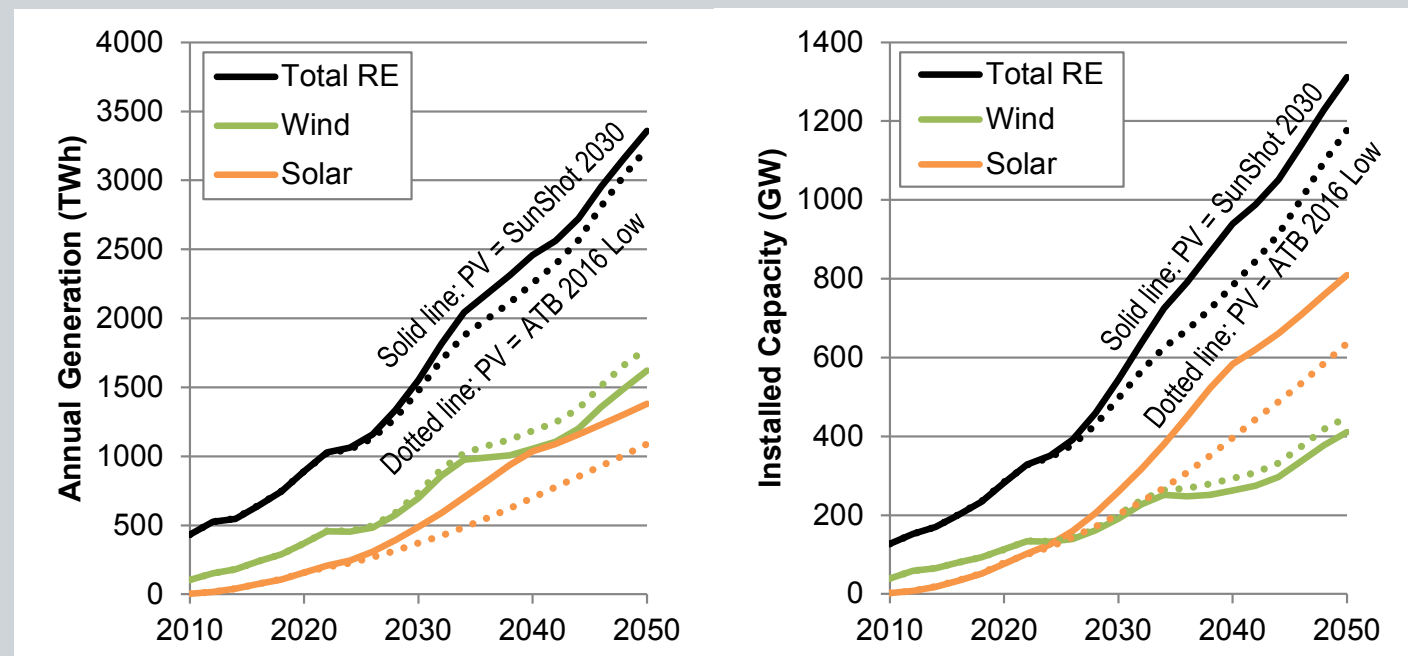

Figure 13. Wind, PV, and total RE generation (left) and capacity (right) in select RE technology sensitivities. 


\subsection{Impacts of Transmission Expansion Constraints}

Renewable energy resources in general, and wind energy specifically, are dispersed and locationspecific. Consequently, electric transmission lines are needed to deliver RE power to load centers, and sites with the highest quality resources are often remote from urban areas with the greatest amount of electricity demand. In addition, much of the existing transmission infrastructure was not historically designed to access and deliver renewable energy. Widespread deployment of new wind capacity could require significant investments in transmission infrastructure or, conversely, a lack of transmission expansion could deter the ability to develop economically favorable wind resources.

The scenario results presented in earlier sections relied on the default transmission representation in ReEDS where economically attractive transmission expansion is allowed within the system least-cost optimization model. ${ }^{35}$ In other words, ReEDS can choose to increase transmission capacity between neighboring model balancing areas and the cost of transmission expansion is considered in the model's objective function. Multiple factors influence transmission expansion in the model, including accessing remote resources such as wind and solar energy, arbitraging fossil fuel between regions with lower-cost fuel and/or more-efficient thermal generators, supporting load diversity, and enabling firm capacity trading between regions.

Under this default representation, ReEDS does not directly weigh non-economic factors that might impact transmission development, but it does consider regionally varying costs for transmission (DOE 2015; Eurek et al. 2016). To test the degree to which the ability to expand transmission capacity might impact wind deployment, we model two "constrained transmission expansion" sensitivities for each of the five core scenarios; one sensitivity does not allow any new interregional or inter-BA transmission capacity expansion and the other prevents new transmission capacity for lines that cross state boundaries. ${ }^{36}$ As there exists multiple model BAs for most states in ReEDS (Eurek et al. 2016), the former sensitivity is more restrictive than the latter.

As expected, constraining transmission lowers estimated wind deployment and the impact is greater, on an absolute basis, for scenarios with the highest amount of estimated wind deployment (Figure 14). ${ }^{37}$ Disallowing new interregional transmission reduces 2050 wind capacity by $26 \mathrm{GW}$ in the A2e scenario, $14 \mathrm{GW}$ in the IEA Low scenario, and $9 \mathrm{GW}$ in the IEA Median scenario. However, on a percentage basis, the national wind deployment impact is quite limited. Across all scenarios, 2050 wind capacity is lower by less than $6 \%$ with the transmission expansion constraints. Constraining transmission expansion can, on the other hand, significantly impact regional wind deployment. Figure 15 shows the regional change in 2050 wind capacity in the transmission expansion sensitivities relative to our default transmission representation for the

\footnotetext{
${ }^{35}$ In ReEDS, transmission expansion is restricted to projects that are already under construction or are in the project pipeline prior to 2022. Endogenous transmission expansion decisions are only allowed on or after 2022 to reflect the long lead times and construction periods for major transmission projects (Eurek et al. 2016).

${ }^{36}$ The constraints do not impact transmission projects that are already complete or under construction as modeled in ReEDS (Eurek et al. 2016).

${ }^{37}$ By design, our analysis excludes new offshore wind capacity; therefore, the modeling applied in this analysis does not consider the potential for offshore wind in transmission-constrained regions. Future research, possibly using ReEDS and more-detailed transmission models, is needed to assess the trade-offs between offshore and land-based wind and the conditions for which offshore wind deployment may become economical.
} 
IEA Median and IEA Low scenarios. In both wind advancement scenarios, constraining transmission expansion reduces deployment in the central regions (with a net reduction in total national deployment as previously described) but actually increases wind deployment in multiple other regions. In the IEA Median scenario, we find an increase in 2050 wind capacity in nearly all other regions with the most-substantial increases in the Great Lakes and Southeast regions. In the IEA Low scenario, where significant wind deployment is found in the Great Lakes and central regions (see Figure 7) by 2050, we observe lower wind capacity in the Great Lakes region due to the transmission constraints but a significant increase of over $20 \mathrm{GW}$ in the Southeast region. Overall, the results shown in Figures 14 and 15 suggest that although transmission expansion may not strongly impact the economical deployment of wind at the national level, local transmission-related decisions and planning can either support or adversely impact regional wind development. The results also suggest little difference to wind deployment between the two interregional and inter-state transmission constraints implying that, for wind, the value of transmission expansion is to move power long distances across multiple states and the minor differences between our two restrictive cases are less significant.

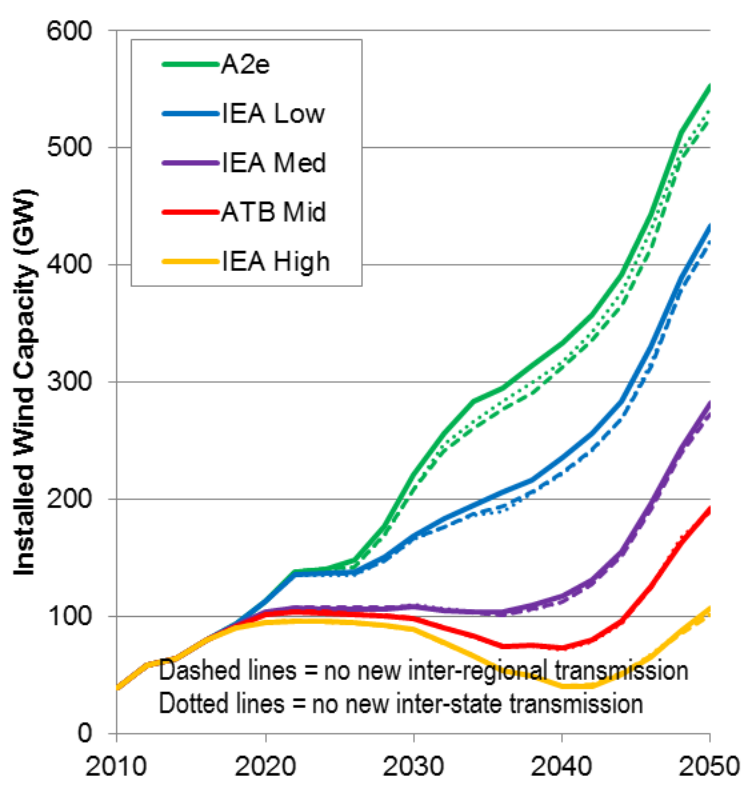

Figure 14. Installed wind capacity in constrained transmission expansion sensitivities

Some caution is warranted in extrapolating the results from our transmission expansion sensitivities too broadly for multiple reasons. First, the sensitivities apply only to interregional transmission and not intraregional transmission (i.e., spurs lines to connect new wind power plants to the bulk transmission system). Wind deployment could be more substantially impacted if intraregional transmission is more constrained or more costly than modeled. Second, the sensitivities are designed to explore the impact of transmission expansion but do not apply to transmission utilization of new or existing lines, which could also impact the ability transmit remote wind power. Third, our analysis reflects some of the broader system value from transmission (e.g., for delivering lowest-cost electricity and supporting resource adequacy) but does not consider other technical reliability factors (e.g., system stability), which could also impact transmission development and, indirectly, future wind development. Finally, higherfidelity modeling may be needed to capture some of the technical and economic impacts related to transmission, such as nodal curtailment impacts and opportunities for high-voltage DC lines 
and advanced transmission technologies (Jorgenson et al. 2017 and MacDonald et al. 2016). Nonetheless, the results from our analysis suggest that the economic opportunities for wind with technology advancements are robust to a range of transmission expansion scenarios. They also highlight the large and shallow wind supply curve at the national and regional scales.

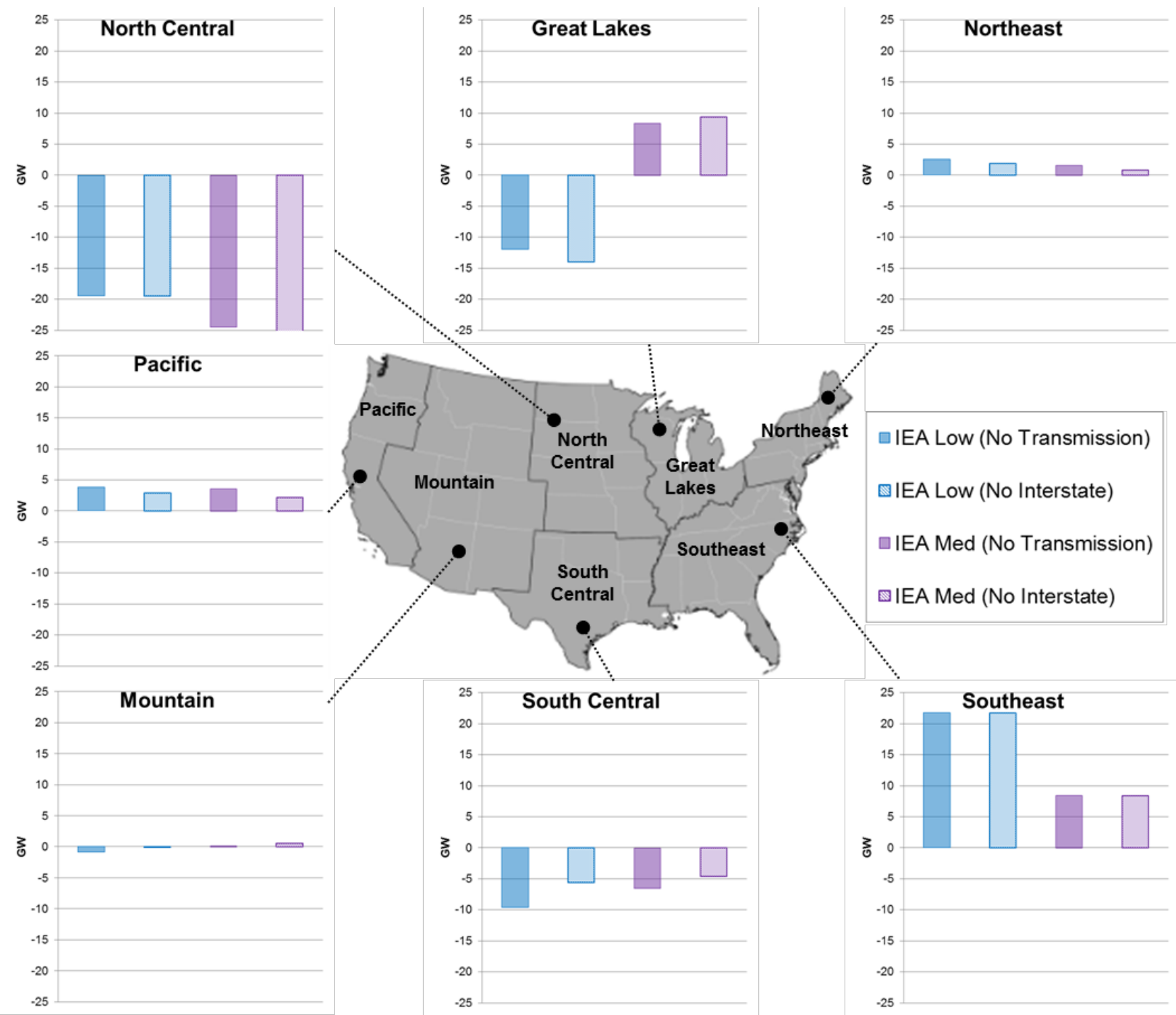

Figure 15. Differences in regional wind capacity due to transmission expansion constraints

"No Transmission" refers scenarios where transmission capacity expansion between model balancing areas is disallowed. "No Interstate" applies similar constraints, but less-restrictively, to lines that cross state boundaries only. 


\subsection{Electric System Costs}

Beyond the impacts to the future U.S. wind industry, wind technology advancements can offer opportunities to the broader electricity system by lowering total system costs and electricity prices. Figure 16 (left) shows the net present value (NPV) of total electricity system costs from 2017 to 2050 (3\% real discount rate ${ }^{38}$ ), including capital, O\&M, and fuel costs for all generation sources, storage, and transmission for the core five scenarios. Figure 16 (right) shows differences in system costs from the IEA Median scenario. The results show that future wind technology advancement can have a measurable impact on overall electricity system costs. Under the core scenarios, system costs can vary by $\$ 240$ billion (equivalent to $7 \%$ of total system costs for the IEA Median scenario). The range of system costs is even greater ( $\$ 564$ billion) across all sensitivities.
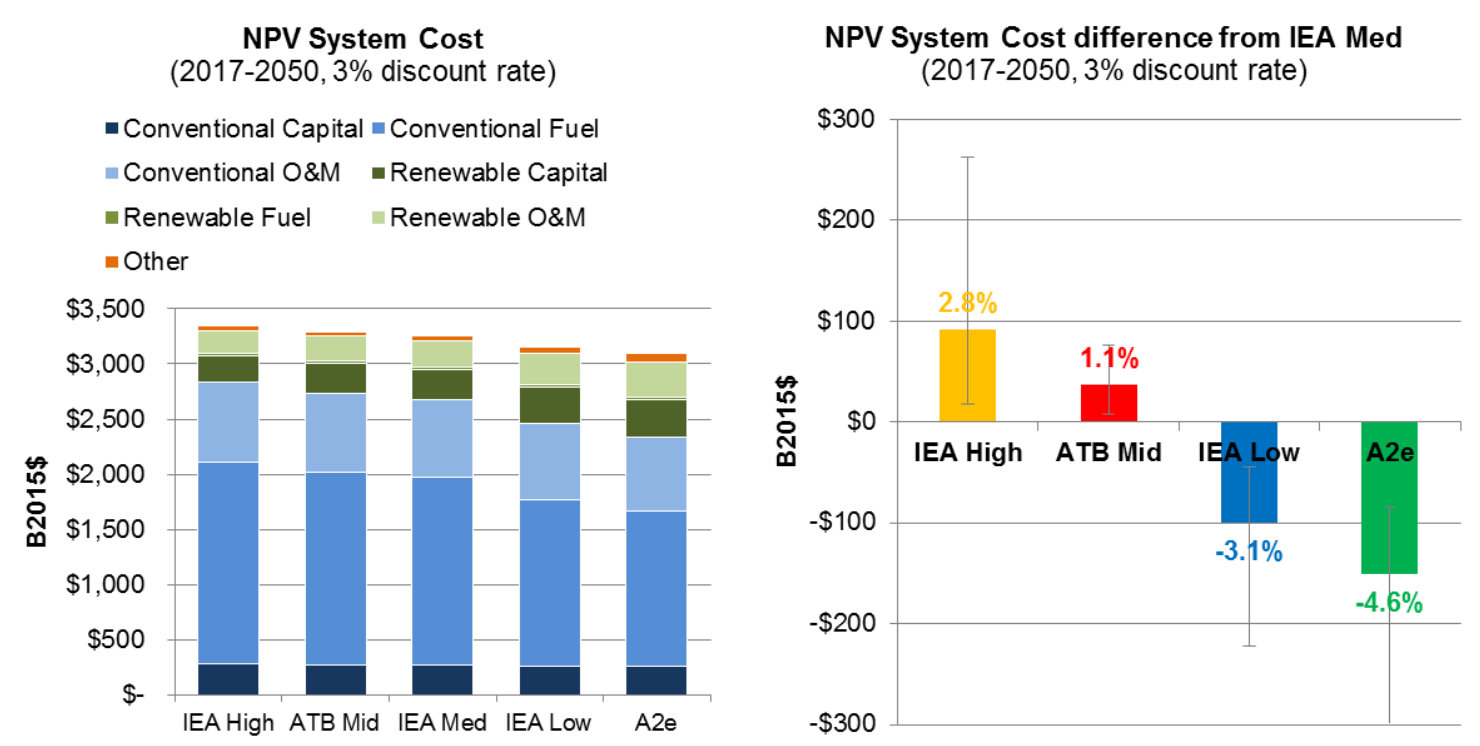

Figure 16. Total system cost for core scenarios (left) and incremental system cost relative to IEA Median scenario (right)

Error bars in the figure on the right show the range across all sensitivities.

As shown in the prior sections, wind technology advancements are estimated to yield greater wind deployment and reduce primarily fossil generation. As a result, in the more-advanced wind technology scenarios we find increased investments in renewable capital costs (and O\&M costs) that are more than offset by reductions in fossil fuel-related costs. Relative to the IEA Median scenario, system cost in the ATB Mid scenario is $\$ 37$ billion (1.1\%) higher. Figure 16 also shows that aggressive wind technology advancements can help lower system costs measurably; system costs are estimated to be $\$ 99$ billion (3.1\%) lower than the IEA Median scenario in the IEA low scenario, and $\$ 151$ billion (4.6\%) lower in the A2e scenario. Conversely, failing to

\footnotetext{
${ }^{38}$ A $3 \%$ social discount rate is consistent with guidance from the White House Office of Management and Budget when assessing long-term costs and impacts. Note that this discount rate differs from the higher discount rate used in the ReEDS model.
} 
achieve wind technology advancements could result in significantly higher costs; the IEA High scenario is estimated to cost $\$ 91$ billion $(2.8 \%)$ more than the IEA Median scenario. ${ }^{39}$

The benefits of wind technology advancements to lowering system costs could cascade downstream to electricity consumers. ${ }^{40}$ Figure 17 shows estimated electricity price ${ }^{41}$ and monthly household bill ${ }^{42}$ differences from the IEA Median scenario for the other core scenarios. Although there are some year-to-year fluctuations in electricity prices-averaged over all regions and across all sectors - driven by changing retirements, technology costs, and policies in the model, the long-term trends are clear. Focusing on the 2050 values, we find average electricity prices to be $\$ 9.4 / \mathrm{MWh}(\$ 7.8 /$ month) greater in the IEA High scenario relative to the IEA Median scenario. More moderate incremental 2050 price $(\$ 4 / \mathrm{MWh})$ and monthly bill $(\$ 3.4 / \mathrm{month})$ impacts are found for the ATB Mid scenario. With technology advancements assumed in the IEA Low scenario, we find savings of up to $\$ 4 / \mathrm{MWh}(\$ 3.4 / \mathrm{month})$ in 2050 relative to the IEA Median scenario. The largest electricity consumer savings are found under the A2e scenario, which is estimated to result in $\$ 6.8 / \mathrm{MWh}(\$ 5.6 /$ month) lower 2050 electricity rates (monthly bills) compared to the IEA Median scenario.
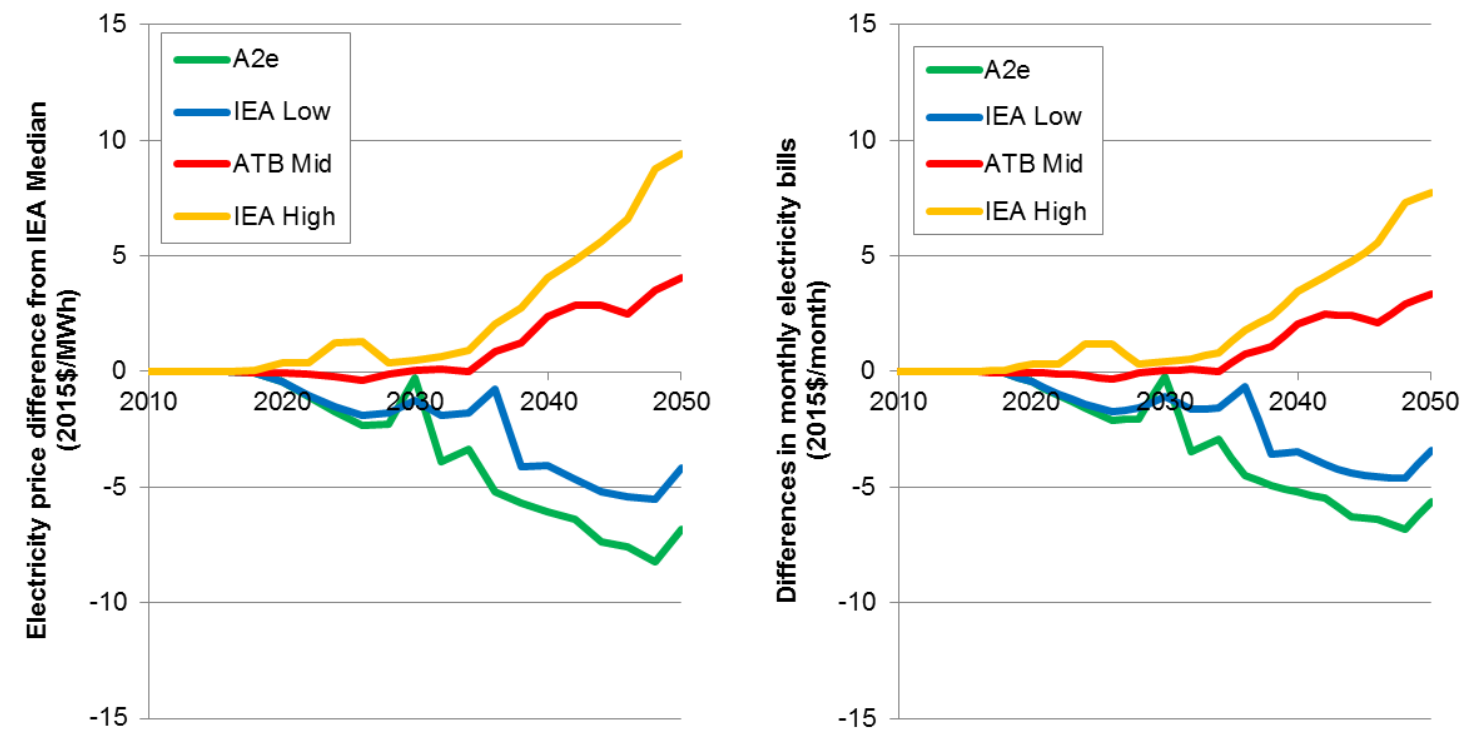

Figure 17. Average retail electricity price (left) and monthly household utility bill impacts (right)

\footnotetext{
${ }^{39}$ To provide additional context to these values, lower and higher natural gas prices drive a system cost range of $-5 \%$ to $+9 \%$ under the IEA Median scenario.

${ }^{40}$ ReEDS does not model electricity price-demand elasticity and, therefore, some of the costs (and savings) could be more muted due to rebound effects.

${ }^{41}$ Reported electricity prices are based on the marginal value of key constraints in ReEDS, including load balancing, operating reserves, and planning reserves. The prices are averaged over all time-slices and cover both fixed and operating costs. ReEDS does not explicitly model retail mark-ups and we, therefore, assume that differences in ReEDS-estimated prices are passed through to retail customers.

${ }^{42}$ Household bill impacts are estimated based on monthly household consumption from the AEO 2017 Reference case (EIA 2017).
} 


\subsection{Air Emissions Benefits}

Wind technology advancements can lead to power sector air emissions reductions by displacing fossil generation with economically competitive wind energy. In this section we report air emissions results for the five core scenarios. More specifically, we report sulfur dioxide, nitrogen oxides, and carbon dioxide emissions estimated directly from the ReEDS model. As described in Section 3, we model current policies only and acknowledge that emissions can be strongly impacted by state and federal policies. ${ }^{43}$ Under this narrow 2017 policy perspective, our results suggest that sizable emission reduction opportunities exist from wind technology advancements.

Figure 18 shows annual emissions estimates for the three pollutants tracked in ReEDS. The results reflect direct combustion-related emissions only and do not include emissions from upstream or downstream processes (e.g., emissions from fuel extraction, embedded emissions in plant equipment, or plant decommissioning related emissions). ${ }^{44}$ As expected, lower power sector emissions are found in scenarios with greater wind deployment. Based on the generation results presented earlier, we find little difference in emissions between the IEA High, ATB Mid, and IEA Median scenarios particularly in the near term. ${ }^{45}$ For example, relative to the IEA Median scenario, $2030 \mathrm{NO}_{\mathrm{x}}$ emissions are only about $2.5 \%$ (31 thousand tons) higher in the IEA High scenario. Percent differences in $\mathrm{SO}_{2}$ and $\mathrm{CO}_{2}$ emissions in 2030 are even smaller. The gap between the three scenarios grows over time with differences of up to about 5\% (33,000 tons), $12 \%$ (103,000 tons), and 15\% (225 MMT) for $\mathrm{SO}_{2}, \mathrm{NO}_{x}$, and $\mathrm{CO}_{2}$ respectively by 2050 . In all three scenarios, emissions tend to stay flat or increase slightly through 2040, but decline during the 2040s in large part through reductions in coal-fired generation.
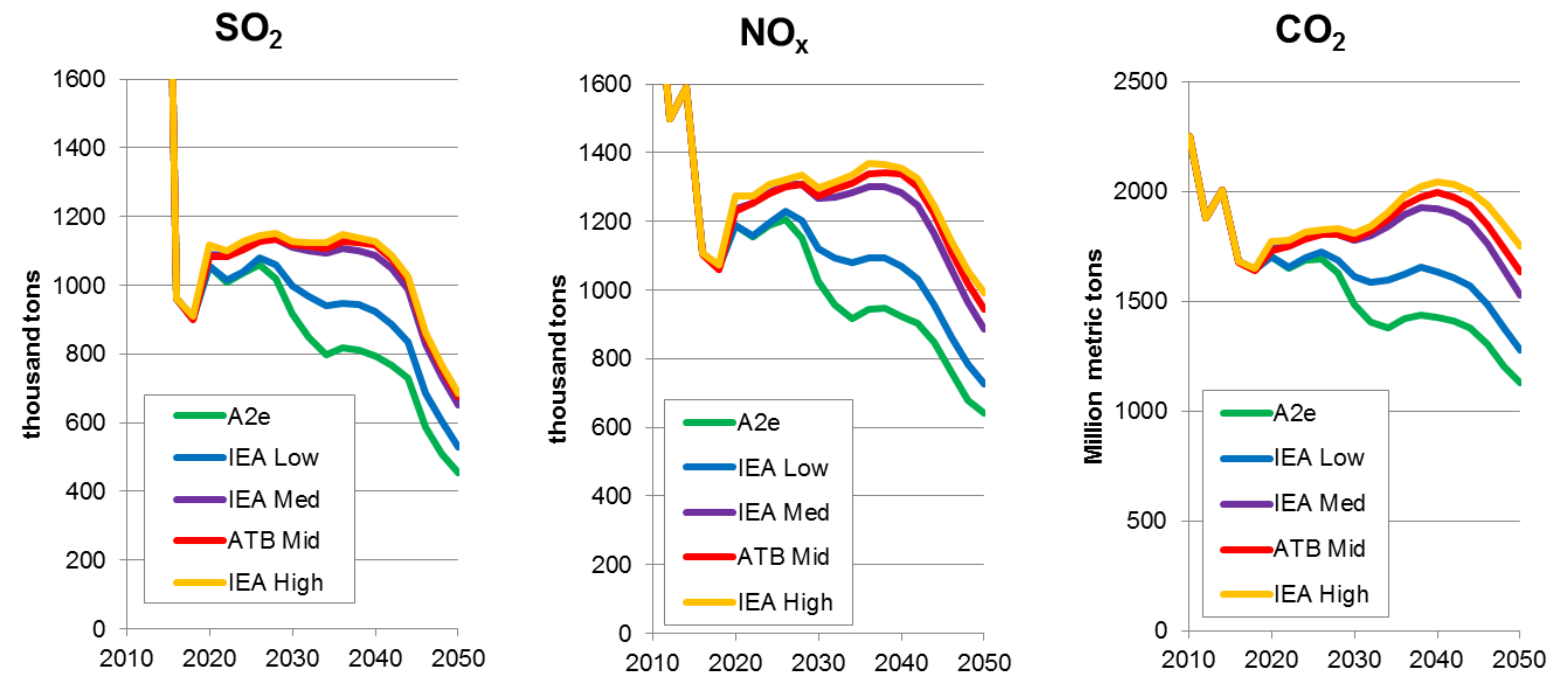

Figure 18. Direct power sector air pollution emissions: $\mathrm{SO}_{2}$ (left), $\mathrm{NO}_{\mathrm{x}}$ (center), and $\mathrm{CO}_{2}$ (right)

$\mathrm{SO}_{2}$ and $\mathrm{NO}_{x}$ emissions are reported in short tons. $\mathrm{CO}_{2}$ is reported in metric tons.

\footnotetext{
${ }^{43}$ We include the U.S. EPA Mercury Air Toxics Standards (MATS) and Cross-State Air Pollution Rule (CSAPR) in all scenarios. The Clean Power Plan is not included in any of the scenarios. Legal challenges exist for many air regulations and our representation reflects a simple assumption and not an endorsement or prediction.

${ }^{44}$ The results also exclude possible increases in emissions through greater power plant cycling and ramping, which are found to represent a small portion of overall emissions and wind-related avoided emission (Lew et al. 2013).

${ }^{45}$ In all scenarios, significant historical (2010-2016) reductions in $\mathrm{SO}_{2}$ and $\mathrm{NO}_{\mathrm{x}}$ result from the impacts of the MATS and CSAPR regulations represented.
} 
Figure 18 reveals more-rapid and greater reductions in air emissions in the IEA Low and A2e scenarios over all time periods. Relative to the IEA Median scenario, we find emissions reductions of 10\% (110,000 tons), 11\% (144,000 tons), and 9\% (165 MMT) for $\mathrm{SO}_{2}, \mathrm{NO}_{\mathrm{x}}$, and $\mathrm{CO}_{2}$ respectively in 2030 and $19 \%$ (121,000 tons), 18\% (161,000 tons), and 16\% (248 MMT) respectively, in 2050 for the IEA Low scenario. Even greater avoided emissions are found in the A2e scenario; for $\mathrm{SO}_{2}, \mathrm{NO}_{\mathrm{x}}$, and $\mathrm{CO}_{2}$ emissions are estimated to be $18 \%$ (195,000 tons), 19\% (239,000 tons), and 16\% (290 MMT) lower in 2030 and 30\% (196,000 tons), 28\% (245,000 tons), and 26\% (399 MMT) lower in 2050 respectively, relative to the IEA Median scenario.

These percentages reflect national emissions reductions, but emissions impacts can vary significantly between regions. Figure 19 shows regional $\mathrm{SO}_{2}$ emissions from the five core scenarios. Wind technology advancements are estimated to have the greatest $\mathrm{SO}_{2}$ emissions impacts in the central regions as wind generation (and corresponding reduction in fossil generation) is found to be the greatest in those regions. Emissions reductions are also sensitive to the type of fossil generation displaced as well as the regional implementation of emissions control equipment. Appendix $\mathrm{B}$ includes regional $\mathrm{NO}_{\mathrm{x}}$ and $\mathrm{CO}_{2}$ emissions results, which show similar qualitative trends as results from Figure 19.

Reductions in air pollution emissions can have health and environmental benefits for local and downwind communities as well as global implications. Previous work, including the Wind Vision study (DOE 2015), Wiser et al. (2016), Mai et al. (2016c), and Millstein et al. (2017), report potential mortality, morbidity, and monetized impacts from air pollution reductionsbeyond just the physical quantities reported here - associated with future and historical wind and other renewable generation. 

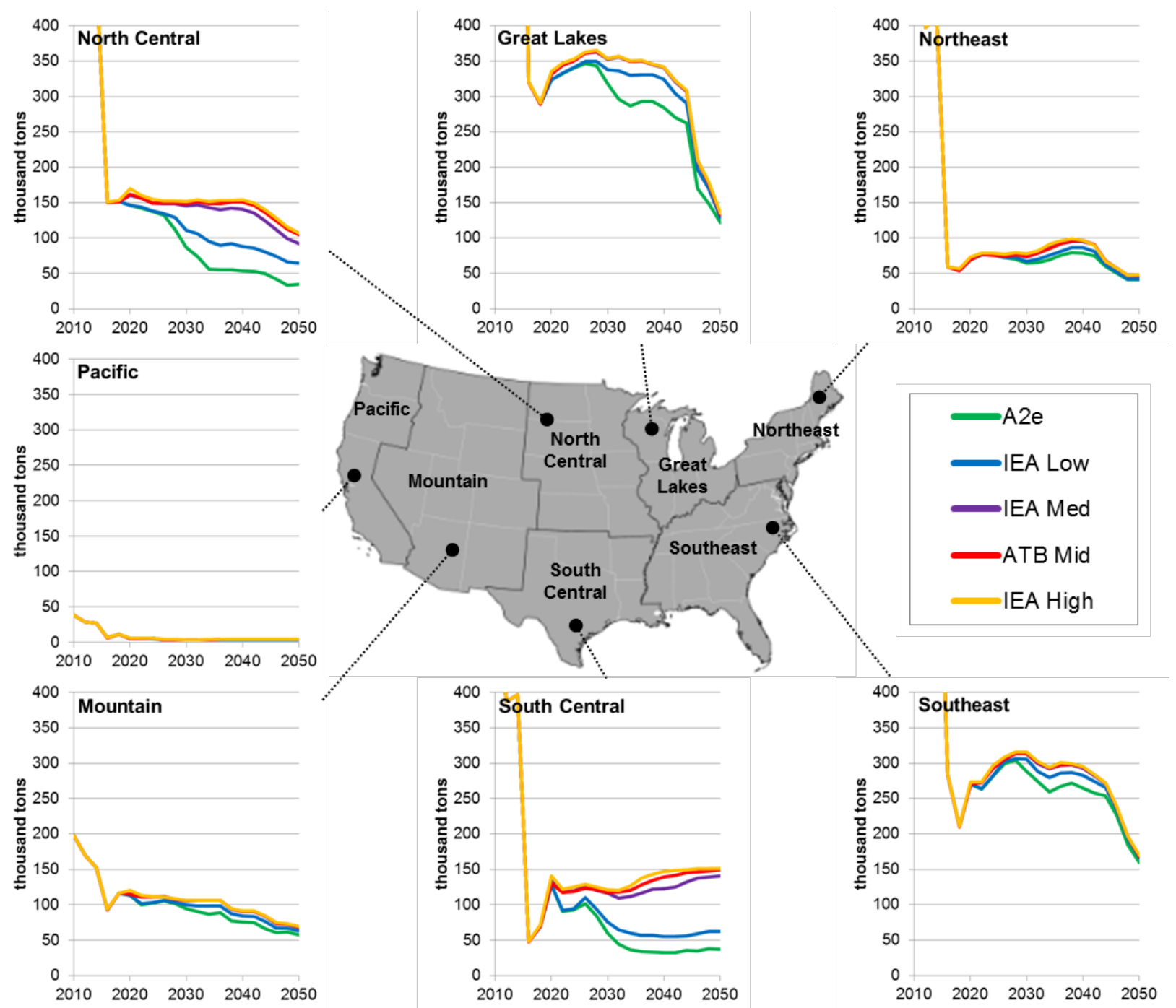

Figure 19. $\mathrm{SO}_{2}$ emissions by region 


\subsection{Water Benefits}

Similar to air emissions, wind technology advancements can also lead to reductions in power sector water use. These savings occur from the low water use of wind power technologies and the reduced reliance on thermal power plants that require cooling water. Water use is estimated within the ReEDS electric sector model based on the performance and characteristics of different generation and cooling system technologies (Macknick et al. 2015). ReEDS distinguishes between water consumption - water removed from the source for power plant cooling and not returned - and water withdrawals - water removed but returned to the source, potentially at higher temperatures. Only operational water use is estimated as it comprises the vast majority of total life-cycle water use for many generation technologies (Meldrum et al. 2013).

Figure 20 shows national annual water consumption and withdrawal estimates across all five core scenarios. Power sector water use (both consumption and withdrawal) is estimated to remain flat in the near term, but decline significantly in the long run in lock-step with estimated reductions in coal-fired and nuclear generation, which have among the highest operational water use factors on a per unit of electricity basis. Little differences in water use are found between the IEA High, ATB Mid, and IEA Median scenarios; 2030 water use is estimated to be about 1\% greater ( 16 billion gallons of consumption and 291 billion gallons of withdrawals) in the IEA High scenario relative to the IEA Median scenario. Consumption differences between the two scenarios grow to $14 \%$ (123 billion gallons) by 2050 while withdrawal differences grow to $7 \%$ (576 billion gallons).
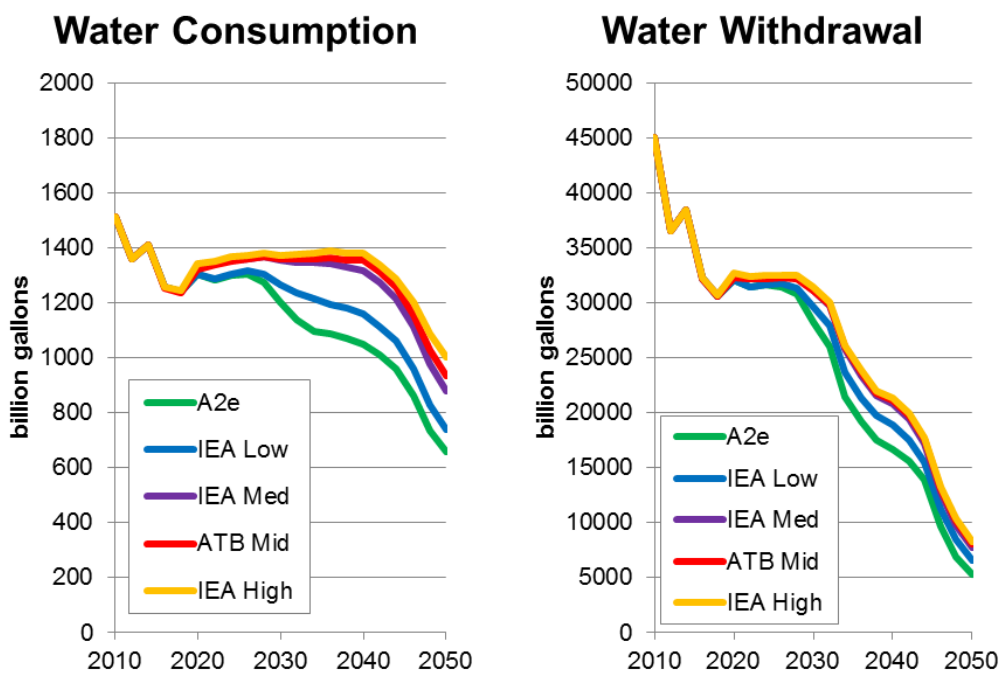

Figure 20. Operational power sector water use: consumption (left) and withdrawals (right) 
As with air emissions, large water savings are found in the IEA Low and A2e scenarios in 2030 and 2050. In terms of water consumption, the IEA Low scenario results in a 7\% (89 billion gallons) reduction in 2030 and $16 \%$ reduction (142 billion gallons) in 2050, relative to the IEA Median scenario. Similar percent savings are found for water withdrawals with 5\% (1.5 trillion gallons) and 15\% (1.2 trillion gallons) reductions in 2030 and 2050 respectively. For the A2e scenario water consumption savings total 11\% (153 billion gallons) and 25\% (223 billion gallons) in 2030 and 2050 respectively, relative to the IEA Median scenario. For this scenario, water withdrawal savings total 9\% (2.9 trillion gallons) in 2030 and 32\% (2.5 trillion gallons) in 2050 .

Although the national results shown in Figure 20 provide a general sense of possible water savings from wind technology advancements, water use is predominantly a regional issue. Figure 21 shows annual water consumption estimates for the five core scenarios for 12 water basins. Water consumption savings in the IEA Low and A2e scenarios are estimated for many regions with the largest absolute savings occurring in the central inland regions of the country. On a relative basis, however, we also find significant water consumption reductions in certain more water-scarce regions in the southwest. For example, 2050 water consumption in the California water basin is 14\% (3 billion gallons) lower in the IEA Low scenario than in the IEA Median scenario. Appendix B shows water withdrawal estimates by region, which could have important environmental and wildlife impacts in many regions. 


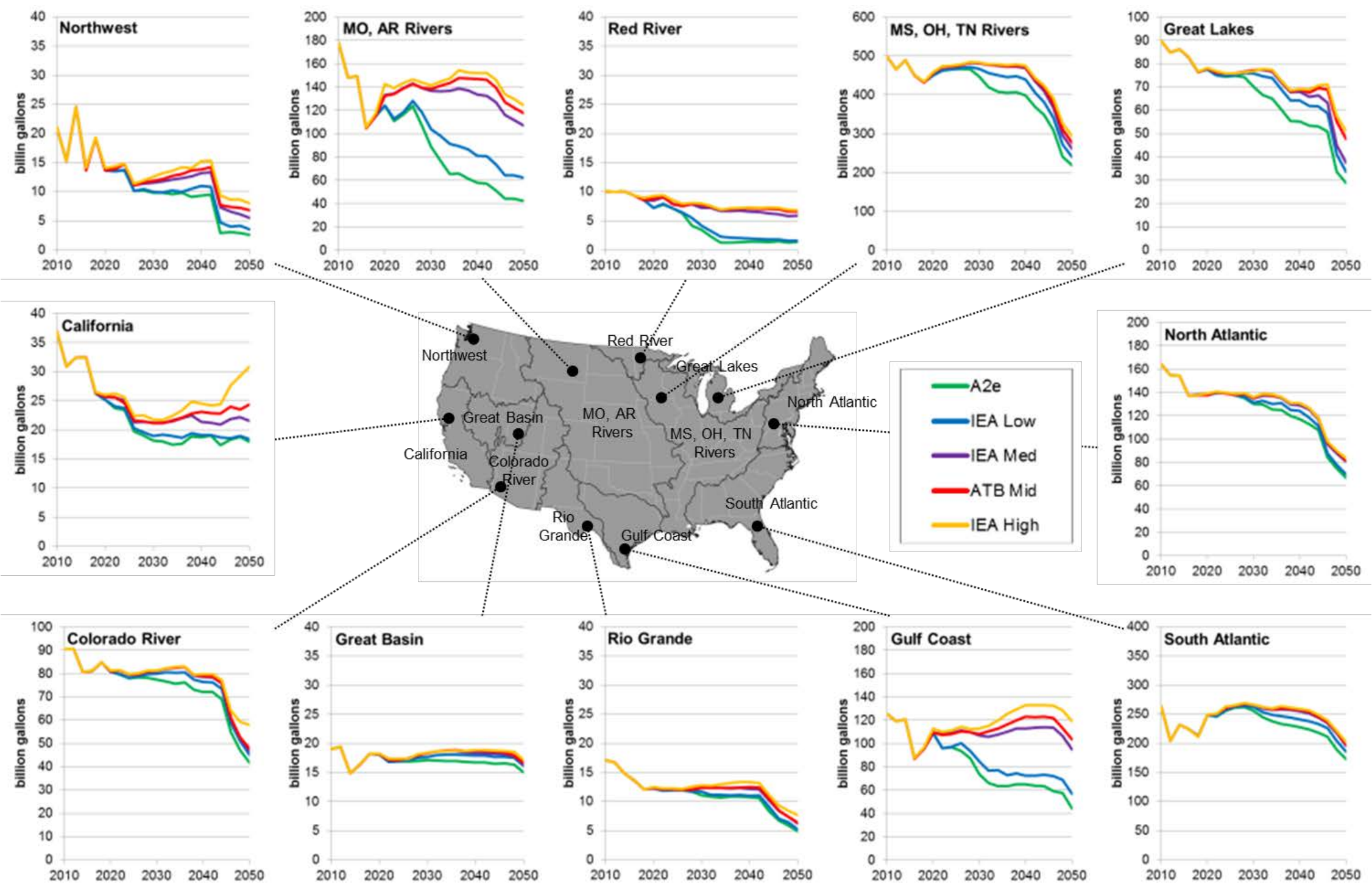

Figure 21. Water consumption by region

Scales differ between regions. 


\subsection{Wind-Related Workforce Impacts}

In this section we report gross wind-related jobs estimated for the five core scenarios. We relied on the NREL Jobs and Economic Development Impacts (JEDI) model for this analysis. In particular, we used investment and capacity scenario results from ReEDS as input to the JEDI wind model, which is an input-output model that reports domestic jobs in full time equivalent (FTE) units. ${ }^{46}$ Our analysis focuses only on gross jobs related to wind deployment and operation. We do not assess workforce impacts for any other technologies, including possible reductions in jobs in other fuels under the higher wind deployment scenarios. As a consequence, we do not claim any net job impacts or other net economy wide macroeconomic effects.

For the most part, default parameters from JEDI were used in the analysis. One exception is the "domestic content" of different wind technology components, which were consistent with assumptions used in the Wind Vision study (DOE 2015). In particular, we processed two sets of JEDI runs that relied on "higher" and "lower" domestic content assumptions. Workforce results are primarily presented as the average of the two, but we also show the full range modeled. Domestic content can have a sizeable impact on estimated domestic jobs, but can also be difficult to predict. Table A-13 ( Appendix A) shows the domestic content assumptions used in our analysis (taken from DOE 2015) as well as estimates for the current U.S. wind industry (Wiser and Bolinger 2017). For many components, the current domestic content rate is within the "lower" and "higher" range from our assumptions, but it tends to fall closer to the low end for many components or even below in the case of nacelle components. As such, if current domestic content holds through 2050, our analysis would overestimate the number of jobs. However, we note that domestic content would likely change with the level of maturity in the U.S. wind industry - a dynamic affect that is not captured by our analysis. For example, increasing wind deployment in the United States could lead to an increase in wind component manufacturing within the country and, hence, raise the domestic content rate. The converse could also occur. As a result, the incremental jobs estimates in our analysis are likely to be lower (at least in percentage terms) than if this dynamic is reflected. Acknowledging these limitations, we report results across the five core scenarios in order to provide high level estimates of the impact of technology advancement on the future wind-related workforce in the United States.

Figure 22 shows annual wind-related jobs estimated for the five core scenarios. Estimated jobs include onsite, supply chain, and induced jobs for both construction and O\&M activities. ${ }^{47}$

The figure shows average results from the higher domestic content and lower domestic content assumptions. The 2017 U.S. wind workforce is estimated to fall in the range from about 120,000 to $130,000 \mathrm{FTE}^{48}$, with significant variations in future years over time and between scenarios. In general, we find that the number of wind-related jobs shrinks just after the PTC ramps down, but generally grows thereafter. The rate and timing of the growth is strongly dependent on wind

\footnotetext{
${ }^{46}$ One FTE is equal to 40-hour work week for one year.

47 "Onsite" jobs refer to jobs directly associated with the development of the project such as construction work located on-site, civil engineers, field technicians, site managers, and administrative staff. "Supply chain" jobs refer to jobs necessary for upstream equipment manufacturing in linked sectors of the economy, e.g., equipment suppliers, replacement part fabricators, insurance agents, and accountants. "Induced" jobs result from income (earnings) spent by workers from the first two categories, e.g., restaurant workers, hotel employees, and other retailers.

${ }^{48}$ DOE (2017) estimates that there were "102,000 workers employed at wind firms across the nation." This value does not include induced jobs so is not directly comparable with our estimates.
} 
technology advancements. In the most-optimistic scenarios for wind energy (IEA Low and A2e), we find wind-related jobs reaching nearly 500,000 FTEs per year in the late 2040s.

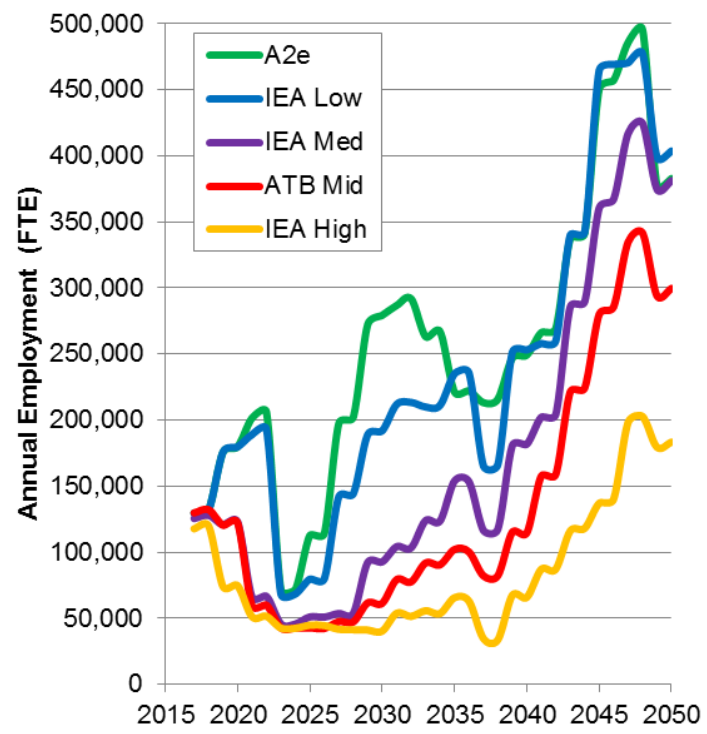

Figure 22. Annual gross wind-related jobs

Figure shows the average between "higher" and "lower domestic content assumptions.

The year-to-year job variations shown in Figure 22, driven by changes in year-to-year wind deployment estimates in ReEDS, make it difficult to quantify the impacts of technology advancements on the U.S. wind workforce. Figure 23 shows annual wind-related jobs averaged over the full study period (2017-2050) broken down by two different sets of job categories. The stacked bars show the job category breakdown using the average of the higher and lower domestic content assumptions. In addition, we show the full range of average wind-related total jobs across the two domestic content assumptions.

For the IEA Median scenario, we estimate average wind-related jobs to total about 170,000 FTE per year. With lower wind technology advancements we estimate average wind-related jobs to be reduced to 134,000 FTE per year under the ATB Mid scenario and to 83,000 FTE per year under the IEA High scenario. On the other hand, the average wind workforce is estimated to expand to 235,000 FTE per year and 256,000 FTE per year under the IEA Low and A2e scenarios respectively. Across all scenarios, the majority of the estimated jobs fall under the equipment supply chain category and for construction-related activities. Total jobs are significantly affected by the amount of domestic content, which can drive a difference of over 70,000 FTE per year in average annual workforce for the IEA Low and A2e scenarios. We also estimate regional onsite average annual wind jobs. Not surprisingly, the greatest onsite construction and O\&M jobs are located in the central regions with the highest amounts of wind deployment (see Appendix B). Other jobs, such as equipment manufacturing and other supply chain jobs can be located in other regions; however, it is impossible to predict their specific locations multiple decades in the future. As such, the geographic distribution of total wind-related jobs cannot be estimated in our analysis. 

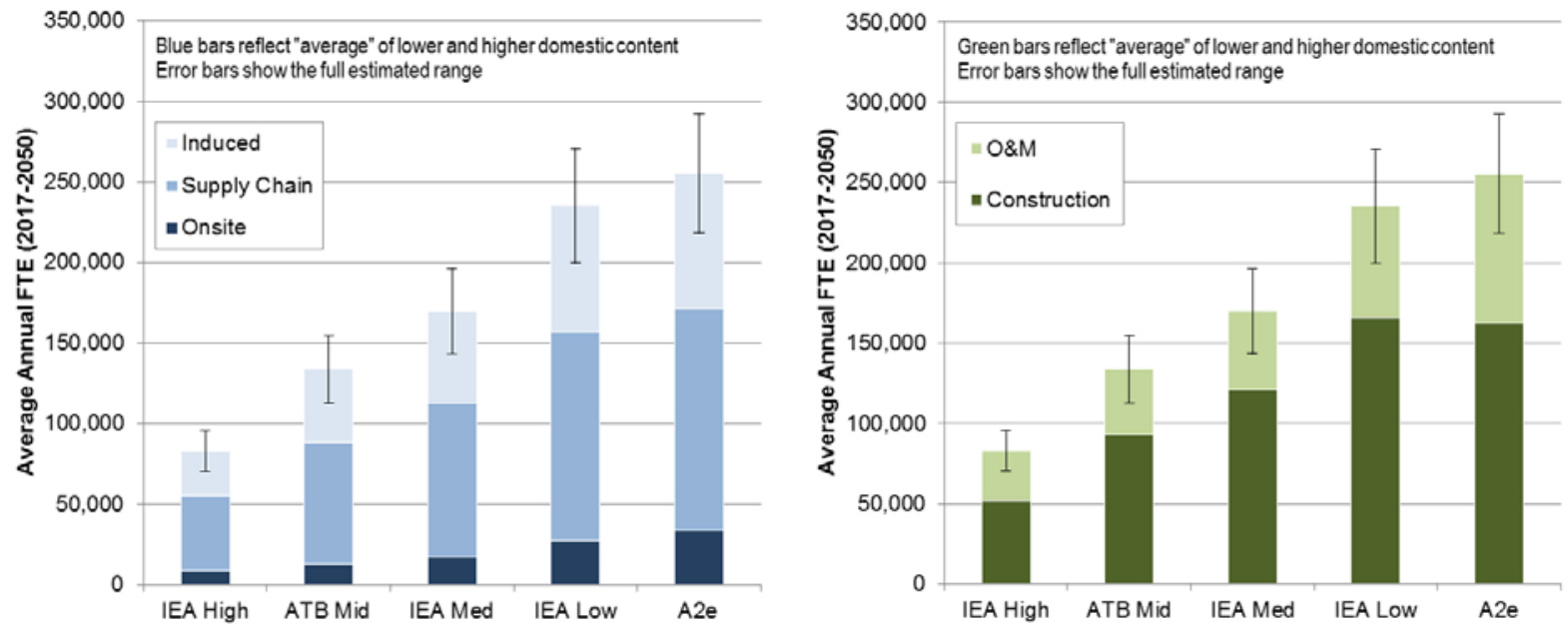

Figure 23. Average annual gross wind-related jobs by job category: (Left) Induced, supply chain, and onsite; (Right) O\&M and construction

$\mathrm{O} \& \mathrm{M}$ and construction jobs in the figure on the right include supply chain and induced jobs from O\&M- and construction-related activities in addition to the direct onsite jobs at wind power plant facilities. 


\section{Summary}

Advancements in wind energy technologies, along with federal and state policy support have driven rapid growth in U.S. wind deployment over the past decade. Although wind technologies will likely continue to evolve, the extent to which costs and/or performance will continue to improve remains uncertain, thereby creating uncertainties in future wind deployment. Other recent and emerging market forces-including historically low natural gas prices, declining solar technology costs, PTC reductions, low demand growth, and market saturation — potentially foreshadow impediments to future wind deployment and underscore the uncertainties. Within this context, we develop projections of the future U.S. electric sector system to assess the potential impacts that wind technology advancements might have on the U.S. wind industry, electricity system investments and consumers, and the environment.

Our assessment explores a suite of wind technology cost and performance projections based on recent analyses: (1) three projections from an expert elicitation of 163 global wind energy experts, (2) another projection reflecting the broader literature and recently used by the U.S. government and national laboratories, and (3) a fifth projection that is derived from potential advancements in fundamental science that are currently the focus of work of the U.S. Department of Energy and are anticipated to seed an array of future public and private sector innovations. We also model a wide range of market conditions for non-wind technologies and fossil fuels.

The analysis identified significant wind deployment opportunities with successful wind technology innovations that reduce the levelized cost of wind by 53\% or more from 2015 levels (IEA Low scenario). Assuming this wind cost reduction, we estimate the installed wind capacity in the contiguous 48 states to reach $169 \mathrm{GW}$ and generate $15 \%$ of total U.S. generation in 2030 under reference market conditions. Even greater wind development is estimated for the long run under this scenario, where wind capacity exceeds $433 \mathrm{GW}$ by 2050 and wind energy comprises $38 \%$ of 2050 generation. This growth in wind would require 235,000 FTE per year averaged over the entire study period. The impact of wind technology advancements reach beyond the wind industry, as we estimate net present value electric system cost savings of $\$ 99$ billion and a reduction in 2050 electricity prices of $\$ 4 / \mathrm{MWh}$, which would save a typical U.S. household about $\$ 3.4 /$ month (IEA Low scenario compared to the IEA Median scenario). In addition to these economic impacts, wind technology advancements are also estimated to support environmental benefits, including reductions in air pollution and water use. Technology advancements are found to yield significant wind deployment in all regions of the country, enabling wind energy to provide benefits on a national basis. Even greater, accelerated, and widespread opportunities and benefits are found with more-significant wind advancements as envisioned in the A2e scenario.

Conversely, we find that failures in wind technology advancement could result in sizable lost opportunities. In fact, in scenarios with no or more-limited wind technology improvements, wind capacity is estimated to remain flat or even decline over the next two decades due primarily to competition from other sources of electricity, such as natural gas and solar power. These lost opportunities could yield higher system costs and electricity rates for consumers as well as greater air emissions and power sector water use. Figure 24 summarizes the long-term impacts estimated for the five core wind advancement scenarios in our analysis. 


\begin{tabular}{|c|c|c|c|c|c|}
\hline & $\begin{array}{l}\text { IEA Med } \\
\text { (Absolute value) }\end{array}$ & IEA High & ATB Mid & $\underset{\text { edian) }}{\text { IEA Low }}$ & $\mathrm{A} 2 \mathrm{e}$ \\
\hline $\begin{array}{l}\text { WIND INSTALLED } \\
\text { CAPACITY 2050 } \\
\text { (GW) }\end{array}$ & 282 & $-62 \%$ & $-32 \%$ & $+53 \%$ & $+96 \%$ \\
\hline WIND GENERATION 2050 & 1,238 & $-66 \%$ & $-29 \%$ & $+50 \%$ & $+76 \%$ \\
\hline $\begin{array}{l}\text { TYSTEM COSTS } \\
2017-2050 \\
\text { (BILLION \$) }\end{array}$ & 3,250 & $+2.8 \%$ & $+1.1 \%$ & $-3.1 \%$ & $-4.6 \%$ \\
\hline $\begin{array}{l}\mathrm{SO}_{2} \text { EMISSIONS } 2050 \\
\text { (THOUSAND TONS) }\end{array}$ & 651 & $+5.0 \%$ & $+3.8 \%$ & $-19 \%$ & $-30 \%$ \\
\hline $\begin{array}{l}\text { NO EMISSIONS } 2050 \\
\text { (THOUSAND TONS) }\end{array}$ & 887 & $+12 \%$ & $+6.4 \%$ & $-18 \%$ & $-28 \%$ \\
\hline $\mathrm{CO}_{2}$ EMISSIONS 2050 & 1,527 & $+15 \%$ & $+6.9 \%$ & $-16 \%$ & $-26 \%$ \\
\hline $\begin{array}{l}\text { WATER } \\
\text { CONSUMPTION 2050 } \\
\text { (BILLION GALLONS) }\end{array}$ & 878 & $+14 \%$ & $+6.2 \%$ & $-16 \%$ & $-25 \%$ \\
\hline $\begin{array}{l}\text { WATER } \\
\text { WITHDRAWALS 2050 } \\
\text { (BILLION GALLONS) }\end{array}$ & 7,716 & $+7.5 \%$ & $+4.4 \%$ & $-15 \%$ & $-32 \%$ \\
\hline $\begin{array}{l}\text { AVERAGE WIND } \\
\text { JOBS 2017-2050 } \\
\text { (THOUSAND FTES) }\end{array}$ & 170 & $-51 \%$ & $-21 \%$ & $+38 \%$ & $+50 \%$ \\
\hline
\end{tabular}

Figure 24. Estimated impacts associated with the wind technology advancement scenarios 
Although our analysis quantifies wind deployment and cost savings opportunities through wind technology advancements, it is not designed to identify the specific innovations needed to achieve the cost and performance levels envisioned. Also, it does not assess the R\&D investments - from domestic or global firms and governments - needed to achieve the deployment, electricity cost savings, and environmental benefits estimated. Future work is needed to translate specific technology R\&D investments to the potential benefits and impacts projected. Nonetheless, the analysis highlights that technology advancements can offer tremendous opportunities not only for the U.S. wind industry but also for the broader electricity system and consumers. 


\section{References}

AWEA (American Wind Energy Association). 2017. AWEA U.S. Wind Industry Annual Market

Report Year Ending 2016. http://www.awea.org/Resources/Content.aspx?ItemNumber=8812.

Barbose, Galen. 2017. U.S. Renewables Portfolio Standards: 2017 Annual Status Report. https://emp.lbl.gov/publications/us-renewables-portfolio-standards-0. Lawrence Berkeley National Laboratory.

Bloom, Aaron, Aaron Townsend, David Palchak, Joshua Novachek, Jack King, Clayton Barrows, Eduardo Ibanez, Matthew O'Connell, Gary Jordan, Billy Roberts, Caroline Draxl, Kenny Gruchalla. 2016. Eastern Renewable Generation Integration Study. Golden, CO: National Renewable Energy Laboratory. NREL/TP-6A20-64472. https://www.nrel.gov/docs/fy16osti/64472-ES.pdf.

Brinkman, Gregory. 2015. Renewable Electricity Futures: Operational Analysis of the Western Interconnection at Very High Renewable Penetrations. Golden, CO: National Renewable Energy Laboratory. NREL/TP-6A20-64467. https://www.nrel.gov/docs/fy15osti/64467.pdf

Brown, Austin, Philipp Beiter, Donna Heimiller, Carolyn Davidson, Paul Denholm, Jennifer Melius, Anthony Lopez, Dylan Hettinger, David Mulcahy, and Gian Porro. 2016. Estimating Renewable Energy Economic Potential in the United States: Methodology and Initial Results. Golden, CO: National Renewable Energy Laboratory. NREL/TP-6A20-64503. https://www.nrel.gov/docs/fy15osti/64503.pdf.

Clarke, Leon E., Allen A. Fawcett, John P. Weyant, James McFarland, Vaibhav Chaturvedi, and Yuyu Zhou. 2014. "Technology and U.S. Emissions Reductions Goals: Results of the EMF 24 Modeling Exercise." The Energy Journal 35(SI1): 9-31. http://dx.doi.org/10.5547/01956574.35.SI1.2.

Cohen, J., T. Schweizer, A. Laxson, S. Butterfield, S. Schreck, L. Fingersh, P. Veers, and T. Ashwilll. 2008. Technology Improvement Opportunities for Low Wind Speed Turbines and Implications for Cost of Energy Reduction. Golden, CO: National Renewable Energy Laboratory. NREL/TP-500-41036. https://www.nrel.gov/docs/fy08osti/41036.pdf.

Cole, Wesley, Trieu Mai, Kelly Eurek, Daniel C. Steinberg, and Robert Margolis. 2015. Considering the Role of Solar Generation under Rate-Based Targets in the EPA's Proposed Clean Power Plan. Paper presented at Energy Policy Institute's Fifth Annual Energy Policy Research Conference. The Electricity Journal 28(8, October 2015): 20-28. doi:10.1016/j.tej.2015.09.002.

Cole, Wesley, Trieu Mai, Jeffrey Logan, Daniel Steinberg, James McCall, James Richards, Benjamin Sigrin, and Gian Porro. 2016a. 2016 Standard Scenarios Report: A U.S. Electricity Sector Outlook. Golden, CO: National Renewable Energy Laboratory. NREL/TP-6A20-66939. http://www.nrel.gov/docs/fy17osti/66939.pdf. 
Cole, Wesley, Parthiv Kurup, Maureen Hand, David Feldman, Benjamin Sigrin, Eric Lantz, Tyler Stehly, Chad Augustine, Craig Turchi, Patrick O’Connor, and Connor Waldoch. 2016 b. 2016 Annual Technology Baseline (ATB). Golden, CO: National Renewable Energy Laboratory. NREL/PR-6A20-66944. http://www.nrel.gov/docs/fy16osti/66944.pdf.

Cole, Wesley, Bethany Frew, Pieter Gagnon, James Richards, Yinong Sun, Jarett Zuboy, Michael Woodhouse, and Robert Margolis. 2017. SunShot 2030 for Photovoltaics (PV): Envisioning a Low-cost PV Future. Golden, CO: National Renewable Energy Laboratory. NREL/TP-6A20-68105. https://www.nrel.gov/docs/fy17osti/68105.pdf.

Crown Estate. 2012. Offshore Wind Cost Reduction Pathways Study. https://www.thecrownestate.co.uk/media/5493/ei-offshore-wind-cost-reduction-pathwaysstudy.pdf.

Denholm, Paul, Maureen Hand, Maddalena Jackson, and Sean Ong. 2009. Land-Use Requirements of Modern Wind Power Plants in the United States. Golden, CO: National Renewable Energy Laboratory. NREL/TP-6A2-45834. https://www.nrel.gov/docs/fy09osti/45834.pdf.

DOE (U.S. Department of Energy). 2008. 20\% Wind Energy by 2030: Increasing Wind Energy's Contribution to U.S. Electricity Supply. DOE/GO-102008-2567.

https://www.nrel.gov/docs/fy08osti/41869.pdf.

- 2012. SunShot Vision Study. NREL/BK-5200-47927; DOE/GO-102012-3037. https://www1.eere.energy.gov/solar/pdfs/47927.pdf.

- 2015. WindVision: A New Era for Wind Power in the United States. U.S. Department of Energy. DOE/GO-102015-4557. https://www.energy.gov/sites/prod/files/WindVision_Report final.pdf.

- 2016. Hydropower Vision: A New Chapter for America's $1^{\text {st }}$ Renewable Electricity Source. DOE/GO-102016-4869 https://energy.gov/sites/prod/files/2016/10/f33/HydropowerVision-10262016 0.pdf.

- 2017. U.S. Energy and Employment Report.

https://energy.gov/sites/prod/files/2017/01/f34/2017\%20US\%20Energy\%20and\%20Jobs\%20Re port 0.pdf.

Donohoo-Vallett, Paul, Trieu Mai, Matthew Mowers, and Gain Porro. 2017. Impact of Clean Energy R\&D on the U.S. Power Sector. Golden, CO: National Renewable Energy Laboratory. NREL/TP-6A20-67691. http://www.nrel.gov/docs/fy17osti/67691.pdf.

Dykes, Katherine, Maureen Hand, Tyler Stehly, Paul Veers, Mike Robinson, Eric Lantz, and Richard Tusing. 2017. Enabling the SMART Wind Power Plant of the Future through ScienceBased Innovation. Golden, CO: National Renewable Energy Laboratory. NREL/TP-5000-68123.

EIA (U.S. Energy Information Administration). 2017a. "Electric Power Annual" and "Electric Power Monthly.” Accessed July 2017. 
—. 2017b. Annual Energy Outlook 2017 with Projections to 2050.

https://www.eia.gov/outlooks/aeo/pdf/0383(2017).pdf.

EPA (U.S. Environmental Protection Agency). 2015. Regulatory Impact Analysis for the Clean Power Plan Final Rule. Docket ID EPA-452/R-15-003 EPA.

Eurek, Kelly, Wesley Cole, David Bielen, Nate Blair, Stuart Cohen, Bethany Frew, Jonathan Ho, Venkat Krishnan, Trieu Mai, Benjamin Sigrin, and Daniel Steinberg. Regional Energy Deployment System (ReEDS) Model Documentation: Version 2016. Golden, CO: National Renewable Energy Laboratory. NREL/TP-6A20-67067. https://www.nrel.gov/docs/fy17osti/67067.pdf

Fingersh, L. M. Hand, and A. Laxson. 2006. Wind Turbine Design Cost and Scaling Model. Golden, CO: National Renewable Energy Laboratory. NREL/TP-500-40566. https://www.nrel.gov/docs/fy07osti/40566.pdf.

Horner, Nathaniel, Ines Azevedo, and David Hounshell. 2013. "Effects of Government Incentives on Wind Innovation in the United States." Environmental Research Letters 8(November 2013): doi:10.1088/1748-9326/8/4/044032.

Jorgenson, Jennie, Trieu Mai, and Greg Brinkman. 2017. Reducing Wind Curtailment through Transmission Expansion in a Wind Vision Future. Golden, CO: National Renewable Energy Laboratory. NREL/TP-6A20-67240. https://www.nrel.gov/docs/fy17osti/67240.pdf.

Lantz, Eric, Daniel Steinberg, Michael Mendelsohn, Owen Zinaman, Ted James, Gian Porro, Maureen Hand, Trieu Mai, Jeffrey Logan, Jenny Heeter, and Lori Bird. 2014. Implications of a PTC Extension on U.S. Wind Deployment. Golden, CO: National Renewable Energy Laboratory. NREL/TP-6A20-61663. https://www.nrel.gov/docs/fy14osti/61663.pdf.

Lantz, Eric, Trieu Mai, Ryan Wiser, and Venkat Krishnan. 2016. "Long-Term Implications of Sustained Wind Power Growth in the United States: Direct Electric System Impacts and Costs." Applied Energy 179(October 2016): 832-46. doi:10.1016/j.apenergy.2016.07.023.

Lantz, Eric, Owen Roberts, and Katherine Dykes. 2017. Trends, Opportunities, and Challenges for Tall Wind Turbine and Tower Technologies. Presented at the American Wind Energy Association Wind Power 2017 Conference, Anaheim, California, May 22, 2017. Golden, CO: National Renewable Energy Laboratory. NREL/PR-6A20-68732. https://www.nrel.gov/docs/fy17osti/68732.pdf.

Lantz, Eric, Ryan Wiser, and Maureen Hand. 2012. IEA Wind Task 26: The Past and Future Cost of Wind Energy: Work Package 2. NREL/TP-6A20-53510. https://www.ieawind.org/index_page_postings/WP2 task26.pdf.

Lew, Debbie, Gregory Brinkman, Eduardo Ibanez, Anthony Florita, Michael Heaney, BriMathias Hodge, Marissa Hummon, Greg Stark, Jack King, Steven A. Lefton, Nikhil Kumar, Dwight Agan, Gary Jordan, and Sundar Venkataraman. 2013. The Western Wind and Solar Integration Study Phase 2. Golden, CO: National Renewable Energy Laboratory. NREL/TP5500-55588. https://www.nrel.gov/docs/fy13osti/55588.pdf. 
Lindman, Åsa, and Patrik Söderholm. 2012. "Wind Power Learning Rates: A Conceptual Review and Meta-Analysis." Energy Econ. 34(3): 754-761.

Lopez, Anthony, Billy Roberts, Donna Heimiller, Nate Blair, and Gian Porro. 2012. U.S. Renewable Energy Technical Potentials: A GIS-Based Analysis. Golden, CO: National Renewable Energy Laboratory. NREL/TP-6A20-51946. https://www.nrel.gov/docs/fy12osti/51946.pdf.

MacDonald, Alexander E., Christopher T. M. Clack, Anneliese Alexander, Adam Dunbar, James Wilczak, and Yuanfu Xie. 2016. "Future Cost-Competitive Electricity Systems and Their Impact on US CO $\mathrm{C}_{2}$ emissions." Nature Climate Change 6(25, January 2016): 526-531. doi:10.1038/nclimate2921.

Macknick, Jordan, Stuart Cohen, Robin Newmark, Andrew Martinez, Patrick Sullivan, and Vince Tidwell. 2015. Water Constraints in an Electric Sector Capacity Expansion Model. Golden, CO: National Renewable Energy Laboratory. NREL/TP-6A20-64270. https://www.nrel.gov/docs/fy15osti/64270.pdf.

Mai, Trieu, M. Maureen Hand, Samuel F. Baldwin, Ryan H. Wiser, Greg L. Brinkman, Paul Denholm, Doug J. Arent, Gian Porro, Debra Sandor, Donna J. Hostick, Michael Milligan, Edgar A. DeMeo, and Morgan Bazilian. 2013. "Renewable Electricity Futures for the United States." IEEE Transactions on Sustainable Energy 5(2, April 2014): 372-378. http://dx.doi.org/10.1109/TSTE.2013.2290472.

Mai, Trieu, David Mulcahy, M. Maureen Hand, and Samuel F. Baldwin. 2014. "Envisioning a Renewable Electricity Future for the United States." Energy 65(1, February 2014): 374-386. http://dx.doi.org/10.1016/j.energy.2013.11.029.

Mai, Trieu, Eric Lantz, Jonathan Ho, Tyler Stehly, and Donna Heimiller. 2016a. Outlooks for Wind Power in the United States: Drivers and Trends under a 2016 Policy Environment. Golden, CO: National Renewable Energy Laboratory. NREL/TP-6A20-67058. http://www.nrel.gov/docs/fy17osti/67058.pdf.

Mai, Trieu, Wesley Cole, Eric Lantz, Cara Marcy, and Benjamin Sigrin. 2016b. Impacts of Federal Tax Credit Extensions on Renewable Deployment and Power Sector Emissions. Golden, CO: National Renewable Energy Laboratory. NREL/TP-6A20-65571. https://www.nrel.gov/docs/fy16osti/65571.pdf.

Mai, Trieu, Ryan H. Wiser, Galen L. Barbose, Lori Bird, Jenny Heeter, David Keyser, Venkat Krishnan, Jordan Macknick, and Dev Millstein. 2016c. A Prospective Analysis of the Costs, Benefits, and Impacts of U.S. Renewable Portfolio Standards. Golden, CO: National Renewable Energy Laboratory, and Berkeley, CA: Lawrence Berkeley National Laboratory. NRELTP6A20-67455/LBNL-1006962. http://www.nrel.gov/docs/fy17osti/67455.pdf.

Meldrum, J., S. Nettles-Anderson, G. Heath, and J. Macknick. 2013. “Life Cycle Water Use for Electricity Generation: A Review and Harmonization of Literature Estimates." Environ. Res. Lett. 8 (2013). 
Mignone, Bryan K., Thomas Alfstad, Aaron Bergman, Kenneth Dubin, Richard Duke, Paul Friley, Andrew Martinez, Matthew Mowers, Karen Palmer, Anthony Paul, Sharon Showalter, Daniel Steinberg, Matt Woerman, and Frances Wood. 2012. "Cost-Effectiveness and Economic Incidence of a Clean Energy Standard." Economics of Energy and Environmental Policy 1(3): 5986. http://dx.doi.org/10.5547/2160-5890.1.3.5

Millstein, Dev, Ryan Wiser, Mark Bolinger, and Galen Barbose. 2017. "The Climate and AirQuality Benefits of Wind and Solar Power in the United States." Nature Energy 2(17134).

Mukora, A., M. Winskel, H. F. Jeffey, and M. Mueller, M. 2009. "Learning Curves for Emerging Energy Technologies.” Proc. Institution of Civil Engineers - Energy 162(4): 151-159.

Neij, Lena. 20018. “Cost Development of Future Technologies for Power Generation: A Study Based on Experience Curves and Complementary Bottom-Up Assessments." Energy Policy 36(6): 2200-2211.

NREL (National Renewable Energy Laboratory). 2012. Renewable Electricity Futures Study. Hand, M.M., S. Baldwin, E. DeMeo, J.M. Reilly, T. Mai, D. Arent, G. Porro, M. Meshek, and D. Sandor, D. eds. 4 vols. NREL/TP-6A20-52409. Golden, CO: National Renewable Energy Laboratory. http://www.nrel.gov/analysis/re_futures/.

—. 2016. “Annual Technology Baseline." https://atb.nrel.gov/.

—. 2017. “Annual Technology Baseline.” https://atb.nrel.gov/.

Rubin, Edward S., Inês M.L. Azevedo, Paulina Jaramillo, and Sonia Yeh. 2015. "A Review of Learning Rates for Electricity Supply Technologies.” Energy Policy 86(November 2015): 198218.

Schmidt, Tobias S., and Sebastian Sewerin. 2017. "Technology as a Driver of Climate and Energy Politics." Nature Energy 2(17084). https://www.nature.com/articles/nenergy201784.

Sigrin, Benjamin, Michael Gleason, Robert Preus, Ian Baring-Gould, and Robert Margolis. 2016. The Distributed Generation Market Demand Model (dGen): Documentation. Golden, CO: National Renewable Energy Laboratory. NREL/TP-6A20-65231. https://www.nrel.gov/docs/fy16osti/65231.pdf.

Valpy, Bruce, and Philip English. 2014. Future Renewable Energy Costs: Offshore Wind. BVG Associates.

Wilkerson, Jordan, Peter Larsen, and Galen Barbose. "Survey of Western U.S. electric utility resource plans." Energy Policy 66(March 2014): 90-103.

Wiser, R., Z. Yang, M. Hand, O. Hohmeyer, D. Infield, P. H. Jensen, V. Nikolaev, M. O’Malley, G. Sinden, and A. Zervos. 2011. "Wind Energy." In IPCC Special Report on Renewable Energy Sources and Climate Change Mitigation. Edenhofer, O., R. Pichs-Madruga, Y. Sokona, K. Seyboth, P. Matschoss, S. Kadner, T. Zwickel, P. Eickemeier, G. Hansen, S. Schlömer, and C. von Stechow (eds). Cambridge, United Kingdom: Cambridge University Press 
Wiser, Ryan, Eric Lantz, Trieu Mai, Jose Zayas, Edgar DeMeo, Ed Eugeni, Jessica Lin-Powers, and Richard Tusing. 2015. "Wind Vision: A New Era for Wind Power in the United States." The Electricity Journal 28 (9, November 2015): 120-132. doi:10.1016/j.tej.2015.09.016.

Wiser, Ryan, Karen Jenni, Joachim Seel, Erin Baker, Maureen Hand, Eric Lantz, and Aaron Smith. 2016. "Expert Elicitation Survey on Future Wind Energy Costs." Nature Energy 1(16135). doi:10.1038/nenergy.2016.135

Wiser, Ryan, and Mark Bolinger. 2017. 2016 Wind Technologies Market Report. U.S. Department of Energy. DOE/GO-102917-5033. https://energy.gov/sites/prod/files/2017/08/f35/2016 Wind Technologies Market Report 0.pdf. 


\section{Appendix A: Wind Technology Cost and Performance Data}

This appendix shows the assumed cost and performance data used in our analysis for the five separate land-based wind projections modeled. It includes tables identifying the full set of scenarios and sensitivities modeled and the domestic content assumptions used in the jobs analysis. The tables include overnight wind capital costs and annual capacity factors, both of which vary by technology-resource group (TRG). TRGs are used to reflect the regional variations in wind quality (average wind speed) within each ReEDS model wind resource region (DOE 2015; Eurek et al. 2016). Fixed O\&M costs are also reported and are assumed to be uniform across TRGs but vary between cost projections. Reported values exclude additional financing costs, grid interconnection costs, and capital cost multipliers, all of which are included in the electric sector modeling. We use real 2016 dollars.

Table A-1. Overnight Wind Capital Costs in the ATB Mid Case (\$/kW)

\begin{tabular}{llllll}
\hline TRG & $\mathbf{2 0 1 7}$ & $\mathbf{2 0 2 0}$ & $\mathbf{2 0 3 0}$ & $\mathbf{2 0 4 0}$ & $\mathbf{2 0 5 0}$ \\
\hline TRG1 & 1,634 & 1,594 & 1,511 & 1,507 & 1,502 \\
TRG2 & 1,684 & 1,650 & 1,566 & 1,563 & 1,550 \\
TRG3 & 1,673 & 1,634 & 1,554 & 1,544 & 1,524 \\
TRG4 & 1,682 & 1,631 & 1,542 & 1,535 & 1,516 \\
TRG5 & 1,695 & 1,646 & 1,560 & 1,556 & 1,538 \\
TRG6 & 1,736 & 1,695 & 1,630 & 1,612 & 1,564 \\
TRG7 & 1,801 & 1,793 & 1,852 & 1,824 & 1,768 \\
TRG8 & 1,878 & 1,910 & 2,019 & 1,978 & 1,919 \\
TRG9 & 2,026 & 2,113 & 2,244 & 2,210 & 2,148 \\
TRG10 & 2,253 & 2,320 & 2,485 & 2,500 & 2,524 \\
\hline
\end{tabular}

Table A-2. Wind Net Capacity Factor in the ATB Mid Case

\begin{tabular}{llllll}
\hline TRG & $\mathbf{2 0 1 7}$ & $\mathbf{2 0 2 0}$ & $\mathbf{2 0 3 0}$ & $\mathbf{2 0 4 0}$ & $\mathbf{2 0 5 0}$ \\
\hline TRG1 & $52.7 \%$ & $53.8 \%$ & $55.8 \%$ & $57.5 \%$ & $59.0 \%$ \\
TRG2 & $50.9 \%$ & $52.1 \%$ & $54.1 \%$ & $55.9 \%$ & $57.1 \%$ \\
TRG3 & $49.4 \%$ & $50.5 \%$ & $52.5 \%$ & $54.0 \%$ & $55.0 \%$ \\
TRG4 & $48.2 \%$ & $48.9 \%$ & $50.7 \%$ & $52.2 \%$ & $53.2 \%$ \\
TRG5 & $45.8 \%$ & $46.5 \%$ & $48.3 \%$ & $49.8 \%$ & $50.8 \%$ \\
TRG6 & $41.1 \%$ & $42.0 \%$ & $44.0 \%$ & $45.1 \%$ & $45.4 \%$ \\
TRG7 & $34.6 \%$ & $35.9 \%$ & $39.8 \%$ & $40.7 \%$ & $40.9 \%$ \\
TRG8 & $27.6 \%$ & $29.1 \%$ & $32.8 \%$ & $33.4 \%$ & $33.6 \%$ \\
TRG9 & $21.6 \%$ & $23.3 \%$ & $26.4 \%$ & $27.0 \%$ & $27.2 \%$ \\
TRG10 & $14.0 \%$ & $14.9 \%$ & $17.1 \%$ & $17.8 \%$ & $18.5 \%$ \\
\hline
\end{tabular}


Table A-3. Overnight Wind Capital Costs in the IEA Median Case (\$/kW)

\begin{tabular}{llllll}
\hline TRG & $\mathbf{2 0 1 7}$ & $\mathbf{2 0 2 0}$ & $\mathbf{2 0 3 0}$ & $\mathbf{2 0 4 0}$ & $\mathbf{2 0 5 0}$ \\
\hline TRG1 & 1,441 & 1,380 & 1,217 & 1,201 & 1,166 \\
TRG2 & 1,460 & 1,400 & 1,238 & 1,224 & 1,191 \\
TRG3 & 1,470 & 1,415 & 1,267 & 1,265 & 1,240 \\
TRG4 & 1,479 & 1,426 & 1,285 & 1,289 & 1,268 \\
TRG5 & 1,496 & 1,454 & 1,339 & 1,363 & 1,357 \\
TRG6 & 1,534 & 1,509 & 1,436 & 1,497 & 1,516 \\
TRG7 & 1,579 & 1,570 & 1,536 & 1,629 & 1,673 \\
TRG8 & 1,615 & 1,615 & 1,604 & 1,719 & 1,777 \\
TRG9 & 1,648 & 1,685 & 1,768 & 1,959 & 2,072 \\
TRG10 & 1,666 & 1,728 & 1,874 & 2,116 & 2,265 \\
\hline
\end{tabular}

Table A-4. Wind Net Capacity Factor in the IEA Median Case

\begin{tabular}{llllll}
\hline TRG & $\mathbf{2 0 1 7}$ & $\mathbf{2 0 2 0}$ & $\mathbf{2 0 3 0}$ & $\mathbf{2 0 4 0}$ & $\mathbf{2 0 5 0}$ \\
\hline TRG1 & $47.9 \%$ & $48.7 \%$ & $51.4 \%$ & $53.8 \%$ & $56.0 \%$ \\
TRG2 & $46.8 \%$ & $47.6 \%$ & $50.3 \%$ & $52.8 \%$ & $55.0 \%$ \\
TRG3 & $45.6 \%$ & $46.6 \%$ & $49.6 \%$ & $52.4 \%$ & $55.0 \%$ \\
TRG4 & $44.2 \%$ & $45.2 \%$ & $48.4 \%$ & $51.3 \%$ & $54.0 \%$ \\
TRG5 & $41.5 \%$ & $42.7 \%$ & $46.4 \%$ & $49.9 \%$ & $53.0 \%$ \\
TRG6 & $37.3 \%$ & $38.7 \%$ & $43.2 \%$ & $47.3 \%$ & $51.0 \%$ \\
TRG7 & $31.8 \%$ & $33.3 \%$ & $37.9 \%$ & $42.1 \%$ & $46.0 \%$ \\
TRG8 & $25.4 \%$ & $26.7 \%$ & $30.8 \%$ & $34.6 \%$ & $38.0 \%$ \\
TRG9 & $19.1 \%$ & $20.5 \%$ & $24.6 \%$ & $28.5 \%$ & $32.0 \%$ \\
TRG10 & $11.8 \%$ & $12.7 \%$ & $15.7 \%$ & $18.5 \%$ & $21.0 \%$ \\
\hline
\end{tabular}


Table A-5. Overnight Wind Capital Costs in the IEA Low Case (\$/kW)

\begin{tabular}{llllll}
\hline TRG & $\mathbf{2 0 1 7}$ & $\mathbf{2 0 2 0}$ & $\mathbf{2 0 3 0}$ & $\mathbf{2 0 4 0}$ & $\mathbf{2 0 5 0}$ \\
\hline TRG1 & 1,385 & 1,270 & 946 & 922 & 897 \\
TRG2 & 1,405 & 1,291 & 967 & 941 & 915 \\
TRG3 & 1,421 & 1,318 & 1,007 & 979 & 950 \\
TRG4 & 1,433 & 1,335 & 1,030 & 1,001 & 971 \\
TRG5 & 1,461 & 1,385 & 1,104 & 1,071 & 1,036 \\
TRG6 & 1,518 & 1,476 & 1,235 & 1,194 & 1,151 \\
TRG7 & 1,581 & 1,570 & 1,364 & 1,316 & 1,265 \\
TRG8 & 1,628 & 1,636 & 1,450 & 1,397 & 1,340 \\
TRG9 & 1,702 & 1,785 & 1,692 & 1,625 & 1,555 \\
TRG10 & 1,748 & 1,881 & 1,851 & 1,775 & 1,695 \\
\hline
\end{tabular}

Table A-6. Wind Net Capacity Factor in the IEA Low Case

\begin{tabular}{llllll}
\hline TRG & $\mathbf{2 0 1 7}$ & $\mathbf{2 0 2 0}$ & $\mathbf{2 0 3 0}$ & $\mathbf{2 0 4 0}$ & $\mathbf{2 0 5 0}$ \\
\hline TRG1 & $48.8 \%$ & $50.8 \%$ & $55.5 \%$ & $55.8 \%$ & $56.0 \%$ \\
TRG2 & $47.7 \%$ & $49.7 \%$ & $54.5 \%$ & $54.8 \%$ & $55.0 \%$ \\
TRG3 & $46.7 \%$ & $49.0 \%$ & $54.5 \%$ & $54.7 \%$ & $55.0 \%$ \\
TRG4 & $45.3 \%$ & $47.7 \%$ & $53.4 \%$ & $53.7 \%$ & $54.0 \%$ \\
TRG5 & $42.8 \%$ & $45.7 \%$ & $52.4 \%$ & $52.7 \%$ & $53.0 \%$ \\
TRG6 & $38.9 \%$ & $42.3 \%$ & $50.2 \%$ & $50.6 \%$ & $51.0 \%$ \\
TRG7 & $33.4 \%$ & $36.9 \%$ & $45.2 \%$ & $45.6 \%$ & $46.0 \%$ \\
TRG8 & $26.9 \%$ & $30.0 \%$ & $37.3 \%$ & $37.6 \%$ & $38.0 \%$ \\
TRG9 & $20.6 \%$ & $23.8 \%$ & $31.3 \%$ & $31.6 \%$ & $32.0 \%$ \\
TRG10 & $12.8 \%$ & $15.1 \%$ & $20.5 \%$ & $20.7 \%$ & $21.0 \%$ \\
\hline
\end{tabular}


Table A-7. Overnight Wind Capital Costs in the IEA High Case $(\$ / k W)$

\begin{tabular}{llllll}
\hline TRG & $\mathbf{2 0 1 7}$ & $\mathbf{2 0 2 0}$ & $\mathbf{2 0 3 0}$ & $\mathbf{2 0 4 0}$ & $\mathbf{2 0 5 0}$ \\
\hline TRG1 & 1,549 & 1,584 & 1,547 & 1,517 & 1,487 \\
TRG2 & 1,568 & 1,603 & 1,566 & 1,535 & 1,505 \\
TRG3 & 1,575 & 1,610 & 1,573 & 1,542 & 1,511 \\
TRG4 & 1,581 & 1,616 & 1,579 & 1,548 & 1,517 \\
TRG5 & 1,591 & 1,627 & 1,589 & 1,558 & 1,527 \\
TRG6 & 1,617 & 1,653 & 1,615 & 1,584 & 1,552 \\
TRG7 & 1,652 & 1,689 & 1,650 & 1,618 & 1,586 \\
TRG8 & 1,681 & 1,719 & 1,679 & 1,647 & 1,615 \\
TRG9 & 1,686 & 1,724 & 1,684 & 1,652 & 1,620 \\
TRG10 & 1,686 & 1,724 & 1,684 & 1,652 & 1,620 \\
\hline
\end{tabular}

Table A-8. Wind Net Capacity Factor in the IEA High Case

\begin{tabular}{llllll}
\hline TRG & $\mathbf{2 0 1 7}$ & $\mathbf{2 0 2 0}$ & $\mathbf{2 0 3 0}$ & $\mathbf{2 0 4 0}$ & $\mathbf{2 0 5 0}$ \\
\hline TRG1 & $47.4 \%$ & $47.4 \%$ & $47.4 \%$ & $47.4 \%$ & $47.4 \%$ \\
TRG2 & $46.2 \%$ & $46.2 \%$ & $46.2 \%$ & $46.2 \%$ & $46.2 \%$ \\
TRG3 & $45.0 \%$ & $45.0 \%$ & $45.0 \%$ & $45.0 \%$ & $45.0 \%$ \\
TRG4 & $43.5 \%$ & $43.5 \%$ & $43.5 \%$ & $43.5 \%$ & $43.5 \%$ \\
TRG5 & $40.7 \%$ & $40.7 \%$ & $40.7 \%$ & $40.7 \%$ & $40.7 \%$ \\
TRG6 & $36.4 \%$ & $36.4 \%$ & $36.4 \%$ & $36.4 \%$ & $36.4 \%$ \\
TRG7 & $30.8 \%$ & $30.8 \%$ & $30.8 \%$ & $30.8 \%$ & $30.8 \%$ \\
TRG8 & $24.6 \%$ & $24.6 \%$ & $24.6 \%$ & $24.6 \%$ & $24.6 \%$ \\
TRG9 & $18.3 \%$ & $18.3 \%$ & $18.3 \%$ & $18.3 \%$ & $18.3 \%$ \\
TRG10 & $11.1 \%$ & $11.1 \%$ & $11.1 \%$ & $11.1 \%$ & $11.1 \%$ \\
\hline
\end{tabular}


Table A-9. Overnight Wind Capital Costs in the A2e Case $(\$ / k W)$

\begin{tabular}{llllll}
\hline TRG & $\mathbf{2 0 1 7}$ & $\mathbf{2 0 2 0}$ & $\mathbf{2 0 3 0}$ & $\mathbf{2 0 4 0}$ & $\mathbf{2 0 5 0}$ \\
\hline TRG1 & 1,387 & 1,270 & 677 & 642 & 572 \\
TRG2 & 1,407 & 1,291 & 692 & 657 & 586 \\
TRG3 & 1,426 & 1,318 & 700 & 674 & 609 \\
TRG4 & 1,437 & 1,335 & 711 & 688 & 625 \\
TRG5 & 1,470 & 1,384 & 721 & 716 & 676 \\
TRG6 & 1,532 & 1,476 & 771 & 787 & 767 \\
TRG7 & 1,596 & 1,570 & 853 & 882 & 855 \\
TRG8 & 1,640 & 1,635 & 962 & 985 & 914 \\
TRG9 & 1,721 & 1,784 & 1,073 & 1,136 & 1,082 \\
TRG10 & 1,756 & 1,881 & 1,336 & 1,376 & 1,232 \\
\hline
\end{tabular}

Table A-10. Wind Net Capacity Factor in the A2e Case

\begin{tabular}{llllll}
\hline TRG & $\mathbf{2 0 1 7}$ & $\mathbf{2 0 2 0}$ & $\mathbf{2 0 3 0}$ & $\mathbf{2 0 4 0}$ & $\mathbf{2 0 5 0}$ \\
\hline TRG1 & $48.9 \%$ & $50.8 \%$ & $54.1 \%$ & $56.1 \%$ & $56.3 \%$ \\
TRG2 & $47.8 \%$ & $49.7 \%$ & $53.0 \%$ & $55.0 \%$ & $55.3 \%$ \\
TRG3 & $46.8 \%$ & $49.0 \%$ & $51.8 \%$ & $54.2 \%$ & $55.0 \%$ \\
TRG4 & $45.4 \%$ & $47.7 \%$ & $50.5 \%$ & $53.1 \%$ & $54.0 \%$ \\
TRG5 & $43.0 \%$ & $45.7 \%$ & $47.5 \%$ & $50.7 \%$ & $53.0 \%$ \\
TRG6 & $39.1 \%$ & $42.3 \%$ & $43.7 \%$ & $47.7 \%$ & $51.0 \%$ \\
TRG7 & $33.7 \%$ & $36.9 \%$ & $39.1 \%$ & $43.1 \%$ & $46.0 \%$ \\
TRG8 & $27.0 \%$ & $30.0 \%$ & $33.4 \%$ & $36.7 \%$ & $38.0 \%$ \\
TRG9 & $20.8 \%$ & $23.8 \%$ & $26.8 \%$ & $30.3 \%$ & $32.0 \%$ \\
TRG10 & $12.8 \%$ & $15.1 \%$ & $19.2 \%$ & $21.4 \%$ & $21.5 \%$ \\
\hline
\end{tabular}


Table A-11. Fixed O\&M Costs for Each Wind Cost Projection

\begin{tabular}{llllll}
\hline \$/kW-year & $\mathbf{2 0 1 7}$ & $\mathbf{2 0 2 0}$ & $\mathbf{2 0 3 0}$ & $\mathbf{2 0 4 0}$ & $\mathbf{2 0 5 0}$ \\
\hline ATB Mid & 50.9 & 50.5 & 49.1 & 47.6 & 46.2 \\
IEA Median & 50.3 & 49.2 & 45.5 & 41.9 & 38.3 \\
IEA Low & 49.3 & 46.7 & 38.2 & 30.6 & 22.9 \\
IEA High & 51.0 & 51.0 & 51.0 & 51.0 & 51.0 \\
A2e & 49.3 & 46.8 & 38.3 & 34.7 & 31.0 \\
\hline
\end{tabular}

Resources in all TRGs are assumed to have the same fixed O\&M costs.

Table A-12. Scenarios and Sensitivities

Nine sets of assumptions are modeled for each of the five wind cost projections considered.
1. Reference
2. Low Natural Gas Price
3. High Natural Gas Price
4. Low Non-wind RE Technology Cost
5. High Non-wind RE Technology Cost
6. (Unfavorable) Combined Low Natural Gas Price and Low Non-wind RE Technology Cost
7. (Favorable) Combined High Natural Gas Price and High Non-wind RE Technology Cost
8. Constrained Transmission Expansion-no interregional transmission
9. Constrained Transmission Expansion-no inter-state transmission

Table A-13. Wind Technology Domestic Content Assumptions

\begin{tabular}{lrrc}
\hline & & $\begin{array}{c}\text { Wind Vision } \\
\text { (DOE 2015) }\end{array}$ & $\begin{array}{c}\text { Wind Technology } \\
\text { Market Report 2016 } \\
\text { (Wiser and } \\
\text { Bolinger 2017) }\end{array}$ \\
\hline Component & Lower & Higher & Current (2016) \\
\hline Towers & $60 \%$ & $90 \%$ & $65 \%-80 \%$ \\
Blades / Blades \& Hubs & $60 \%$ & $90 \%$ & $50 \%-70 \%$ \\
Nacelle components / Nacelle & $20 \%$ & $50 \%$ & $>90 \%$ \\
Assembly & $80 \%$ & $95 \%$ & $\mathrm{n} / \mathrm{a}$ \\
Balance of plant materials & $100 \%$ & $100 \%$ & $\mathrm{n} / \mathrm{a}$ \\
Labor (construction and O\&M) & $30 \%$ & $60 \%$ & $\mathrm{n} / \mathrm{a}$ \\
Replacement parts & & & \\
\hline
\end{tabular}

Our analysis uses the Wind Vision assumptions. Estimates from Wiser and Bolinger (2017) are shown for reference only. Component categories may not align; the three categories shown in Wiser and Bolinger (2017) include "Towers," "Blades \& Hubs," and "Nacelle Assembly." 


\section{Appendix B: Additional Results}
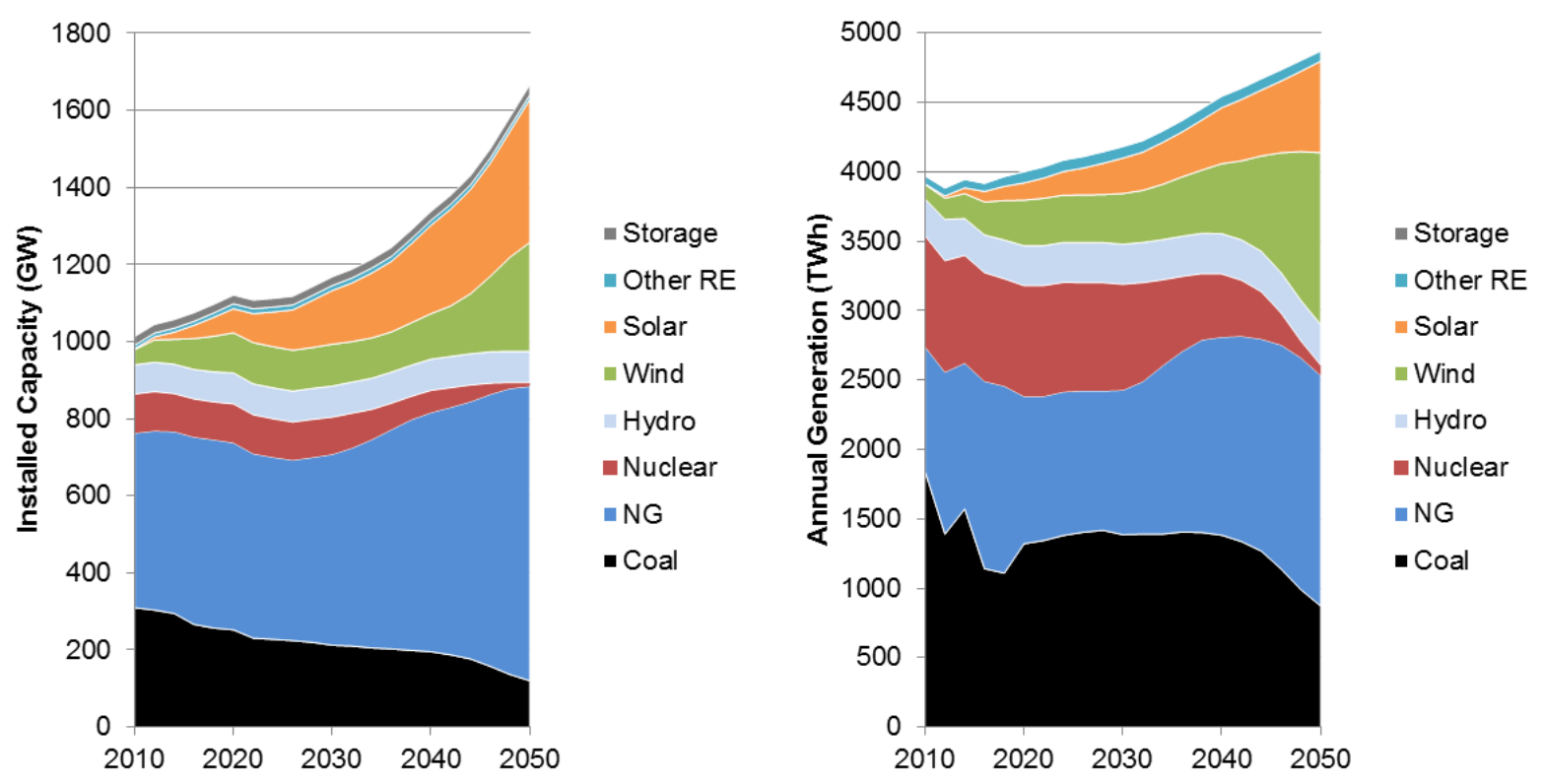

Figure B-1. Capacity (left) and generation (right) mix in the IEA Median scenario. 

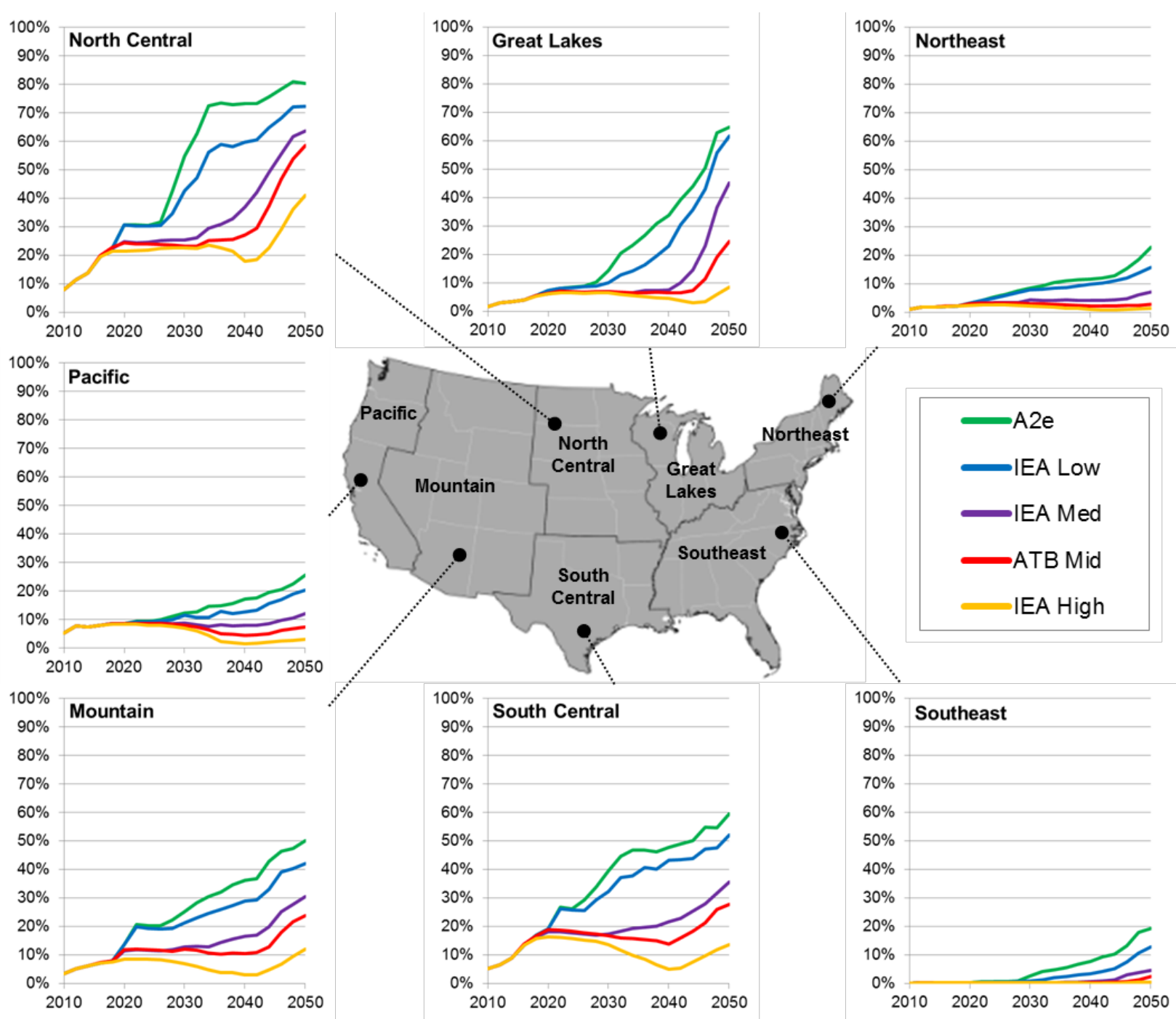

Figure B-2. Regional wind penetration 

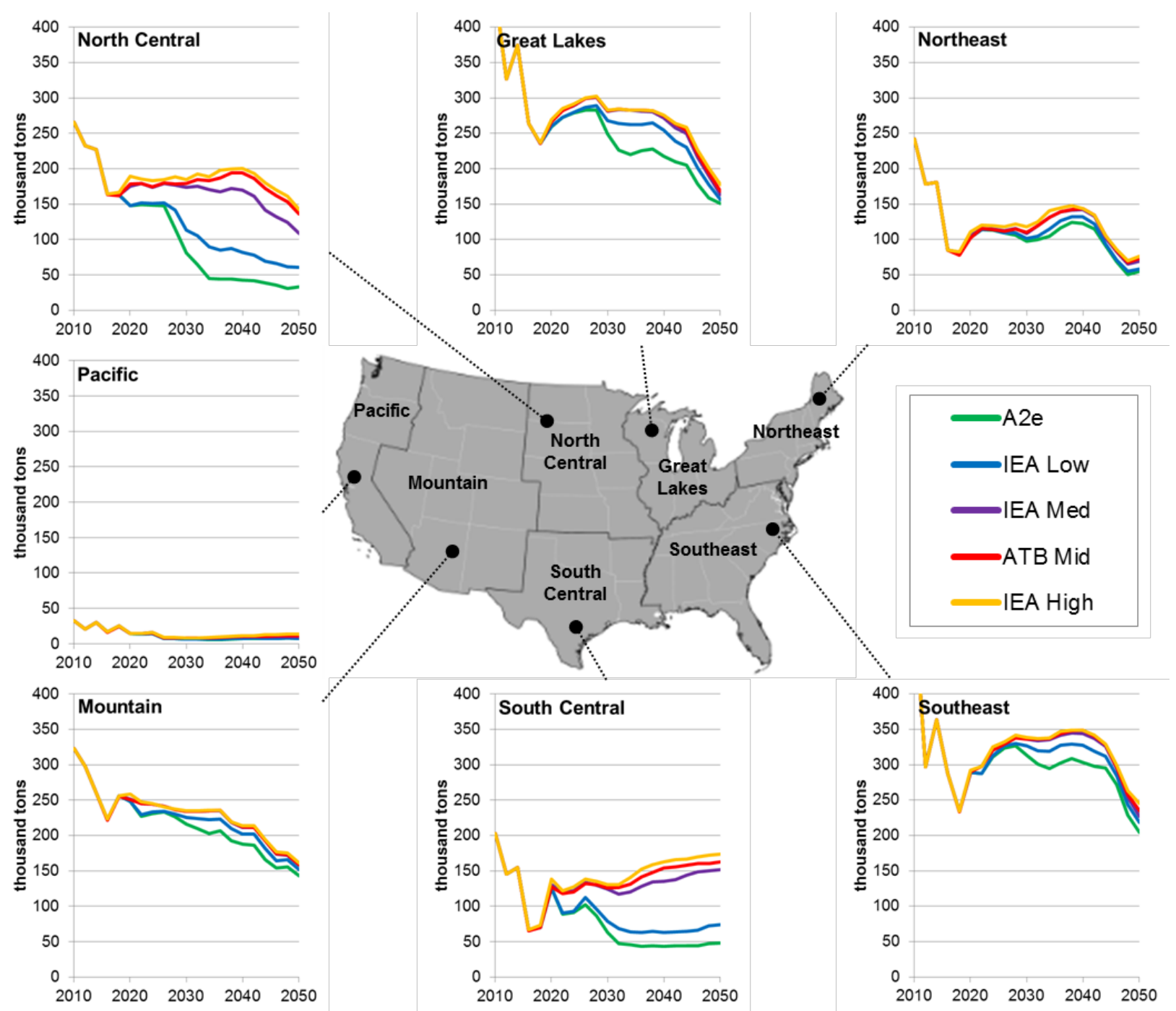

Figure B-3. Regional $\mathrm{NO}_{x}$ emissions 

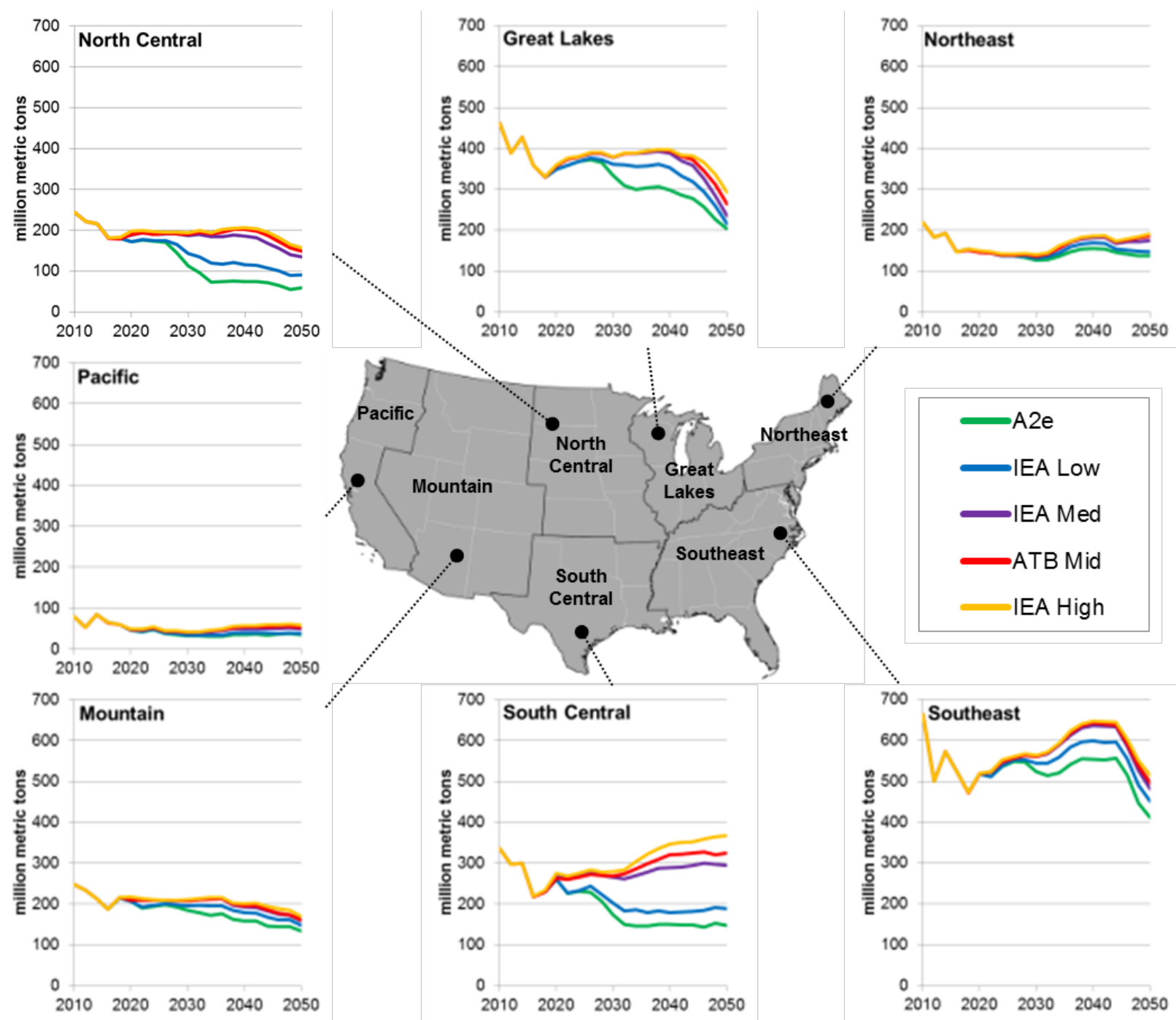

Figure B-4. Regional $\mathrm{CO}_{2}$ emissions 


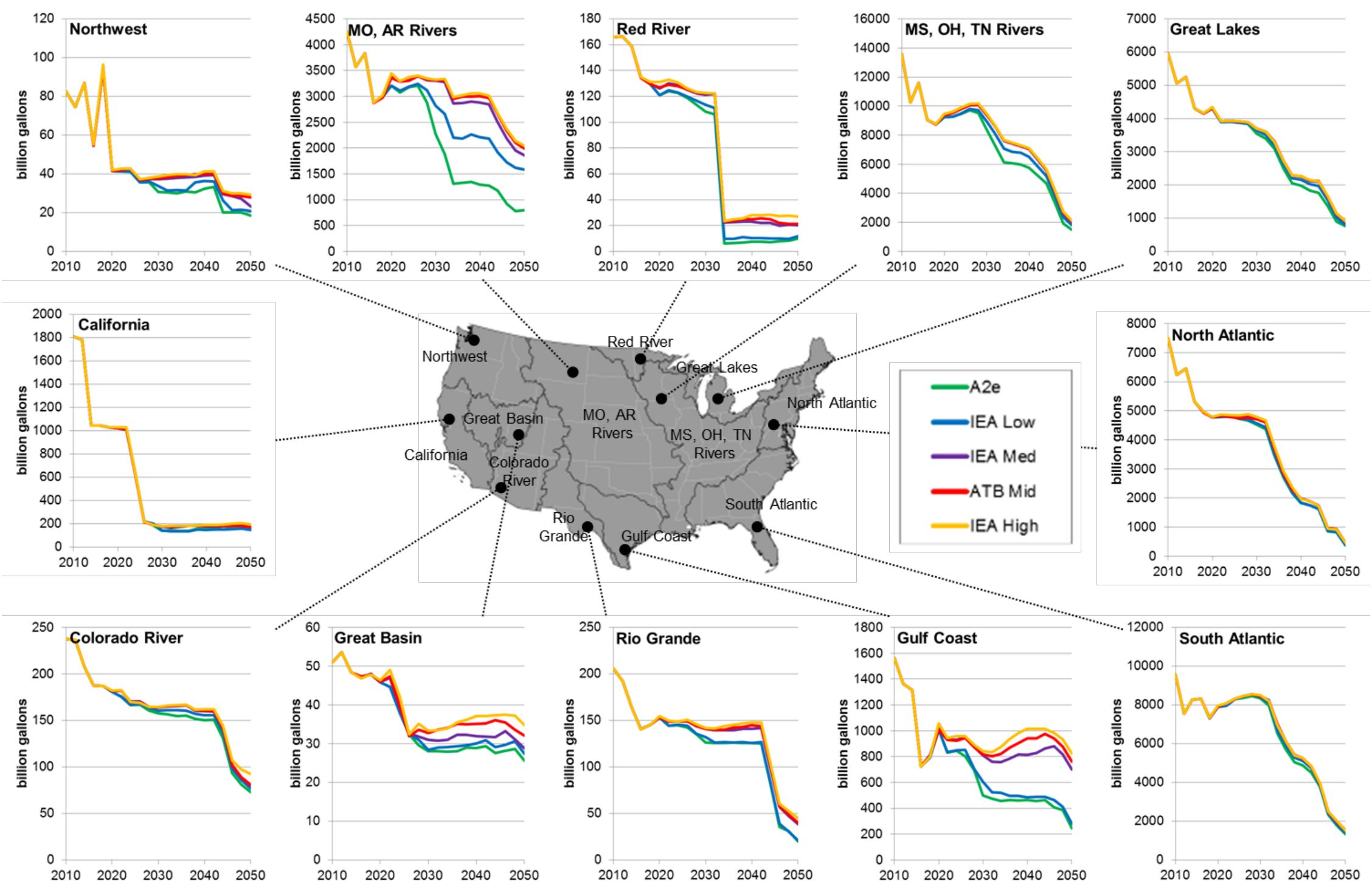

Figure B-5. Regional water withdrawals

Scales differ between regions. 


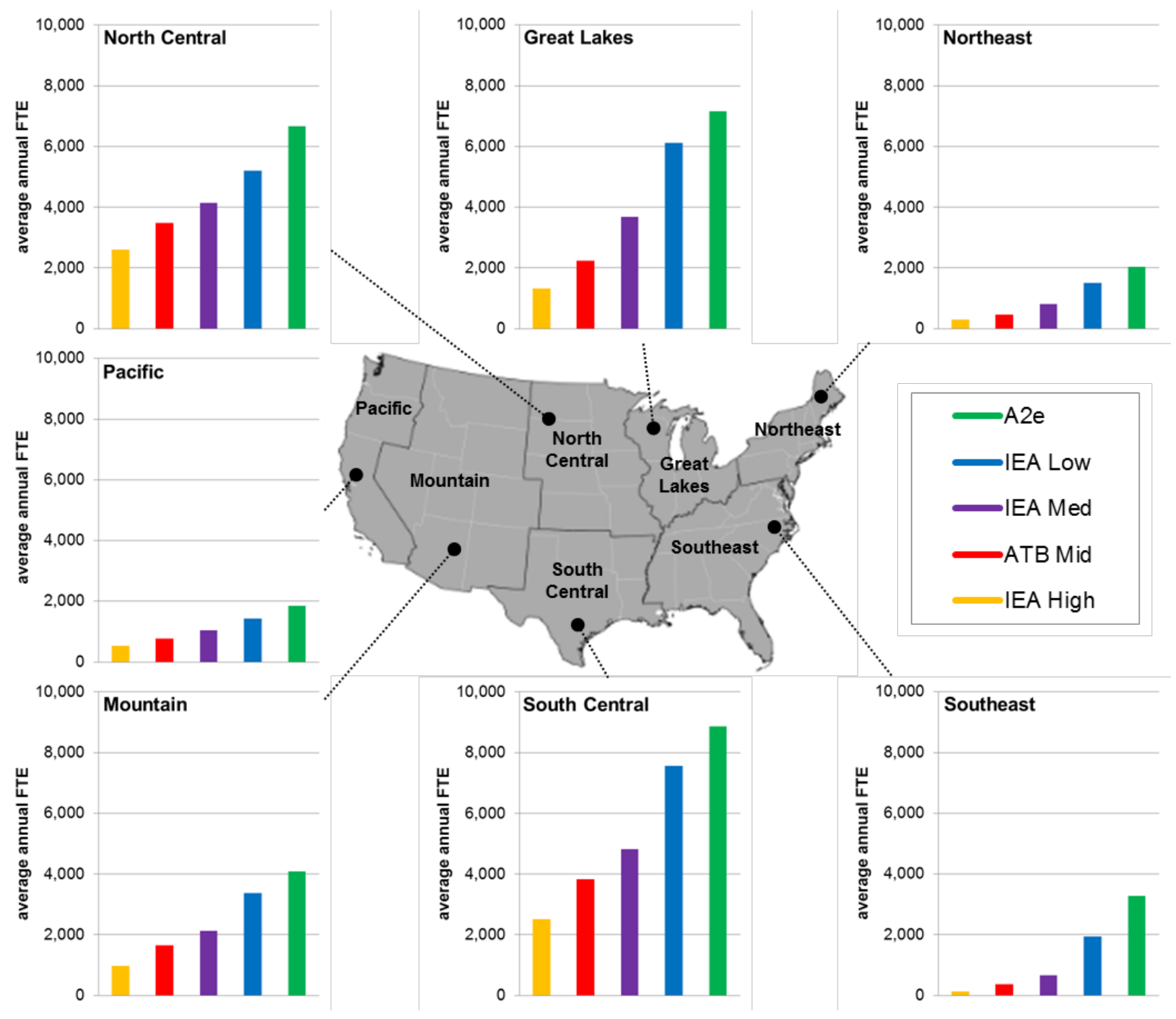

Figure B-6. Regional average onsite wind jobs 